\title{
Acordo de chaves criptográficas hierárquico e sem certificado
}

\author{
Vilc Queupe Rufino
}

\author{
DiSSERTAÇÃO APRESENTADA \\ $\mathrm{AO}$ \\ Instituto de Matemática e EstatísticA \\ DA \\ Universidade De SÃo Paulo \\ PARA \\ OBTENÇÃO DO TÍTULO \\ $\mathrm{DE}$ \\ Mestre em CiÊnCias
}

\author{
Programa: Ciência da Computação \\ Orientador: Prof. Dr. Routo Terada
}

Durante o desenvolvimento deste trabalho o autor recebeu auxílio financeiro da Marinha do Brasil

São Paulo, outubro de 2009 


\section{Acordo de Chaves Hierárquico sem Certificado}

Este exemplar corresponde à redação final da dissertação devidamente corrigida e defendida por Vilc Queupe Rufino e aprovada pela Comissão Julgadora.

Banca Examinadora:

- Prof. Dr. Routo Terada (orientador) - IME-USP.

- Prof. Dr. Flávio Soares Corrêa da Silva - IME-USP.

- Prof. Dr. Julio López Hernádez - IC-UNICAMP. 


\section{Agradecimentos}

Agradeço a Deus pela capacitação e por me permitir viver este momento, ao professor Routo Terada por seu apoio, sua orientação e incentivos, aos amigos Eduardo Ueda, Denise Goya, Mateus Santos e Cleber Okida por seus conselhos, livros, textos e pelas muitas discussões que contribuiram de forma significativa para o enriquecimento e aperfeiçoamento deste trabalho. Agradeço ao professor Flávio Soares por ter sido também meu orientador, por despertar em seus alunos a satisfação pelo estudo e pela ciência. Agradeço ao professor Julio Lopez pela sua amizade, pela participação na banca de avaliação e pelos seus comentários. Aos amigos do LSD que compartilharam comigo momentos de felicidade, ansiedade e torceram juntos para que esse trabalho chegasse ao seu final. Agradeço ainda a minha esposa Ane Rose que pelo seu amor conseguiu abrir mão de uma convivência diária e ainda contribuir para que eu pudesse ter momentos de tranquilidade para estudar e trabalhar, minha mãe Angelica pela suas orações, aos meus irmãos Valc e Neide pelos seus incentivos e ao meu pai Rufino pelo ombro amigo sempre presente. Agradeço ao IME e a USP e a todos que contribuiram para a manutenção do curso de Mestrado. Agradeço a Marinha do Brasil que confiou em seu oficial o futuro de suas comunicações seguras.

Obrigado a todos que de alguma forma direta ou indiretamente contribuiram para a conclusão deste trabalho. 


\section{Resumo}

Este trabalho apresenta um novo esquema de acordo de chaves criptográficas hierárquico, não Interativo e seguro contra comprometimento de múltiplos nós. Esquemas para Acordo de chaves criptográficas (KAS - Key Agreement Scheme), são usados quando duas ou mais entidades desejam compartilhar uma chave secreta única, afim de realizar uma comunicação segura por meio de um protocolo de criptografia simétrico. O acordo de chaves proposto possui as seguintes características:

- Não interativo: Chaves compartilhadas são calculadas sem interação dos nós participantes;

- Chaves Públicas sem certificados (Certificateless): Para o cálculo da chave compartilhada o nó utiliza sua chave secreta e a chave pública do destinatário, que é certificada pela identidade do destinatário;

- Hierárquico: Permite que seja utilizado um gerenciamento hierárquico, para concessão, revogação e distribuição de chaves; e

- Resistente: Permite segurança do sistema mesmo quando nós dentro da hierarquia são comprometidos em qualquer ordem e quantidade.

Este trabalho é uma nova abordagem do artigo "Strongly-Resilent and Non-Interactive Hierarchical Key-Agreement in MANETs" onde substituímos o uso de sistemas baseados na identidade por sistemas sem certificado, eliminando a custódia de chaves em todos os níveis hierárquicos, aumentando a segurança do sistema quanto ao comprometimento de nós. É apresentado ainda uma discussão sobre a segurança do esquema proposto e de acordos de chaves não interativos.

Palavras-chave: sem certificado, acordo de chaves, criptografia, hierarquia, segurança. 


\section{Abstract}

This work presents a new resilient, hierarchical, non-interactive and certificateless key agreement scheme. Cryptographic key agreement schemes (KAS) are used when two or more entities want to share a secret key, in order to realize secure communication using a symmetric encryption protocol. The proposed key agreement has the following characteristics:

- Non-interactive: Any two nodes can compute a unique shared secret key without interaction;

- Certificateless: To compute the shared secret key, each node only needs its own secret key, the identity of its peer and his public key implicitly certified;

- Hierarchical: The scheme is decentralized through a hierarchy where all nodes in the hierarchy can derive the secret keys for each of its children without any limitations or prior knowledge on the number of such children or their identities;

- Resilient: The scheme is resilient against compromise of any number of nodes in the hierarchy.

This work is a new approach about article "Strongly-Resilient and Non-Interactive Hierarchical Key-Agreement in MANETs" which replaces id based system for certificateless system, eliminating the key escrow on all levels, increasing system security against compromised nodes. It also presents a discussion on the security of the proposed scheme and non-interactive key agreement. Keywords: certificateless, criptography, hierarchy, security. 


\section{Sumário}

Lista de Abreviaturas e Siglas $\quad$ ix

Lista de Figuras $\quad$ xi

Lista de Tabelas $\quad$ xiii

1 Introdução 1

1.1 Considerações Preliminares . . . . . . . . . . . . . . . . . . . 1

1.1.1 Criptografia Assimétrica . . . . . . . . . . . . . . . . . 2

1.1 .2 Sistemas Hierárquicos . . . . . . . . . . . . . . . . . . . 3

1.2 Motivação . . . . . . . . . . . . . . . . . . . . . . 3

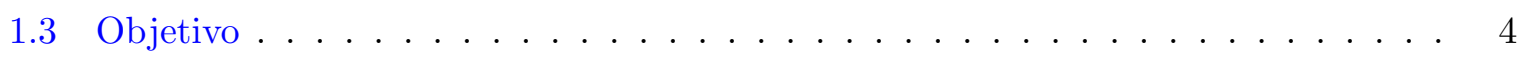

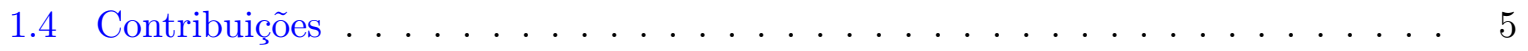

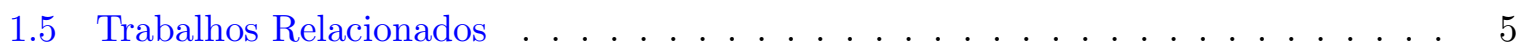

1.6 Organização do Trabalho . . . . . . . . . . . . . . . . . 5

2 Conceitos Preliminares $\quad 7$

2.1 Notações. . . . . . . . . . . . . . . . . . . . . . . . . 7

2.2 Criptografia Simétrica . . . . . . . . . . . . . . . . . . 7

2.3 Criptografia Assimétrica . . . . . . . . . . . . . . . . 8

2.3.1 Infra-estrutura de Chaves Públicas (ICP) $\ldots \ldots \ldots \ldots$

2.3.2 Sistemas Baseados na Identidade . . . . . . . . . . . . . . . . . . . . . . . 9

2.3.3 Sistemas sem Certificados . . . . . . . . . . . . . . . . . . . 10

2.4 Acordo de Chaves . . . . . . . . . . . . . . . . . . . 12

2.4.1 Adversários em Acordos de Chaves sem Certificados . . . . . . . . . . . . 13

2.4.2 Atributos de Segurança em Acordos de Chaves . . . . . . . . . . . . . . . 14

2.5 Níveis de Confiança . . . . . . . . . . . . . . . . . . . . . . . . 14

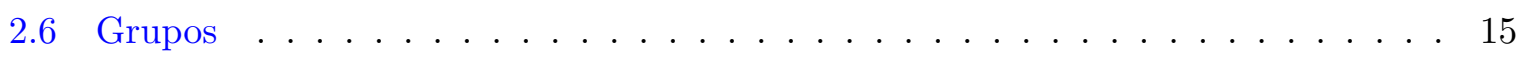

2.7 Emparelhamento Bilinear . . . . . . . . . . . . . . . . . 15

2.8 Problemas Computacionais de Interesse . . . . . . . . . . . . . . . 16

3 Esquema Proposto $r$

3.1 Acordo de Chaves de Mandt . . . . . . . . . . . . . . . . . . . . . . . . . 19

3.2 Vulnerabilidade de Swanson . . . . . . . . . . . . . . . . . . 21

3.2.1 Correção da Vulnerabilidade de Swanson no protocolo de Mandt . . . . . 21

3.3 Acordo de Chaves de Mandt para KGCs Diferentes sem Vulnerabilidade de Swanson 22 
3.4 Deficiência no Protocolo de Mandt para KGCs Diferentes . . . . . . . . . . . . . 24

3.5 Correção da Deficiência para KGCs Diferentes . . . . . . . . . . . . . . . . 24

3.6 Uso em Esquemas Hierárquicos . . . . . . . . . . . . . . . . . 26

3.7 Operação não interativa . . . . . . . . . . . . . . . . . . . . . 29

4 Implementação $\quad 31$

4.1 Escolha da Curva . . . . . . . . . . . . . . . . . . . . . . . . . 31

4.2 Emparelhamento bilinear . . . . . . . . . . . . . . . . . . 31

4.3 Funções Hash . . . . . . . . . . . . . . . . . . . . . . . . . . . . . . . . 31

4.4 Mapeamento das identidades em pontos da curva . . . . . . . . . . . . . . 31

4.5 Parâmetros de segurança . . . . . . . . . . . . . . . . . 32

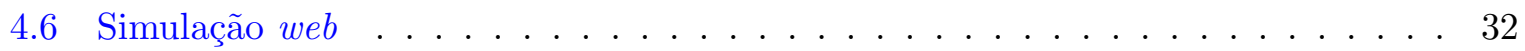

$5 \quad$ Análise do Modelo $\quad 33$

5.1 Modelo de Segurança . . . . . . . . . . . . . . . . . . . . . . 33

5.2 Segurança do Modelo Proposto . . . . . . . . . . . . . . . . . . 35

5.2 .1 Redução para o modelo com $1 \mathrm{KGC}$. . . . . . . . . . . . . . . . 35

5.2 .2 Redução para o modelo com 2 KGC . . . . . . . . . . . . . . . . . 36

5.2.3 Segurança independente dos elementos hierárquicos . . . . . . . . . . . . . . 37

5.3 Eficiência Computacional . . . . . . . . . . . . . . . . . . 37

6 Conclusões $\quad 39$

6.1 Considerações Finais . . . . . . . . . . . . . . . . . . . . . . . . . 39

6.2 Tabela Comparativa . . . . . . . . . . . . . . . . . . . . . . 39

6.3 Sugestões para Pesquisas Futuras . . . . . . . . . . . . . . . . . 40

$\begin{array}{ll}\text { A Mandt corrigido } & 41\end{array}$

B Mandt 2 KGC corrigido $\quad 55$

$\begin{array}{ll}\text { Referências Bibliográficas } & 65\end{array}$ 


\section{Lista de Abreviaturas e Siglas}

CL-KAS - Esquema para acordo de chaves baseado em chaves públicas sem certificados

- (Certificateless Key Agreement Schema).

KAS - Esquema para acordo de chaves (Key Agreement Schema).

KGC - Autoridade de confiança em sistemas sem certificado.

PKI - Infra Estrutura de Chaves Públicas (Public Key Infra-estructure). 


\section{Lista de Figuras}

2.1 Criação de chaves em um sistema com ICP $\ldots \ldots \ldots \ldots$

2.2 Criar chave em Sistemas Baseados na Identidade . . . . . . . . . . . . . . 10

2.3 Criar chave em sistemas sem certificados . . . . . . . . . . . . . . . . 11

2.4 Acordo de chaves . . . . . . . . . . . . . . . . . . . . . . . . 12

2.5 Adversário em acordo de chaves . . . . . . . . . . . . . . . . . . 13

3.1 Acordo de chaves de Mandt . . . . . . . . . . . . . . . . . . . . 20

3.2 Vulnerabilidade de Swanson sobre o acordo de chaves de Mandt . . . . . . . . . . 21 


\section{Lista de Tabelas}

2.1 Notações utilizadas no texto . . . . . . . . . . . . . . . . . . . . . . . . . 7

6.1 Tabela comparativa do protocolo proposto e o protocolo de Gennaro . . . . . . . 39 


\section{Capítulo 1}

\section{Introdução}

A proteção de informações é uma prática e preocupação antiga da humanidade, desde o uso de proteções físicas como selos, chancelas e lacres até e o uso de procedimentos (algoritmos) para mascaramento e ocultamento de informações, que são conhecidos desde os conflitos entre gregos e persas, estendendo-se ao Império Romano, Primeira e Segunda Guerra Mundial e agora com seu principal foco na proteção de informações econômicas e estratégicas.

Os procedimentos que manipulam as informações permitindo sua ocultação e mascaramento deram origem à criptografia, cuja palavra tem origem grega, resultado da união de kryptós (escondido) e grápho (grafia), ou seja, escrita secreta.

Mais informações sobre a criptografia na história, sua evolução e influências até os dias atuais podem ser obtidas em [Kahan 1996] e [Singh 2000], que são obras de leituras bastante agradáveis.

\subsection{Considerações Preliminares}

Apesar de ser usada a criptografia em larga escala desde a história antiga, foi o pesquisador Shannon que definiu formalmente o que significa exatamente "ser seguro" [Shannon 1945] e [Shannon 1949], baseado na teoria da informação, estabeleceu os principais alicerces sobre os quais a criptografia, enquanto ciência, se desenvolveria nas próximas décadas. Ele conseguiu definir, entre outras coisas, o que é "segurança perfeita", quais são os requisitos indispensáveis para se alcançá-la e como analisar quão perto um dado criptossistema está deste ideal de segurança, criando um modelo matemático razoavelmente completo para descrever e analisar sistemas criptográficos. Isto é de extrema importância para o desenvolvimento de qualquer ciência, pois consegue-se assim uma abstração (adequada) da realidade definida por um conjunto de axiomas a partir dos quais se descobrem fatos/verdades (teoremas) sobre a realidade, ou pelo menos sobre a abstração da realidade.

Contudo o conceito de segurança perfeita visa a total incapacidade de obtenção de informação a partir do texto cifrado (mesmo considerando-se um adversário com capacidade ilimitada), inexistindo qualquer relação entre o texto em claro e o texto cifrado. Este estudo é facilmente aplicável a cifras simétricas, onde a chave utilizada para cifrar é a mesma utilizada para decifrar. Por outro lado quando se fala em "Criptografia Assimétrica" ou "Criptografia de Chave Pública"já está subentendido que existem duas chaves, uma secreta de acesso privativo e uma chave pública, de conhecimento de todos os participantes do sistema. A idéia desse sistema é que se use uma chave é utilizada para criptografar, somente com a outra chave é possível descriptografar. A implementação de um sistema criptográfico de chave pública implica que as 
chaves secreta e pública mantém uma relação matemática entre si.

Se a chave pública possui uma relação matemática com a chave secreta, basta utilizar esta relação para obter informações da chave secreta e consequentemente obter o texto original. Contudo num ambiente realista o adversário do sistema estará sujeito as limitações imposta pela tecnologia atual. Foi a partir desta idéia que Goldwasser e Micali em [Goldwasser e Micali 1984] puderam definir a segurança baseada na teoria da complexidade e na intratabilidade de alguns problemas da teoria dos números, e que a possibilidade de um adversário obter informações do texto em claro a partir do texto cifrado é computacionalmente inviável, em outras palavras, um sistema criptográfico será tão seguro quanto um problema computacional conhecido e de difícil solução.

Os criptossistemas simétricos em geral são construídos por algoritmos iterativos, onde cada iteração aumenta a difusão e confusão do texto, já os criptossistemas assimétricos são baseados em propriedade(s) matemática(s) que em geral são construíveis usando-se algoritmos de maior complexidade computacional. Por isso em situações práticas utiliza-se inicialmente um criptossistema assimétrico para a realização de um acordo de chave, em seguida utiliza-se a chave gerada em outro criptossistema simétrico; dois exemplos bem conhecidos são os protocolos SSL/TLS definido pela RFC-2246 que é comumente utilizado para acesso a sítios web seguros (famoso https), e SSH definido pela RFC-4251 que é um terminal de acesso seguro, muito utilizado em conexões de terminais remotos (similar ao telnet).

\subsubsection{Criptografia Assimétrica ou de Chave Pública}

A criptografia de chave pública teve seu marco inicial em [Diffie e Hellman 1976], no qual é proposto um algoritmo de criptografia que possui um par de chaves, por exemplo uma chave 'S' secreta e ' $\mathrm{P}$ ' pública, estas chaves possuem uma relação matemática. De tal maneira que para cifrar um texto em claro para o usuário 'A', basta utilizar o algoritmo de cifração com a chave pública de 'A', o qual poderá decifrar com sua chave secreta de posse exclusiva. Semelhantemente o usuário 'A' pode autenticar um documento, utilizando o algoritmo de assinatura com sua chave privada, e a verificação é feita usando-se a chave pública de 'A'.

Surgiram novos conceitos os de autenticidade e irretratabilidade, onde é possível comprovar que o documento não foi alterado após ter saída da origem e a certeza de quem foi o usuário que enviou o documento pois somente este possui a chave secreta.

Contudo surgiu uma dificuldade, a comprovação de que a chave pública era realmente do usuário que a emitiu, este foi um problema resolvido inicialmente com uma autoridade de confiança que gerava certificados para as chaves públicas. Esse procedimento é conhecido como Infra-estrutura de Chaves Públicas (PKI - Public Key Infra-estruct).

Contudo a manutenção de uma PKI tornou-se complexa para ambientes menores, e com restrições de acesso ou armazenamentos, além do que possui seus próprios riscos tais como os descritos em [Ellison e Schneier 2000]. Surgiu então outras abordagens que dispensam ou que minimizam a utilização da PKI, tal como os sistemas baseado na identidade e sem certificado. O trabalho de [Goya et al. 2009a] sintetiza os principais modelos alternativos de criptografia de chave pública. 


\subsubsection{Sistemas Hierárquicos}

Os sistemas hierárquicos se aplicam em muitas áreas da computação, seja para um melhor gerenciamento ou para uma divisão de tarefas e um controle distribuído. Dentro da área de segurança de dados é fundamental compartimentar segredos, de modo que se uma entidade sofra algum comprometimento, o sistema possa se reorganizar o mais rápido possível e da forma organizada.

Além disso como no caso da PKI, as autoridades de confiança ficariam sobrecarregadas caso tivessem que gerenciar todas as solicitações de autenticação, e certificação. Por isso elas utilizam autoridades em níveis hierárquicos de modo que cada uma autoridade abaixo da hierarquia possua uma função específica e todas são certificadas pela autoridade imediatamente acima, exceto pela autoridade raiz que se certifica a si própria.

Sistemas criptográficos hierárquicos baseados na identidade são muito comuns, contudo, talvez devido a custódia de chaves inerente ao modelo, em [Boneh et al. 2005] é lançado um desafio para que se crie um sistema de criptografia hierárquico baseado na identidade no qual não haja uma degradação exponencial de sua segurança a cada nível da hierarquia.

O trabalho de [Gennaro et al. 2008] apresenta um sistema hierárquico não interativo que é extremamente forte contra comprometimento de nós folhas, esses nós são em geral os mais susceptíveis a comprometimento.

Em contrapartida nos sistemas sem certificado cada entidade possui um segredo privativo de seu conhecimento exclusivo, se garantida a segurança deste segredo, é possível criar sistemas hierárquicos onde o comprometimento de um nó em um determinado nível não degradará a segurança dos níveis superiores ou de outros ramos.

\subsection{Motivação}

Inicialmente apresentamos duas citações a respeito de acordos de chaves, que são: "A distribuição de chaves criptográficas é o principal problema em sistemas criptográficos" [Blundo et al. 1993]; e

"Protocolos de Acordo de Chaves são fundamentais para assegurar comunicação autêntica e privada entre duas entidades sobre uma rede insegura" . [Strangio 2006]

As duas citações possuem o mesmo contexto, apresentando o acordo de chaves como parte do protocolo para estabelecimento de comunicações seguras.

Contudo existem outros aspectos que nos levam a procurar um protocolo específico, e que normalmente não há na literatura, ou pelo menos quando existe um protocolo que atende, este não é prático em uma implementação real. Vejamos algumas características dos protocolos de acordos de chaves não interativos mais comuns e de seus ambientes:

- Os protocolos não interativos normalmente se baseiam em comunicações restritas em ambas as direções tal como o protocolo de [Sakai et al. 2000] utilizado em [Gennaro et al. 2008] e [Oliveira et al. 2007], porém em muitos casos a autoridade de confiança possui meios de transmissão de maior capacidade, e os sistemas receptores podem receber tais transmissões desde que ela seja unidirecional;

- As transmissões podem obedecer alguma ordem, em geral os meios de menor capacidade 
transmitem para os meios de maior capacidade que agrega informações de um grupo e então retransmitem para outros meios de maior capacidade, podemos utilizar com exemplo usuários individuais de internet, que possuem uma capacidade limitada e são ligados a um provedor de maior capacidade de transmissão, o qual concentra vários usuários, e que por sua vez se conecta em entroncamentos de altas velocidades reunindo vários provedores. Em sistemas hierárquicos os nós que estão em níveis superiores também tendem a possuir maior capacidade e maior proteção, tal como os militares, onde os superiores são responsáveis por meios de maior capacidade;

- Se o ambiente for geograficamente distribuído é útil a capacidade de gerar novas entidades que sejam capazes de interagir com todo o sistema, independente de comunicação com a autoridade central. Esta capacidade é útil em onde os sistemas criados devem possuir sigilo máximo, e no caso de serviços de inteligência, as entidades devem ser independentes para não revelar os níveis superiores, os quais salvaguardam vida de agentes e podem desencadear ações terroristas.

Um exemplo prático da aplicação deste trabalho será em comunicações seguras de meios navais em áreas de conflito militar, ou mesmo em exercícios militares. As características deste ambiente são:

- Equipes pequenas devem evitar a comunicação irradiada ao máximo, pois ela permite a localização da fonte emissora;

- Há uma comunicação periódica e unidirecional de estações fixas para todos os integrantes do sistema;

- Entidades podem ser criadas em plena área de conflito para atender alguma necessidade específica, e esta entidade deve estar apta a operar com o sistema sem restrições;

- A maior parte das comunicações obedecem uma hierarquia, e normalmente são de entidades superiores para entidades inferiores; e

- É possível que em operações combinadas (tal como Navios e Fuzileiros), haja a necessidade de comunicação de entidades de diferentes filiação hierárquica.

\subsection{Objetivo}

O objetivo principal deste trabalho é apresentar um algoritmo, para "Acordo de Chaves", obedecendo uma estrutura hierárquica para distribuição e controle de chaves criptográficas; O algoritmo apresentado possui pelo menos um modo não interativo, contudo ele é mais forte se operado no modo interativo; Resistente ao comprometimento ${ }^{1}$ de nós ${ }^{2}$.

Além do objetivo principal é desejável que o algoritmo proposto seja eficiente computacionalmente, demonstravelmente seguro de acordo com um "Modelo de Segurança" e possua uma implementação viável com a tecnologia atual.

\footnotetext{
${ }^{1}$ Considera-se comprometimento a incerteza sobre a manutenção de algum segredo, como exemplo uma falha na segurança de armazenamento da chave secreta.

${ }^{2} \mathrm{~A}$ informação comprometida do nó não deve ser útil para se obter informações sigilosas de outros nós
} 


\subsection{Contribuições}

As principais contribuições deste trabalho são:

- Um estudo sobre acordos de chaves sem certificados;

- Definição e demonstração de acordos de chaves próprios para operações militares;

- Obtenção de um algoritmo eficiente que pode ser implementável em um ambiente real;

- Estender uma aplicação originalmente baseada em identidade para uma baseada em sistemas sem certificados;

- Correção do protocolo de Mandt para uma única autoridade de confiança;

- Identificação de restrições ao uso de mais de uma autoridade de confiança em protocolos de acordos de chaves;

- Correção do protocolo de Mandt para uso com duas autoridades de confiança;

- Utilização do protocolo de Mandt corrigido para utilização em níveis hierárquicos.

\subsection{Trabalhos Relacionados}

O principal trabalho é [Gennaro et al. 2008] o qual propuseram um algoritmo não interativo baseado em identidades para ser usado em ambientes militares, especificamente em MANETs, contudo o algoritmo proposto é eficiente em um ambiente simulado, mas bastante rígido para ser implementado em um ambiente real;

Em [Sakai et al. 2000] é proposto talvez o primeiro acordo de chaves não interativo baseado em identidades que demonstrou-se eficiente; porém não é hierárquico, mas junto com o trabalho de Blom [Blom 1985] e Blundo e outros [Blundo et al. 1993] foi possível construir algoritmos baseados em identidades hierárquicos como os trabalhos de Horwitz e Lynn [Horwitz e Lynn 2002] e o trabalho de Gennaro [Gennaro et al. 2008]. O trabalho de Horwitz e Lynn se destaca pela proteção do nó inicial, que é a "Autoridade de Confiança" do sistema, já Gennaro e outros têm um enfoque na proteção dos nós folhas, onde é previsto uma maior chance de comprometimentos.

No trabalho de Swanson [Swanson 2008], é feito uma extensa investigação de protocolos de acordo de chaves baseados em sistemas sem certificados, inclusive é apresentado um novo modelo de segurança e aplicado modelos de seguranças já definidos para acordos de chaves sem certificados. Swanson também mostrou vulnerabilidades em protocolos de acordo de chaves, os quais não haviam sido identificados por seus autores. Apesar da identificação, Swanson não apresentava possíveis soluções para as vulnerabilidades encontradas. Além disso lançou um desafio para que fosse implementado um protocolo de acordo de chaves que atendesse o modelo proposto, o que foi atendido por [Lippold et al. 2009].

\subsection{Organização do Trabalho}

No Capítulo 2, apresentamos os conceitos principais que usaremos em todo o decorrer deste texto; no Capítulo 3 apresentamos um possível protocolo para acordo de chaves hierárquico baseado em sistemas sem certificados e numa correção do protocolo de Mandt [Mandt e Tan 2006]; 
No capítulo 4 verificamos uma implementação para um ambiente simulado, onde será descrito quais as modificações para uma aplicação em um ambiente real; no capítulo 5 verificamos as restrições e os modelos de segurança; finalmente, no capítulo 6 discutimos algumas conclusões obtidas neste trabalho. Analisamos as vantagens e desvantagens do método proposto em relação ao trabalho anterior [Gennaro et al. 2008]. 


\section{Capítulo 2}

\section{Conceitos Preliminares}

Inicialmente apresentamos as notações mais comuns utilizadas ao longo do texto, em seguida definimos as bases para um acordo de chaves e as ferramentas matemáticas necessárias para implementá-lo sob o modelo sem certificado.

O objetivo deste capítulo é apresentar as noções necessárias e suficientes para o entendimento de todas as demonstrações e resoluções dos próximos capítulos. Não é objetivo do capítulo ser uma referência única dos conceitos aqui apresentados, quando conveniente, e sem perder a completude do assunto, indicamos ao leitor referências que possam complementar eventuais aperfeiçoamentos.

\subsection{Notações}

As principais notações utilizadas em todo o decorrer deste texto, estão sumarizadas na tabela 2.1 .

\begin{tabular}{|l|l|}
\hline Notação & Descrição \\
\hline$q$ & um valor primo grande; \\
\hline $\mathbb{G}_{1}$ & grupo aditivo cíclico de ordem $q ;$ \\
\hline $\mathbb{G}_{2}$ & grupo multiplicativo cíclico de ordem $q ;$ \\
\hline $\mathbb{G}=\langle g\rangle$ & $g$ é um valor gerador do grupo $\mathbb{G}$ \\
\hline $\mathbb{Z}_{q}$ & conjunto dos números inteiros $\bmod q ;$ \\
\hline $\mathbb{Z}_{q}^{*}$ & conjunto dos números inteiros $\bmod q$ relativamente primos a $q ;$ \\
\hline$a, b, c, x, y$ & valores inteiros mod $q ;$ \\
\hline$Q, R \in \mathbb{G}_{1}$ & pontos da curva elíptica em $\mathbb{G}_{1} ;$ \\
\hline$A, B$ & usuários do sistema criptográfico (entidades); \\
\hline$I D A$ & Identificação da entidade A; \\
\hline$n \in \mathbb{N}$ & um valor natural; \\
\hline$H(\cdot) \rightarrow\{0,1\}^{n}$ & Função hash que retorna um valor de $n$ bits; \\
\hline
\end{tabular}

Tabela 2.1: Notações utilizadas no texto

\subsection{Criptografia Simétrica}

São os algoritmos que utilizam uma única chave para cifrar e decifrar um texto, esses algoritmos em geral são iterativos, no qual a cada ciclo são aplicados operações sobre o texto de modo a modificá-lo, aumentando a confusão e difusão no texto em claro, até que não se possa obter informações sobre o texto original a partir do texto cifrado.

A complexidade de tempo destes algoritmos normalmente é linear no tamanho da entrada. 
A definição formal segue o apresentado em [Stinson 2006]:

Definição 2.2.1. Um criptossistema $\mathfrak{C}$ é uma tupla $(\mathcal{P}, \mathcal{C}, \mathcal{K}, \mathcal{E}, \mathcal{D}$,$) onde:$

1. $\mathcal{P}$ é um conjunto enumerável de possíveis textos em claro;

2. $\mathcal{C}$ é um conjunto enumerável de possíveis textos cifrados;

3. $\mathcal{K}$ é um conjunto enumerável de possíveis chaves;

4. Para cada $K \in \mathcal{K}$, exite uma regra de ciframento $e_{K} \in \mathcal{E}$ e uma regra de deciframento $d_{K} \in \mathcal{D}$ correspondente. Cada $e_{K}: \mathcal{P} \rightarrow \mathcal{E}$ e $d_{K}: \mathcal{C} \rightarrow \mathcal{P}$ tais que $d_{K}\left(e_{K}(x)\right)=x, \forall x \in \mathcal{P}$

\subsection{Criptografia Assimétrica}

A "Criptografia de Chave Pública" ou "Criptografia Assimétrica" teve seu marco inicial com o trabalho de [Diffie e Hellman 1976], neste artigo é proposto um algoritmo de criptografia onde são utilizados um par de chaves, por exemplo uma chave 'S' secreta e 'P' pública, onde estas chaves possuem uma relação matemática e caso seja usado a chave pública para cifrar, somente a chave secreta poderá decifrar, caso seja usado a chave secreta para assinar somente a chave pública poderá verificar a assinatura.

Desta maneira para cifrar um texto em claro para o usuário 'A', basta utilizar o algoritmo com a chave pública de 'A', o qual poderá decifrar com sua chave secreta de posse exclusiva. De maneira semelhante o usuário ' $\mathrm{A}$ ' pode assinar (autenticar) um documento, utilizando o algoritmo com sua chave privada, e a verificação é feita usando-se a chave pública de 'A'.

A partir deste trabalho, surgiram os conceitos os de autenticidade, certeza de que o documento não foi alterado, e irretratabilidade, onde o detentor único da chave privada não pode negar sua utilização. Contudo também surgiu uma dificuldade, a comprovação de que a chave pública era realmente do usuário que a emitiu, este foi um problema resolvido inicialmente com uma "Autoridade de Confiança" que passou a gerar certificados para as chaves públicas. As chave públicas da "Autoridade de Confiança" é conhecida aceita por todos os participantes do sistema como válida.

Esse procedimento é conhecido como Infra-estrutura de Chaves Públicas (PKI - Public Key Infra-estruct).

Um criptossistema assimétrico amplia a definição anterior, incluindo a existência de duas chaves relacionadas:

Definição 2.3.1. Um criptossistema assimétrico $\mathfrak{C}$ é uma tupla $(\mathcal{P}, \mathcal{C}, \mathcal{K}, \mathcal{E}, \mathcal{D}$,$) :$

1. Cada entidade possui um par de chaves $\left\langle K_{S}, K_{P}\right\rangle \in \mathcal{K}$, denominadas $K_{S}$ chave privada e $K_{P}$ chave pública;

2. Para cada par de chaves $\left\langle K_{S}, K_{P}\right\rangle \in \mathcal{K}$, exite uma regra de ciframento $e_{K_{P}} \in \mathcal{E}$ e uma regra de deciframento $d_{K_{S}} \in \mathcal{D}$ correspondente. Cada $e_{K_{P}}: \mathcal{P} \rightarrow \mathcal{E}$ e $d_{K_{S}}: \mathcal{C} \rightarrow \mathcal{P}$ tais que $d_{K_{S}}\left(e_{K_{P}}(x)\right)=x, \forall x \in \mathcal{P}$.

Contudo as definições de criptossistemas acima não representa a segurança do protocolo, sendo possível construir sistemas elementares que atendam as definições acima mas que seriam trivialmente inseguros. 
Uma característica dos sistemas assimétricos convencionais é a certificação da chave pública, ou seja, a garantia de que a chave pública pertença a entidade que lhe é atribuída. Esta certificação exigiu a construção de um esquema hierárquico com uma "Autoridade de Confiança", que é uma entidade do sistema na qual todos os participantes aceitam como confiável, e também é responsável para certificar outras entidades e estabelecer novas autoridades. Tal estrutura é conhecida como infra-estrutura de chaves públicas.

\subsubsection{Infra-estrutura de Chaves Públicas (ICP)}

A infra-estrutura de chaves públicas serve para garantir a autenticidade das chaves públicas no sistema; Nesta estrutura existe uma autoridade de confiança, a qual é reconhecida e aceita por todos os participantes do sistema.

Quando o sistema é esparso e distribuído, a autoridade de confiança usa outras entidades para realizar registros e certificações, daí surgem as "Autoridades de Registro", "Autoridades de Certificação" de usuários e de outras autoridades. Esta estrutura torna o modelo de criptossistema com ICP burocrático e custoso.

A comprovação do certificado deve ser feita a todo momento que uma entidade for utilizar uma chave pública. A figura 2.1 apresenta como é feita a criação de uma chave no modelo com ICP, destacamos que a geração do certificado exige o comparecimento da entidade à uma autoridade de registro.

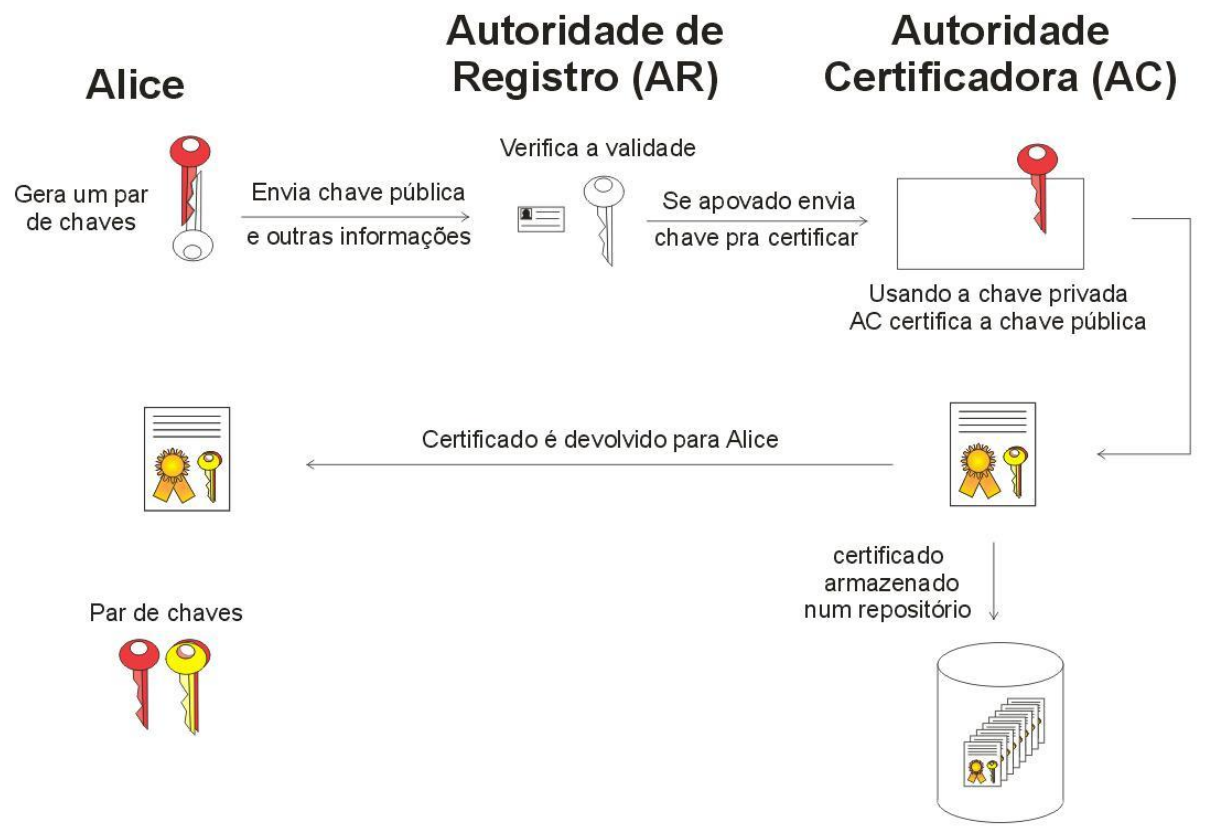

Figura 2.1: Criação de chaves em um sistema com ICP

\subsubsection{Sistemas Baseados na Identidade}

A manutenção de uma PKI tornou-se complexa com o número crescente de usuários, por isso o processo ficou burocrático e demorado, surgindo oportunidade para outras abordagens que dispensam ou que minimizam a utilização da PKI.

A principal abordagem e difundida é a utilização de sistemas baseados na identidade, onde a chave pública é a própria identidade do usuário. Tal sistema foi inicialmente proposto 
por [Shamir 1984], mas o primeiro protocolo eficiente foi baseado em "Emparelhamento Bilineares" sobre curvas elíptica apresentado no Japão por [Sakai et al. 2000] em seguida apresentado no Crypto'2001 com o trabalho de [Boneh e Franklin 2001].

O conceito de "Sistemas Baseados na Identidade" que foi proposto por [Shamir 1984] era baseado na dificuldade de fatoração de grandes números; Neste modelo criptográfico a chave pública é uma identificação pertencente ao usuário, tal como seu número de identidade, o número do CPF, e-mail, nome, e possivelmente adicionada uma indicação de validade. A principal vantagem deste modelo é dispensar a necessidade de uma PKI, pois a chave pública é um valor inerente ao usuário.

Porém neste modelo é requerido que uma "Autoridade de Confiança" emita as chaves secretas para as entidades participantes, isto faz com que a "Autoridade de Confiança" tenha conhecimento de todas as chaves secretas de todas entidades do sistema. Dizemos que o sistema possui custódia das chaves secretas, e muitos sistemas práticos essa custódia não pode ser admitida.

A figura 2.2 apresenta como é criada a chave secreta neste modelo, destaca-se a necessidade da entidade se apresentar pessoalmente para a "Autoridade de Confiança" do sistema, e neste caso a autoridade de confiança possui conhecimento total da chave privada da entidade (custódia de chaves).

Em alguns sistemas a custódia de chaves não é desejada, e por isso foram desenvolvido novos modelos, tal como o modelo "Auto-certificado" e "Sem Certificados".

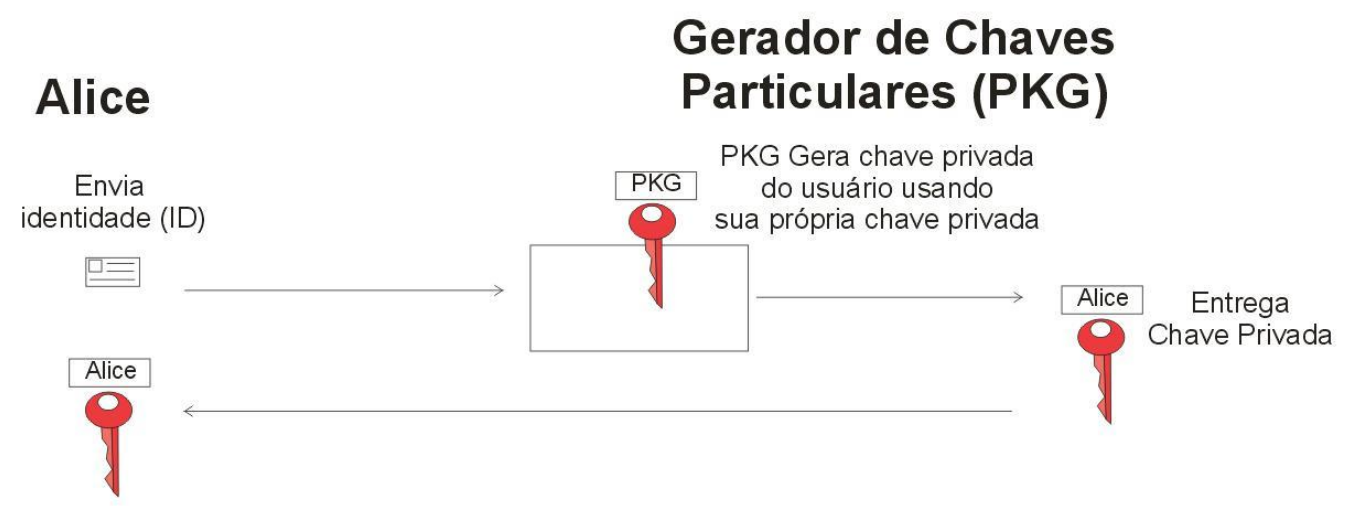

Figura 2.2: Criar chave em Sistemas Baseados na Identidade

\subsubsection{Sistemas sem Certificados}

Uma variante do modelo de sistemas baseados na identidade foi o trabalho apresentado por [Al-Riyami e Paterson 2003] e que deu origem ao modelo de "Chaves Públicas Sem Certificado" (CL - Certificateless), neste modelo a autoridade do sistema não possui custódia de chaves, 
apenas possui uma informação parcial da chave secreta das entidades participantes.

Neste modelo a chave pública não é somente a identificação do usuário, porém a identidade é utilizada para a confirmação da chave pública, ou seja, a identidade do usuário faz parte do processo de criptografia para garantir que a chave pública pertença à entidade a qual se refere.

O modelo de sistemas sem certificados o qual é uma combinação das idéias dos modelos auto-certificado e baseados na identidade. O resultado obtido é um modelo intermediário entre o modelo baseado na identidade e o modelo tradicional com ICP, isto porque:

- usa a identidade como parte da chave pública;

- dispensa os certificados digitais e PKI (certificação implícita);

- elimina custódia de chaves (inerente ao IBS);

Uma característica deste modelo é que a geração da chave pública depende exclusivamente de valores públicos do sistema e valores secretos de posse exclusiva do dono da chave. Em outra palavras, para gerar a chave pública a entidade não precisa ter gerado sua chave secreta completa, basta ter acesso aos parâmetros públicos.

A autoridade de confiança é chamada de "Centro Gerador de Chaves", ou KGC (Key Generation Center). Ela é responsável para entregar para as entidades a chave privada parcial direita, nos esquemas apresentados neste trabalho esta chave corresponde à um ponto sobre uma curva elíptica.

Cada entidade escolhe um valor aleatório que é a sua chave privada parcial esquerda. A partir de sua chave privada parcial esquerda e usando-se de valores públicos cada entidade gera sua chave pública.

A figura 2.3 mostra como é criada a chave pública e privada no modelo sem certificados.

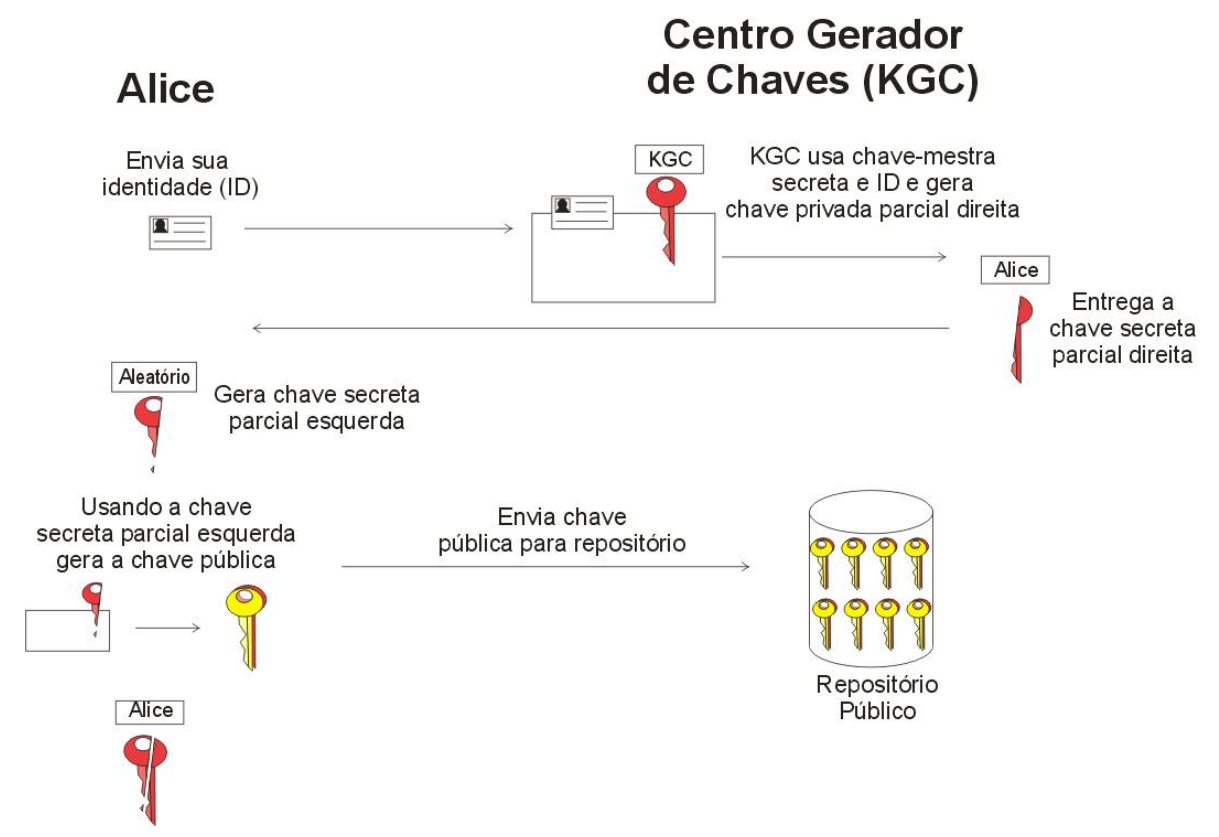

Figura 2.3: Criar chave em sistemas sem certificados 


\subsection{Acordo de Chaves}

Embora a "Criptografia de Chave Pública" tenha permitido que duas entidades se comuniquem de modo seguro sobre um canal inseguro sem uma chave comum compartilhada, os protocolos que implementam normalmente são baseados em conceitos matemáticos, e possuem alta "complexidade computacional", muito superior aos algoritmos simétricos.

Uma aplicação comum nos sistemas criptográficos é algum algoritmo que permita o estabelecimento de uma chave comum (chave única) às entidades a partir de valores públicos. $\mathrm{O}$ protocolo (ou esquema) que permite o estabelecimento da chave simétrica comum é chamado de "Protocolo (ou esquema) para Acordo de Chaves Criptográficas".

Definição 2.4.1. Acordos de Chaves são protocolos que permitem o estabelecimento de uma chave simétrica única, por duas ou mais entidades, através de um canal inseguro, usando-se de informações públicas.

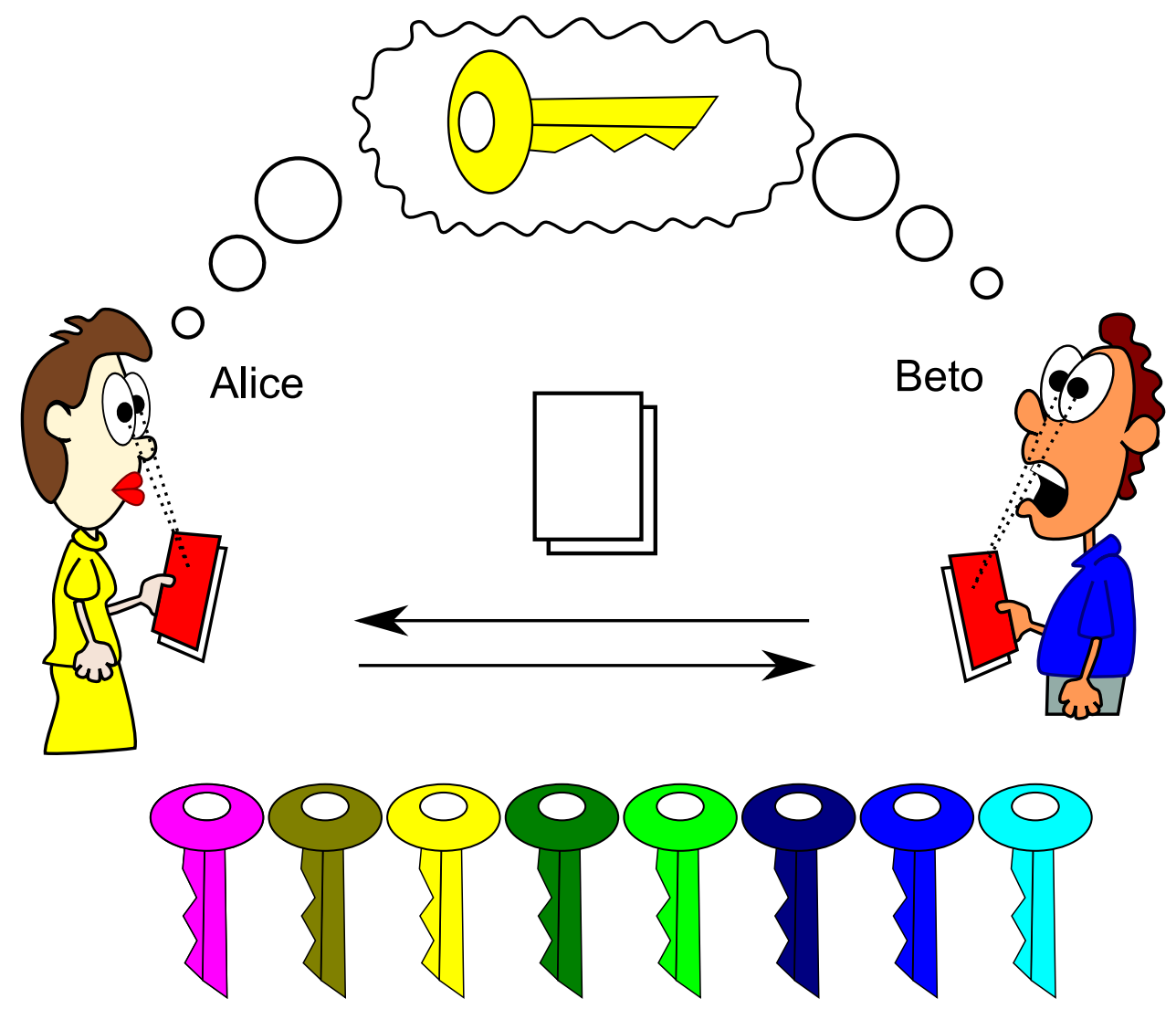

Figura 2.4: Acordo de chaves

Os protocolos para acordo de chaves normalmente se baseiam em valores públicos e secretos de longa duração, também podem possuir valores públicos e secretos de curta duração (valores efêmeros). Os valores efêmeros são criados a cada novo acordo de chaves realizado, normalmente são valores escolhidos aleatoriamente. A figura 2.4 ilustra um acordo de chaves genérico.

Os valores públicos efêmeros são trocados durante o início do acordo de chaves, e o momento em que ocorre a troca destes valores é chamado de tempo de sessão. 
Quando o protocolo não possui valores efêmeros, dizemos que é um protocolo não interativo pois as informações disponíveis para a troca de chaves são valores de longa duração, que podem estar em um repositório público. Na referência [Stinson 2006] Stinson apresenta o conceito similar ao conceito de protocolo para acordo de chaves não interativos o qual chama-o de "PréDistribuição de Chaves"

A chave resultante do acordo de chaves é chamada de chave de sessão.

\subsubsection{Adversários em Acordos de Chaves sem Certificados}

É necessário que identifiquemos as ameaças ao acordo de chaves pretendido, a figura 2.5 ilustra um adversário (Carlos) ao acordo de chaves. O adversário possui conhecimento de todo conteúdo público e deseja descobrir qual chave foi estabelecida pelas entidades Alice e Beto.

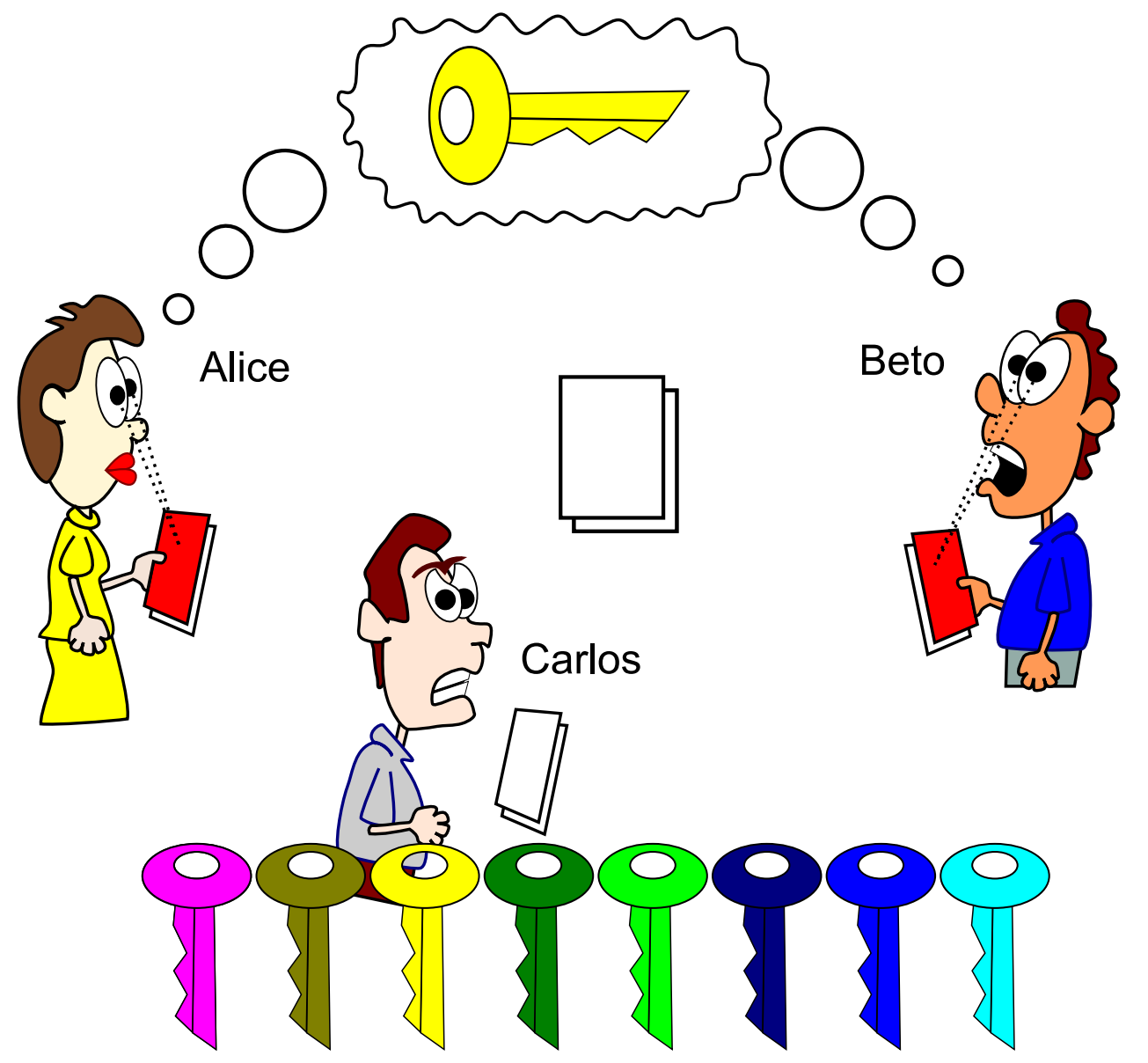

Figura 2.5: Adversário em acordo de chaves

Existem adversários específicos para acordos de chaves sem certificados, como os adversários abaixo:

\section{- Adversários externos}

Não possuem acesso a chave mestra, porém são capazes de substituir as chaves públicas;

- Adversários internos

Possuem acesso a chave mestra, mas não são capazes de substituir as chaves públicas; 


\section{- KGC mal intencionado}

KGC que não estabelece honestamente os parâmetros do sistema, e neste caso estaremos assumindo que seja um adversário interno, e não possa substituir as chaves públicas.

\subsubsection{Atributos de Segurança em Acordos de Chaves}

- Segurança de personificação quanto ao comprometimento da chave:

- Se a chave da entidade $A$ foi comprometida, um atacante $C$ não pode se passar por um outro usuário $B$;

- Todos os sistemas não interativos estão sujeitos a este ataque, pois o atacante tem o mesmo poder que $A$ para calcular a chave compartilhada;

- Nosso esquema proposto operará também no modo não interativo, e tentamos minimizar este problema usando parte da chave pública como valores temporários (duração superior à sessão).

- Segurança de informações temporárias em seções específicas:

- Se um atacante conhecer os valores temporários para estabelecimento da chave de sessão, ele não deve ser capaz de recuperar a chave de sessão estabelecida.

- Segurança da chave de sessão:

- Um atacante que eventualmente tenha acesso a algumas chaves de sessão, não deve ser capaz de calcular futuras chaves de sessão;

- Em sistemas não interativos a chave comum é a mesma, ou é deterministicamente estabelecida em função das chaves anteriores.

- Segredo transmitido:

- Um atacante de posse de uma ou mais chaves secretas, não é capaz de determinar qual a chave de sessão previamente estabelecida;

- Segredo perfeito transmitido, ocorre quando o atacante possui todas as chaves secretas do sistema e não é capaz de determinar chaves de sessões já estabelecidas;

- Segredo parcial transmitido, ocorre quando o atacante possui algumas chaves secretas, mas não todas, e mesmo assim não é capaz de determinar chaves de sessões já estabelecidas;

- Segredo do KGC transmitido, o atacante possui a chave mestra da autoridade de confiança KGC;

\subsection{Níveis de Confiança}

No trabalho de [Girault 1991] é apresentado níveis de confiança para sistemas criptográficos, tal como mostrado abaixo:

Nível 1. autoridade conhece (ou calcula facilmente) chaves secretas dos usuários; pode personificar qualquer entidade sem ser detectada; 
Nível 2. autoridade desconhece (ou dificilmente calcula) chaves secretas dos usuários; pode personificar qualquer entidade, gerando falsas chaves públicas, sem ser detectada;

Nível 3. autoridade desconhece (ou dificilmente calcula) chaves secretas dos usuários; pode personificar qualquer entidade, porém é detectada;

Modelo convencional com PKI geralmente é nível 3; Sistemas IBS em geral são nível 1; O modelo descrito por [Gennaro et al. 2008] é nível 1; Sistemas CLS em geral são nível 2; O Sistema Hierárquico baseado em [Mandt e Tan 2006] é nível 2.

\subsection{Grupos}

Um grupo $\mathbb{G}$ é um conjunto não vazio dotado de uma operação binária o, que satisfaz as seguintes propriedades [Koblitz 1994]:

- Possui um elemento identidade: $\exists i \in \mathbb{G}: \forall a \in \mathbb{G}: i \circ a=a \circ i=a$;

- Possui o elemento inverso: $\forall a \in \mathbb{G}: \exists \bar{a} \in \mathbb{G}: a \circ \bar{a}=i$

- Associatividade: $\forall Q, R, S \in \mathbb{G}:(Q \circ R) \circ S=Q \circ(R \circ S)$;

- Fechamento: $\forall Q, R \in \mathbb{G}: Q \circ R \in \mathbb{G}$.

Quando um grupo é definido para operações de adição podemos dizer que é um grupo aditivo, e iremos representá-lo por $\mathbb{G}_{1}$; quando um grupo é definido para operações de multiplicação dizemos que é um grupo multiplicativo e iremos representá-lo por $\mathbb{G}_{2}$.

Quando o número de elementos de um grupo é finito, este número e chamado de ordem do grupo.

Podemos aplicar a operação o sobre o mesmo elemento $Q \in \mathbb{G}$ do grupo várias vezes, tal como $\underbrace{Q \circ Q \circ Q \circ \cdots \circ Q}_{\text {a vezes }}$. Para $Q \in \mathbb{G}_{1}$ representamos por $a Q$, para $Q \in \mathbb{G}_{2}$ representamos por $Q^{a}$, onde $a \in \mathbb{N}$.

$Q \in \mathbb{G}_{1}$ é um elemento gerador do grupo se $\exists a \in \mathbb{N}: \forall R \in \mathbb{G}_{1}: R=a Q$ ou se $Q \in \mathbb{G}_{2}$, $\exists a \in \mathbb{N}: \forall R \in \mathbb{G}: R=Q^{a}$.

Se o grupo possui um elemento gerador é chamado de cíclico.

\subsection{Emparelhamento Bilinear}

O protocolo proposto por Mandt usa emparelhamentos bilineares admissíveis, que foi proposto inicialmente para fins criptográficos em [Sakai et al. 2000], mas foi em [Boneh e Franklin 2001] onde propuseram o primeiro esquema cifragem baseado na identidade considerado eficiente e demonstrado seguro. A definição a seguir segue esses artigos:

Definição 2.7.1. Sejam $\mathbb{G}_{1}$ e $\mathbb{G}_{2}$ grupos cíclicos de ordem prima $q$. Um emparelhamento bilinear admissível é um mapeamento $e: \mathbb{G}_{1} \times \mathbb{G}_{1} \rightarrow \mathbb{G}_{2}$, que satisfaz as seguintes propriedades:

1. Bilinear: Para qualquer $P, Q, R \in \mathbb{G}_{1}$, temos:

$e(P+Q, R)=e(P, R) \cdot e(Q, R)$

$e(P, Q+R)=e(P, Q) \cdot e(P, R)$

em particular para $a, b \in \mathbb{Z}_{q}$, temos:

$e(a Q, b Q)=e(Q, Q)^{a b}=e(a b Q, Q)=e(Q, a b Q)$ 
2. Não Degeneração: Não leva todos os pares $\mathbb{G}_{1} \times \mathbb{G}_{1}$ à identidade em $\mathbb{G}_{2}$

3. Computável: Existe um algoritmo eficiente que calcula $e(P, Q)$ para todos $P, Q \in \mathbb{G}_{1}$

\subsection{Problemas Computacionais de Interesse}

Em [de Castro et al. 2007] é apresentado uma introdução de noções fortes de segurança, e descrita a metodologia para demonstrar a segurança de um algoritmo criptográfico assimétrico, em suma, é feita uma redução de algum problema difícil à quebra do protocolo alvo. O protocolo de Mandt está baseado nas dificuldades dos problemas do logaritmo discreto sobre curvas elípticas (PLD-CE), problema de Diffie-Hellman bilinear (BDH) e o problema de decisão de Diffie-Hellman bilinear (DBDH).

O Problema do logaritmo discreto sobre curvas elípticas provavelmente é mais difícil que o problema equivalente em $\mathbb{Z}_{q}$; apresentamos abaixo a definição deste problema tal como em [Terada 2008]:

Definição 2.8.1. "Problema do Logaritmo Discreto sobre Curvas Elípticas" (PLD$C E)$ :

- Seja $\mathbb{G}$ um grupo finito com a operação o, $Q \in \mathbb{G}$ gerador do subgrupo $\mathbb{J} \subseteq \mathbb{G}$

- Dado $R \in \mathbb{J}$, onde $R \neq Q$

- Encontrar $a \in \mathbb{Z}_{q}^{*}$, tal que $R=\underbrace{Q \circ Q \circ \ldots Q}_{\text {a vezes }}$, onde $1 \leq a \leq(|\mathbb{J}|-1)$

Se $\mathbb{G}$ é o conjunto finito de pontos sobre uma curva elíptica e a operação o é a soma de dois pontos, então encontrar o valor $a$, tal que $R=a Q$.

Seguem as definições do problemas de Diffie-Hellman Bilinear como apresentado em [Boneh e Franklin 2001]:

Definição 2.8.2. "Problema Computacional de Diffie-Hellman" $(C D H)$ :

Dado $a Q$ e $b Q \in \mathbb{G}$,

onde $Q$ um gerador do grupo $\mathbb{G}$ :

Encontrar o valor de $a b Q$.

Definição 2.8.3. "Problema de Decisão Computacional de Diffie-Hellman" (DDH):

Dados $a Q, b Q$ e $c Q \in \mathbb{G}$,

onde $Q$ um gerador do grupo $\mathbb{G}$ :

decidir se $a Q=b c Q$. 
Definição 2.8.4. "Problema de Diffie-Hellman Bilinear" (BDH):

- Sejam $\mathbb{G}_{1}$ e $\mathbb{G}_{2}$ grupos cíclicos de ordem prima $q$, o valor $Q$ um gerador do grupo $\mathbb{G}_{1}$, valores $a, b, c \in \mathbb{Z}_{q}^{*}$ e a função $e: \mathbb{G}_{1} \times \mathbb{G}_{1} \rightarrow \mathbb{G}_{2}$ um emparelhamento bilinear admissível;

- $\operatorname{Dados} Q, a Q, b Q, c Q \in \mathbb{G}_{1}$;

- Encontrar $e(Q, Q)^{a b c} \in \mathbb{G}_{2}$.

Definição 2.8.5. "Problema de Decisão de Diffie-Hellman Bilinear" ( $D B D H)$ :

- Sejam $\mathbb{G}_{1}$ e $\mathbb{G}_{2}$ grupos cíclicos de ordem prima $q$, o valor $Q$ um gerador do grupo $\mathbb{G}_{1}$, valores $a, b, c \in \mathbb{Z}_{q}^{*}$ e a função $e: \mathbb{G}_{1} \times \mathbb{G}_{1} \rightarrow \mathbb{G}_{2}$ um emparelhamento bilinear admissível;

- $\operatorname{Dados} Q, a Q, b Q, c Q \in \mathbb{G}_{1}$ e $z \in \mathbb{G}_{2}$;

- Decidir se $z=e(Q, Q)^{a b c}$.

Usaremos os problemas acima para evidenciarmos as correções de vulnerabilidades e deficiências identificadas. 


\section{Capítulo 3}

\section{Esquema Proposto}

Neste capítulo iremos descrever nossa proposta de protocolo não interativo baseado em criptografia sem certificado, partimos de um protocolo implementado inicialmente por [Mandt e Tan 2006], e que foi corrigido e ampliado para operação em ambientes hierárquicos não interativos.

Cabe ressaltar que o conteúdo deste capítulo foi apresentado no SBSeg'2009, publicado em seus anais e consta da referência [Rufino 2009].

\subsection{Acordo de Chaves de Mandt}

A seguir apresentamos os acordos de chaves iniciando pelas definições gerais, valores definidos pela autoridade de confiança, seguidos pelas definições específicas das entidades participantes, cálculo do valor comum entre duas entidades $A$ e $B$ (codinomes para Alice e Beto) e terminamos com a verificação da consistência das chaves.

\section{Definições gerais}

- $q$ um valor primo grande;

- $\mathbb{G}_{1}$ e $\mathbb{G}_{2}$ grupos cíclicos de ordem $q$;

- $e: \mathbb{G}_{1} \times \mathbb{G}_{1} \rightarrow \mathbb{G}_{2}$ um emparelhamento bilinear admissível.

\section{Definições da autoridade de confiança (KGC)}

- Define $\mathbb{G}_{1}$ e $\mathbb{G}_{2}$;

- Escolhe $e: \mathbb{G}_{1} \times \mathbb{G}_{1} \rightarrow \mathbb{G}_{2}$;

- Escolhe um valor $Q$ gerador do grupo $\mathbb{G}_{1}$;

- Calcula o valor público $Q_{o}=s Q$;

- Escolhe um valor aleatório secreto $s \in \mathbb{Z}_{q}^{*}$;

- Escolhe uma função hash $H:\{0,1\}^{*} \rightarrow \mathbb{G}_{1}$;

- Escolhe a função de derivação da chave de sessão $f: \mathbb{G}_{2} \times \mathbb{G}_{1} \times \mathbb{G}_{1} \rightarrow\{0,1\}^{n}$, onde $n \in \mathbb{N}$.

Definições para uma entidade qualquer (por exemplo Alice)

- Define-se o valor público $R_{\text {Alice }}=H\left(I D_{\text {Alice }}\right)$

- Recebe de KGC o valor secreto $d_{\text {Alice }}=s R_{\text {Alice }}$; 
- Escolhe um valor aleatório secreto $x_{\text {Alice }} \in \mathbb{Z}_{q}^{*}$;

- Chave secreta completa $s_{\text {Alice }}=\left\langle x_{\text {Alice }}, d_{\text {Alice }}\right\rangle$;

- Chave pública $P_{\text {Alice }}=x_{\text {Alice }} Q$

- Durante a fase de sessão:

- Escolhe um valor aleatório $a \in \mathbb{Z}_{q}^{*}$ (Beto escolhe um valor $b$ )

- Calcula e envia o valor público $T_{\text {Alice }}=a Q$

Cálculo do valor comum $v_{A B}$ entre as entidades Alice e Beto

$$
v_{A B}=e\left(R_{\text {Beto }}, P_{\text {Beto }}+Q_{o}\right)^{a} \cdot e\left(x_{\text {Alice }} R_{\text {Alice }}+d_{\text {Alice }}, T_{\text {Beto }}\right)
$$

Cálculo da chave de sessão $k_{A B}$ entre as entidades Alice e Beto

$$
\begin{aligned}
k_{A B} & =f\left(v_{A B}, a T_{\text {Beto }}, x_{\text {Alice }} P_{\text {Beto }}\right) \\
& =f\left(v_{A B}, a b Q, x_{\text {Alice }} x_{\text {Beto }} Q\right)
\end{aligned}
$$

\section{Consistência das chaves de sessão}

Para verificar que a chave $k_{A B}$, calculada pela Alice, é igual à chave $k_{B A}$, calculada pelo Beto, basta observar que os valores comuns são iguais:

$$
\begin{aligned}
& v_{\text {AB }}=e\left(R_{\text {Beto }}, P_{\text {Beto }}+Q_{o}\right)^{a} \quad \cdot e\left(x_{\text {Alice }} R_{\text {Alice }}+d_{\text {Alice }}, T_{\text {Beto }}\right) \\
& =e\left(R_{\text {Beto }}, x_{\text {Beto }} Q+s Q\right)^{a} \quad \cdot e\left(x_{\text {Alice }} R_{\text {Alice }}+s R_{\text {Alice }}, b Q\right) \\
& =e\left(R_{\text {Beto }},\left(x_{\text {Beto }}+s\right) Q\right)^{a} \quad \cdot e\left(\left(x_{\text {Alice }}+s\right) R_{\text {Alice }}, b Q\right) \\
& =e\left(R_{\text {Beto }}, Q\right)^{a\left(x_{\text {Beto }}+s\right)} \quad \cdot e\left(R_{\text {Alice }}, Q\right)^{b\left(x_{\text {Alice }}+s\right)} \\
& =e\left(\left(x_{\text {Beto }}+s\right) R_{\text {Beto }}, a Q\right) \quad \cdot e\left(R_{\text {Alice }},\left(x_{\text {Alice }}+s\right) Q\right)^{b} \\
& =e\left(x_{\text {Beto }} R_{\text {Beto }}+s R_{\text {Beto }}, a Q\right) \cdot e\left(R_{\text {Alice }}, x_{\text {Alice }} Q+s Q\right)^{b} \\
& v_{B A}=e\left(x_{\text {Beto }} R_{\text {Beto }}+d_{\text {Beto }}, T_{\text {Alice }}\right) \cdot e\left(R_{\text {Alice }}, P_{\text {Alice }}+Q_{o}\right)^{b}
\end{aligned}
$$

Com esta igualdade comprova-se que a chave $k_{A B}$ é consistente com a chave $k_{B A}$.

As considerações de segurança podem ser vistas no artigo original em [Mandt e Tan 2006]. A figura 3.1 apresenta a interação entre os usuários para estabelecimento da chave comum.

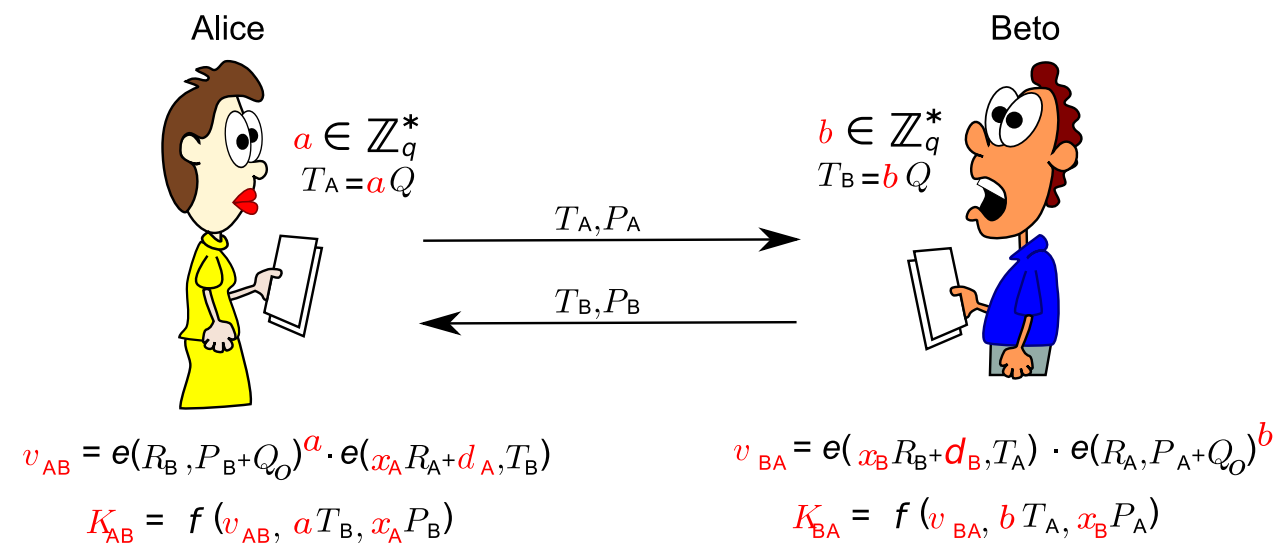

Figura 3.1: Acordo de chaves de Mandt 


\subsection{Vulnerabilidade de Swanson}

Em [Swanson 2008] é mostrado como um adversário externo $E$ pode assumir a identidade de um usuário legítimo $B$ perante o usuário $A$, conhecendo apenas o valor secreto $x_{A}$, como apresentado a seguir:

- O adversário $E$ substitui a chave pública de $B$ por $P_{B}^{*}=-Q_{o}+\beta Q$, onde $\beta$ é um valor aleatório escolhido;

- Envia para o usuário $A$ a chave pública $P_{B}^{*}$ e o valor $T_{B}=b Q$;

- No protocolo original a chave pública $P_{B}$ é somente o valor $x_{B} Q$ (que corresponde a um ponto na curva), e portanto $A$ somente verificará se $P_{B}^{*} \in \mathbb{G}_{1}$;

- O usuário $A$ calculará normalmente o valor comum $v_{A B}$ :

$$
\begin{array}{rlrl}
v_{A B} & =e\left(R_{B}, P_{B}^{*}+Q_{o}\right)^{a} & & \cdot e\left(x_{A} R_{A}+d_{A}, T_{B}\right) \\
& =e\left(R_{B},-Q_{o}+\beta Q+Q_{o}\right)^{a} \cdot e\left(x_{A} R_{A}+s R_{A}, b Q\right) \\
& =e\left(R_{B}, \beta Q\right)^{a} & \cdot e\left(\left(x_{A}+s\right) R_{A}, b Q\right) \\
& =e\left(R_{B}, Q\right)^{a \beta} & \cdot e\left(R_{A}, Q\right)^{b\left(x_{A}+s\right)} \\
& =e\left(\beta R_{B}, a Q\right) & \cdot e\left(R_{A},\left(x_{A}+s\right) Q\right)^{b} \\
& =e\left(\beta R_{B}, a Q\right) & & \cdot e\left(R_{A}, x_{A} Q+s Q\right)^{b} \\
v_{B A}^{*} & =e\left(\beta R_{B}, T_{A}\right) & & \cdot e\left(R_{A}, P_{A}+Q_{o}\right)^{b}
\end{array}
$$

- O valor de $x_{A}$ é necessário na função de derivação da chave de sessão $f$, pois o adversário precisa do valor $x_{A} X_{B}=x_{A} x_{B} Q$.

Esta vulnerabilidade ocorre porque o valor da chave pública do protocolo original de Mandt não é assegurado quanto a sua legitimidade. A figura 3.2 ilustra como o adversário obtém a identidade do usuário legítimo Beto perante Alice.

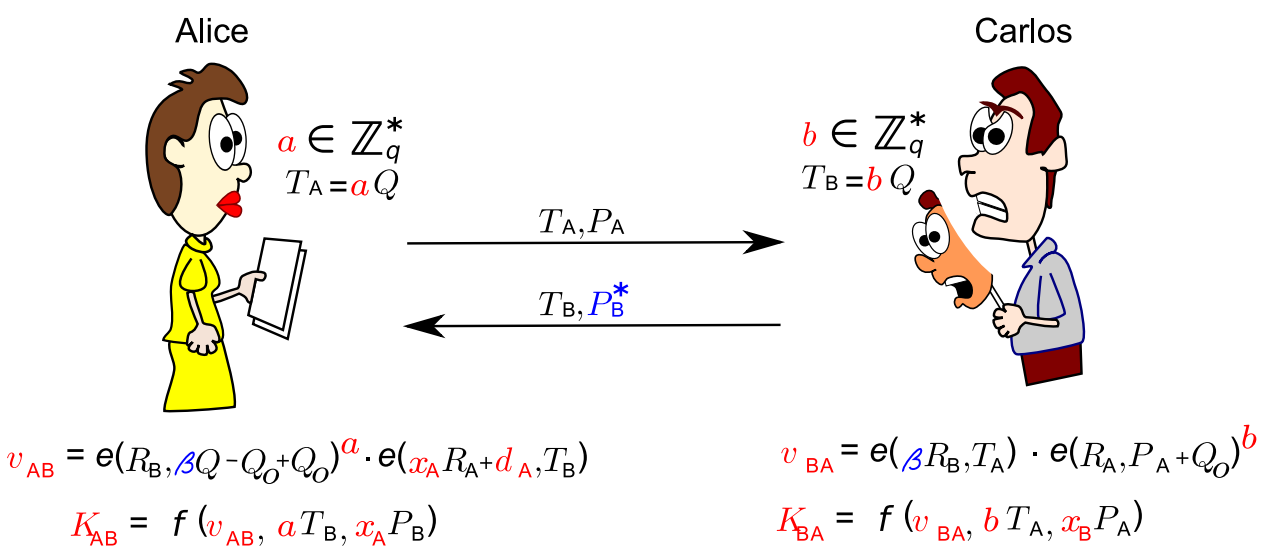

Figura 3.2: Vulnerabilidade de Swanson sobre o acordo de chaves de Mandt

\subsubsection{Correção da Vulnerabilidade de Swanson no protocolo de Mandt}

Sugerimos como solução para este problema estabelecer a chave pública tal qual [Al-Riyami e Paterson 2003], idealizadores do modelo sem certificados:

$$
P_{A}=\left\langle X_{A}, Y_{A}\right\rangle=\left\langle x_{A} Q, x_{A} Q_{o}\right\rangle
$$


Então cada usuário deve conferir o emparelhamento a seguir, antes de calcular o valor comum:

$$
\begin{array}{cl}
e\left(Q, Y_{A}\right) & \stackrel{?}{=} e\left(Q_{o}, X_{A}\right) \text { pois } \\
e\left(Q, x_{A} s Q\right) & =e\left(s Q, x_{A} Q\right)=e(Q, Q)^{x_{A} s}
\end{array}
$$

Para que o adversário tenha êxito em substituir $P_{B}=\left\langle X_{B}, Y_{B}\right\rangle$, ele poderia substituir $X_{B}$ por $X_{B}^{*}=-Q_{o}+\beta Q$, mas precisaria calcular o valor:

$$
Y_{B}^{*}=x_{B}^{*} s Q=(\beta-s) s Q
$$

Para este cálculo o adversário precisa do valor $s$, contudo este valor está protegido pelo PLD-CE.

Esta vulnerabilidade provavelmente fez com que pesquisadores optassem por usar outros esquemas, e por isto uma deficiência específica para KGCs diferentes tenha ficado oculta. Além disso o emparelhamento bilinear é a operação mais complexa nos acordos de chaves de Mandt e Al-Riyami, e provavelmente a principal vantagem do acordo de chaves proposto em [Mandt e Tan 2006] é ter um número menor de emparelhamentos do que a proposta original de [Al-Riyami e Paterson 2003]. Como a correção implica necessariamente no uso de mais emparelhamentos, não houve interesse pela proposta de Mandt.

\subsection{Acordo de Chaves de Mandt para KGCs Diferentes sem Vulnerabilidade de Swanson}

Para usuários pertencentes a KGCs diferentes o protocolo é bem similar, o protocolo mostrado a seguir foi modificado da versão original para evitar a vulnerabilidade descrita em [Swanson 2008]:

\section{Definições gerais}

- $q$ um valor primo grande;

- $\mathbb{G}_{1}$ e $\mathbb{G}_{2}$ grupos cíclicos de ordem $q$;

- $e: \mathbb{G}_{1} \times \mathbb{G}_{1} \rightarrow \mathbb{G}_{2}$ um emparelhamento bilinear admissível.

\section{Definições da autoridade de confiança principal}

Não é claro, na definição de Mandt, quem estabelece os parâmetros para o sistema, mas podemos supor que exista uma autoridade de confiança principal que define os seguintes parâmetros:

- Define $\mathbb{G}_{1}$ e $\mathbb{G}_{2}$;

- Escolhe $e: \mathbb{G}_{1} \times \mathbb{G}_{1} \rightarrow \mathbb{G}_{2}$;

- Escolhe um valor $Q$ gerador do grupo $\mathbb{G}_{1}$;

- Escolhe um valor aleatório secreto $s \in \mathbb{Z}_{q}^{*}$;

- Calcula o valor público $Q_{o}=s Q$;

- Escolhe uma função hash $H:\{0,1\}^{*} \rightarrow \mathbb{G}_{1}$;

- Escolhe a função de derivação da chave de sessão $f: \mathbb{G}_{2} \times \mathbb{G}_{1} \times \mathbb{G}_{1} \rightarrow\{0,1\}^{n}$, onde $n \in \mathbb{N}$. 
Definições da autoridade de confiança $\left(\mathrm{KGC}_{i}\right)$

- Escolhe um valor aleatório secreto $s_{i} \in \mathbb{Z}_{q}^{*}$;

- Calcula o valor público $Q_{i}=s_{i} Q$;

- Calcula o valor público $Q_{o_{i}}=s_{i} Q_{o}$

Definições para uma entidade $A$ pertencente ao $\mathrm{KGC}_{i}$

- Define-se o valor público $R_{A}=H\left(I D_{A}\right)$

- Recebe de $\mathrm{KGC}_{i}$ o valor secreto $d_{A_{i}}=s_{i} R_{A}$;

- Escolhe um valor aleatório secreto $x_{A} \in \mathbb{Z}_{q}^{*}$;

- Chave secreta completa $s_{A}=\left\langle x_{A}, d_{A_{i}}\right\rangle$;

- Chave pública $P_{A}=\left\langle X_{A}, Y_{A}\right\rangle=\left\langle x_{A} Q, x_{A} Q_{o}\right\rangle$

- Durante a fase de sessão:

- Escolhe um valor aleatório $a \in \mathbb{Z}_{q}^{*}$

- Calcula e envia o valor público $T_{A}=a Q$

Cálculo do valor comum $v_{A B}$ pela entidade $A$ do $K G C_{1}$ para com $B$ do $K G C_{2}$

- Verifica a validade da chave pública de $B$ e $\mathrm{KGC}_{2}$ :

$e\left(Q, Y_{B}\right) \stackrel{?}{=} e\left(Q_{o}, X_{B}\right)$

$e\left(Q, Q_{o_{2}}\right) \stackrel{?}{=} e\left(Q_{o}, Q_{2}\right)$

- Se os emparelhamento forem iguais, calcula o valor comum:

$$
v_{A B}=e\left(R_{B}, X_{B}+Q_{2}\right)^{a} \cdot e\left(x_{A} R_{A}+d_{A_{1}}, T_{B}\right)
$$

Cálculo da chave de sessão $k_{A B}$ entre as entidades $A$ e $B$

$$
\begin{aligned}
k_{A B} & =f\left(v_{A B}, a T_{B}, x_{A} X_{B}\right) \\
& =f\left(v_{A B}, a b Q, x_{A} x_{B} Q\right)
\end{aligned}
$$

\section{Consistência das chaves de sessão}

Não há alterações na função de derivação da chave de sessão, por isso só precisamos verificar que o valor comum calculado pela entidade $A$ é igual ao valor comum calculado pela entidade $B$ :

$$
\begin{aligned}
& v_{A B}=e\left(R_{B}, X_{B}+Q_{2}\right)^{a} \quad \cdot e\left(x_{A} R_{A}+d_{A_{1}}, T_{B}\right) \\
& =e\left(R_{B}, x_{B} Q+s_{2} Q\right)^{a} \cdot e\left(x_{A} R_{A}+s_{1} R_{A}, b Q\right) \\
& =e\left(R_{B},\left(x_{B}+s_{2}\right) Q\right)^{a} \cdot e\left(\left(x_{A}+s_{1}\right) R_{A}, b Q\right) \\
& =e\left(R_{B}, Q\right)^{a\left(x_{B}+s_{2}\right)} \quad \cdot e\left(R_{A}, Q\right)^{b\left(x_{A}+s_{1}\right)} \\
& =e\left(\left(x_{B}+s_{2}\right) R_{B}, a Q\right) \cdot e\left(R_{A},\left(x_{A}+s_{1}\right) Q\right)^{b} \\
& =e\left(x_{B} R_{B}+s_{2} R_{B}, a Q\right) \cdot e\left(R_{A}, x_{A} Q+s_{1} Q\right)^{b} \\
& v_{B A}=e\left(x_{B} R_{B}+d_{B_{2}}, T_{A}\right) \cdot e\left(R_{A}, X_{A}+Q_{1}\right)^{b}
\end{aligned}
$$




\subsection{Deficiência no Protocolo de Mandt para KGCs Diferentes}

Apresentamos como um adversário externo $E$ pode assumir a identidade de um usuário legítimo $B$ perante o usuário $A$, desde que estejam sob KGCs diferentes:

- O adversário $E$ escolhe aleatoriamente um valor $s_{E} \in \mathbb{Z}_{q}^{*}$;

- Constrói um falso $\mathrm{KGC}_{E}$ e lhe atribui o valor de $Q_{E}=s_{E} Q$ e $Q_{o E}=s_{E} Q_{o}$, substituindo a chave pública do verdadeiro KGC da entidade $B$;

- Calcula sua chave pública como $P_{B}^{*}=\left\langle X_{B}^{*}, Y_{B}^{*}\right\rangle=\left\langle x_{B}^{*} Q, x_{B}^{*} Q_{o}\right\rangle$

- Envia normalmente para a entidade $A$ a chave pública $P_{B}^{*}$ e o valor $T_{B}^{*}=b Q$

- A entidade $A$ irá verificar a chave pública com os emparelhamentos:

$e\left(Q, Y_{B}^{*}\right) \stackrel{?}{=} e\left(Q_{o}, X_{B}^{*}\right)$ $e\left(Q, Q_{o_{E}}\right) \stackrel{?}{=} e\left(Q_{o}, Q_{E}\right)$;

- A verificação é válida;

- A entidade $A$ do $\mathrm{KGC}_{1}$ irá calcular a chave de sessão normalmente com a entidade $E$, sem perceber que o KGC usado pelo adversário é falso, como segue:

$$
\begin{aligned}
& v_{A B}=e\left(R_{B}, X_{B}^{*}+Q_{E}\right)^{a} \quad \cdot e\left(x_{A} R_{A}+d_{A_{1}}, T_{B}^{*}\right) \\
& =e\left(R_{B}, x_{B}^{*} Q+s_{E} Q\right)^{a} \cdot e\left(x_{A} R_{A}+s_{1} R_{A}, b Q\right) \\
& =e\left(R_{B},\left(x_{B}^{*}+s_{E}\right) Q\right)^{a} \cdot e\left(\left(x_{A}+s_{1}\right) R_{A}, b Q\right) \\
& =e\left(R_{B}, Q\right)^{a\left(x_{B}^{*}+s_{E}\right)} \quad \cdot e\left(R_{A}, Q\right)^{b\left(x_{A}+s_{1}\right)} \\
& =e\left(\left(x_{B}^{*}+s_{E}\right) R_{B}, a Q\right) \cdot e\left(R_{A},\left(x_{A}+s_{1}\right) Q\right)^{b} \\
& =e\left(x_{B}^{*} R_{B}+s_{E} R_{B}, a Q\right) \cdot e\left(R_{A}, x_{A} Q+s_{1} Q\right)^{b} \\
& v_{B A}=e\left(x_{B}^{*} R_{B}+s_{E} R_{B}, T_{A}\right) \cdot e\left(R_{A}, X_{A}+Q_{1}\right)^{b}
\end{aligned}
$$

A solução trivial para evitar esta deficiência é entregar para todas as entidades as chaves públicas de todos os KGCs. Contudo isso deve ser feito através de um canal autêntico. Para garantir autenticidade normalmente se usa algum tipo de certificação, mas se for usada a certificação tradicional, seriam perdidas as vantagens de um sistema sem certificado. Daí surge a questão, por que não usar o próprio algoritmo para garantir a certificação dos KGCs? A resposta a este questionamento é a base da nossa solução proposta.

Esta deficiência ocorre porque não existem relações privadas entre as chaves secretas dos KGCs, isto permite que qualquer participante do sistema gere seu próprio KGC.

\subsection{Correção da Deficiência para KGCs Diferentes}

Nossa proposta para corrigir esta deficiência é construir uma relação privada entre cada novo KGC do sistema e uma autoridade de confiança comum a todos os usuários, e todos os KGCs deverão ser construídos a partir desta autoridade de confiança. É desejável que após criado um novo KGC, este tenha independência da autoridade de confiança que o criou, podendo gerar novas entidades participantes do sistema, as quais serão autenticadas através de valores públicos. Vejamos como isto pode ser feito: 


\section{Definições gerais}

- $q$ um valor primo grande;

- $\mathbb{G}_{1}$ e $\mathbb{G}_{2}$ grupos cíclicos de ordem $q$;

- $e: \mathbb{G}_{1} \times \mathbb{G}_{1} \rightarrow \mathbb{G}_{2}$ um emparelhamento bilinear admissível.

Definições da autoridade de confiança comum (KGC $\left.{ }_{o}\right)$

- Define $\mathbb{G}_{1}$ e $\mathbb{G}_{2}$;

- Escolhe $e: \mathbb{G}_{1} \times \mathbb{G}_{1} \rightarrow \mathbb{G}_{2}$;

- Escolhe um valor $Q$ gerador do grupo $\mathbb{G}_{1}$;

- Escolhe um valor aleatório secreto $s_{o} \in \mathbb{Z}_{q}^{*}$;

- Calcula o valor público $Q_{o}=s_{o} Q$;

- Escolhe uma função hash $H:\{0,1\}^{*} \rightarrow \mathbb{G}_{1}$;

- Escolhe a função de derivação da chave de sessão $f: \mathbb{G}_{2} \times \mathbb{G}_{1} \times \mathbb{G}_{1} \rightarrow\{0,1\}^{n}$, onde $n \in \mathbb{N}$.

Definições da autoridade de confiança $\left(\mathrm{KGC}_{i}\right)$

- Define-se o valor público $R_{K G C_{i}}=H\left(I D_{K G C_{i}}\right)$

- Recebe de $K G C_{o}$ o valor secreto $d_{K G C_{i}}=s_{o} R_{K G C_{i}}$;

- Escolhe um valor aleatório secreto $s_{i} \in \mathbb{Z}_{q}^{*}$;

- Chave secreta completa $s_{K G C_{i}}=\left\langle s_{i}, d_{K G C_{i}}\right\rangle$;

- Chave pública $P_{K G C_{i}}=\left\langle X_{K G C_{i}}, Y_{K G C_{i}}\right\rangle=\left\langle s_{i} Q, s_{i} Q_{o}\right\rangle$

Definições para uma entidade $A$ pertencente ao $\mathrm{KGC}_{i}$

- Define-se o valor público $R_{A}=H\left(I D_{A}\right)$

- Recebe de $\mathrm{KGC}_{i}$ o valor secreto $d_{A_{i}}=s_{i} R_{A}+d_{K G C_{i}}$;

- Escolhe um valor aleatório secreto $x_{A} \in \mathbb{Z}_{q}^{*}$;

- Chave secreta completa $s_{A}=\left\langle x_{A}, d_{A_{i}}\right\rangle$;

- Chave pública $P_{A}=\left\langle X_{A}, Y_{A}\right\rangle=\left\langle x_{A} Q, x_{A} Q_{o}\right\rangle$

- Durante a fase de sessão:

- Escolhe um valor aleatório $a \in \mathbb{Z}_{q}^{*}$

- Calcula e envia o valor público $T_{A}=a Q$ 
Cálculo do valor comum $v_{A B}$ pela entidade $A$ do $K G C_{1}$ para com $B$ do $K G C_{2}$

- Verifica a chave pública de $B$ e $\mathrm{KGC}_{2}$ :

$$
\begin{aligned}
& e\left(Q, Y_{B}\right) \stackrel{?}{=} e\left(Q_{o}, X_{B}\right) \\
& e\left(Q, Y_{K G C_{2}}\right) \stackrel{?}{=} e\left(Q_{o}, X_{K G C_{2}}\right)
\end{aligned}
$$

- Se a verificação for válida, calcula o valor comum:

$$
v_{A B}=\left[e\left(R_{B}, X_{B}+X_{K G C_{2}}\right) \cdot e\left(R_{K G C_{2}}, Q_{o}\right)\right]^{a} \cdot e\left(x_{A} R_{A}+d_{A_{1}}, T_{B}\right)
$$

O cálculo da chave comum utiliza um emparelhamento a mais, que é a conferência da relação do $K G C_{2}$ e o $K G C_{o}$, neste novo emparelhamento permanece a exponenciação do valor efêmero $a$, que continua protegido pela dificuldade dos problemas BDH e DBDH.

Cálculo da chave de sessão $k_{A B}$ entre as entidades $A$ e $B$

$$
\begin{aligned}
k_{A B} & =f\left(v_{A B}, a T_{B}, x_{A} X_{B}\right) \\
& =f\left(v_{A B}, a b Q, x_{A} x_{B} Q\right)
\end{aligned}
$$

\section{Consistência das chaves de sessão}

De igual forma não há alterações na função de derivação da chave de sessão, por isso só precisamos verificar que o valor comum calculado pela entidade $A$ é igual ao valor comum calculado pela entidade $B$ :

$$
\begin{aligned}
K_{A B}^{\prime} & =\left[e\left(R_{B}, X_{B}+X_{K G C_{2}}\right) \cdot e\left(R_{K G C_{2}}, Q_{o}\right)\right]^{a} \cdot e\left(x_{A} R_{A}+d_{A_{1}}, T_{B}\right) \\
& =e\left(R_{B}, x_{B} Q+s_{2} Q\right)^{a} \cdot e\left(R_{K G C_{2}}, s_{o} Q\right)^{a} \cdot e\left(x_{A} R_{A}+s_{1} R_{A}+d_{K G C_{1}}, b Q\right) \\
& =e\left(R_{B},\left(x_{B}+s_{2}\right) Q\right)^{a} \cdot e\left(R_{K G C_{2}}, s_{o} Q\right)^{a} \cdot e\left(\left(x_{A}+s_{1}\right) R_{A}+s_{o} R_{K G C_{1}}, b Q\right) \\
& =e\left(\left(x_{B}+s_{2}\right) R_{B}, a Q\right) \cdot e\left(s_{o} R_{K G C_{2}}, a Q\right) \cdot e\left(\left(x_{A}+s_{1}\right) R_{A}, b Q\right) \cdot e\left(s_{o} R_{K G C_{1}}, b Q\right) \\
& =e\left(\left(x_{B}+s_{2}\right) R_{B}+s_{o} R_{K G C_{2}}, a Q\right) \cdot e\left(\left(x_{A}+s_{1}\right) R_{A}, Q\right)^{b} \cdot e\left(s_{o} R_{K G C_{1}}, Q\right)^{b} \\
& =e\left(x_{B} R_{B}+s_{2} R_{B}+s_{o} R_{K G C_{2}}, a Q\right) \cdot e\left(R_{A},\left(x_{A}+s_{1}\right) Q\right)^{b} \cdot e\left(R_{K G C_{1}}, s_{o} Q\right)^{b} \\
& =e\left(x_{B} R_{B}+\left(s_{2} R_{B}+s_{o} R_{K G C_{2}}\right), a Q\right) \cdot e\left(R_{A}, x_{A} Q+s_{1} Q\right)^{b} \cdot e\left(R_{K G C_{1}}, s_{o} Q\right)^{b} \\
K_{B A}^{\prime} & =e\left(x_{B} R_{B}+d_{B_{2}}, T_{A}\right) \cdot\left[e\left(R_{A}, X_{A}+X_{K G C_{1}}\right) \cdot e\left(R_{K G C_{1}}, Q_{o}\right)\right]^{b}
\end{aligned}
$$

Verificamos que a nova proposta continua sendo consistente. E ainda, conseguimos proteger nosso sistema contra a criação de um falso $K G C^{*}$, pois os valores $d_{K G C_{i}}$ ou $d_{A}$ são secretos, e os valores $a$ e $s_{o}$ estão protegidos no emparelhamento $e\left(R_{K G C_{2}}, Q_{o}\right)^{a}$ pelo $\mathrm{BDH}$.

\subsection{Uso em Esquemas Hierárquicos}

A relação criada entre os $K G C_{o}$ e os $K G C_{i}$ s pode ser estendida para níveis hierárquicos, onde o $K G C_{o}$ define os parâmetros do sistema, e cada $K G C_{i}^{(l)}$ no nível $l$ passa para o $K G C_{j}^{(l+1)}$ no nível $l+1$ uma chave parcial secreta $d_{K G C_{j}^{(l+1)}}=s_{K G C_{i}^{(l)}} H\left(I D_{K G C_{i}^{l+1}}\right)+d_{K G C_{i}^{l}}$. A chave comum será calculada usando-se um novo emparelhamento para cada nível, a demonstração pode ser vista no apêndice.

Embora nossa solução use quatro novos emparelhamentos, tornando o esquema original mais complexo que o esquema original de Al-Riyami; esta nova abordagem permitirá a construção de acordos de chaves hierárquicos onde a complexidade aumenta linearmente com a profundidade da entidade de nível mais baixo. Além disso os cálculos dos emparelhamentos são independentes, podendo-se realizá-los em paralelo, tornando-o eficientes em sistemas multiprocessados. 


\section{Definições gerais}

- $q$ um valor primo grande;

- $\mathbb{G}_{1}$ e $\mathbb{G}_{2}$ grupos cíclicos de ordem $q$;

- $e: \mathbb{G}_{1} \times \mathbb{G}_{1} \rightarrow \mathbb{G}_{2}$ um emparelhamento bilinear admissível;

- Convencionamos que a entidade $A_{(l-1)}$ no nível $(l-1)$ é a entidade geradora da entidade $A_{(l)}$ no nível $l$.

Definição da autoridade de confiança raiz $\left(\mathrm{KGC}_{o}\right.$ ou $\left.A_{(0)}\right)$

- Escolhe um valor aleatório secreto $s_{o} \in \mathbb{Z}_{q}^{*}$;

Definições globais da autoridade de confiança raiz para todo sistema

- Define $\mathbb{G}_{1}$ e $\mathbb{G}_{2}$;

- Escolhe $e: \mathbb{G}_{1} \times \mathbb{G}_{1} \rightarrow \mathbb{G}_{2}$;

- Escolhe um valor $Q$ gerador do grupo $\mathbb{G}_{1}$;

- Calcula o valor público $Q_{o}=s_{o} Q=X_{A_{(0)}}$;

- Escolhe uma função hash $H:\{0,1\}^{*} \rightarrow \mathbb{G}_{1}$;

- Escolhe a função de derivação da chave de sessão $f: \mathbb{G}_{2} \times \mathbb{G}_{1} \times \mathbb{G}_{1} \rightarrow\{0,1\}^{n}$, onde $n \in \mathbb{N}$.

Definições para uma entidade $A_{(l)}$ no nível $l$

- Define-se o valor público $R_{A_{(l)}}=H\left(I D_{A_{(l)}}\right)$

- Recebe de $A_{(l-1)}$ o valor secreto $d_{A_{(l)}}=s_{A_{(l-1)}} R_{A_{(l)}}+d_{A_{(l-1)}}=\sum_{m=1}^{l} s_{A_{(m-1)}} R_{A_{(m)}}$;

- Escolhe um valor aleatório secreto $s_{A_{(l)}} \in \mathbb{Z}_{q}^{*}$;

- Chave secreta completa $\xi_{A_{(l)}}=\left\langle s_{A_{(l)}}, d_{A_{(l)}}\right\rangle$;

- Chave pública $P_{A_{(l)}}=\left\langle X_{A_{(l)}}, Y_{A_{(l)}}\right\rangle=\left\langle s_{A_{(l)}} Q, s_{A_{(l)}} Q_{o}\right\rangle$

- Durante a fase de sessão:

- Escolhe um valor aleatório $a \in \mathbb{Z}_{q}^{*}$

- Calcula e envia o valor público $T_{A_{(l)}}=a Q$ 
Cálculo do valor comum $v_{A_{(l)} B_{(u)}}$ pela entidade $A_{(l)}$ para com $B_{(u)}$

Note que as entidades $A_{(l)}$ e $B_{(u)}$ podem estar em ramos hierárquicos diferentes.

- Verifica todos emparelhamentos de $t=1$ até $t=u$ : $e\left(Q, Y_{B_{(t)}}\right)=e\left(Q_{o}, X_{B_{(t)}}\right)$

Esta verificação corresponde a todos os nós pais do ramo hierárquico da entidade $B_{(u)}$

- Se todos emparelhamento forem válidos, calcula o valor comum:

$$
v_{A_{(l)} B_{(u)}}=\left[e\left(R_{B_{(u)}}, X_{B_{(u)}}+X_{B_{(u-1)}}\right) \cdot\left(\prod_{z=1}^{u-1} e\left(R_{B_{(z)}}, X_{B_{(z-1)}}\right)\right)\right]^{a} \cdot e\left(s_{A_{(l)}} R_{A_{(l)}}+d_{A_{(l)}}, T_{B_{(u)}}\right)
$$

Cálculo do valor comum $v_{B_{(u)} A_{(l)}}$ pela entidade $B_{(u)}$ para com $A_{(l)}$

De forma semelhante as entidades $A_{(l)}$ e $B_{(u)}$ podem estar em ramos hierárquicos diferentes.

- Verifica todos emparelhamentos de $w=1$ até $w=l$ :

$e\left(Q, Y_{B_{(w)}}\right)=e\left(Q_{o}, X_{B_{(w)}}\right)$

Esta verificação corresponde a todos os nós pais do ramo hierárquico da entidade $A_{(l)}$

- Se todos emparelhamento forem válidos, calcula o valor comum:

$$
v_{B_{(u)} A_{(l)}}=e\left(s_{B_{(u)}} R_{B_{(u)}}+d_{B_{(u)}}, T_{A_{(l)}}\right) \cdot\left[e\left(R_{A_{(l)}}, X_{A_{(l)}}+X_{A_{(l-1)}}\right) \cdot \prod_{m=1}^{l-1} e\left(R_{A_{(m)}}, X_{A_{(m-1)}}\right)\right]^{b}
$$

Cálculo da chave de sessão $k_{A_{(l)} B_{(u)}}$ pela entidade $A_{(l)}$ para com $B_{(u)}$

Aqui também as entidades $A_{(l)}$ e $B_{(u)}$ podem estar em ramos hierárquicos diferentes.

$$
\begin{aligned}
k_{A_{l} B_{u}} & =f\left(v_{A_{(l)} B_{(u)}}, a T_{B_{(u)}}, x_{A_{(l)}} X_{B_{(u)}}\right) \\
& =f\left(v_{A_{(l)} B_{(u)}}, a b Q, x_{A_{(l)}} x_{B_{(u)}} Q\right)
\end{aligned}
$$

\section{Consistência das chaves de sessão}

De igual forma não há alterações na função de derivação da chave de sessão, por isso só precisamos verificar se o valor comum calculado pela entidade $A_{(l)}$ é igual ao valor calculado pela entidade $B_{(u)}$ : 


$$
\begin{aligned}
& v_{A_{(l)} B_{(u)}}=\left[e\left(R_{B_{(u)}}, X_{B_{(u)}}+X_{B_{(u-1)}}\right) \cdot \prod_{z=1}^{u-1} e\left(R_{B_{(z)}}, X_{B_{(z-1)}}\right)\right]^{a} \cdot e\left(s_{A_{(l)}} R_{A_{(l)}}+d_{A_{(l)}}, T_{B_{(u)}}\right) \\
& =\left[e\left(R_{B_{(u)}}, s_{B_{(u)}} Q+s_{B_{(u-1)}} Q\right) \cdot \prod_{z=1}^{u-1} e\left(R_{B_{(z)}}, s_{B_{(z-1)}} Q\right)\right]^{a} \cdot e\left(s_{A_{(l)}} R_{A_{(l)}}+d_{A_{(l)}}, T_{B_{(u)}}\right) \\
& =\left[e\left(R_{B_{(u)}},\left(s_{B_{(u)}}+s_{B_{(u-1)}}\right) Q\right) \cdot \prod_{z=1}^{u-1} e\left(R_{B_{(z)}}, s_{B_{(z-1)}} Q\right)\right]^{a} \cdot e\left(s_{A_{(l)}} R_{A_{(l)}}+d_{A_{(l)}}, T_{B_{(u)}}\right) \\
& =\left[e\left(\left(s_{B_{(u)}}+s_{B_{(u-1)}}\right) R_{B_{(u)}}, Q\right) \cdot \prod_{z=1}^{u-1} e\left(s_{B_{(z-1)}} R_{B_{(z)}}, Q\right)\right]^{a} \cdot e\left(s_{A_{(l)}} R_{A_{(l)}}+d_{A_{(l)}}, T_{B_{(u)}}\right) \\
& =e\left(\left(s_{B_{(u)}}+s_{B_{(u-1)}}\right) R_{B_{(u)}}+\sum_{z=1}^{u-1} s_{B_{(z-1)}} R_{B_{(z)}}, Q\right)^{a} \cdot e\left(s_{A_{(l)}} R_{A_{(l)}}+d_{A_{(l)}}, T_{B_{(u)}}\right) \\
& =e\left(s_{B_{(u)}} R_{B_{(u)}}+s_{B_{(u-1)}} R_{B_{(u)}}+\sum_{z=1}^{u-1} s_{B_{(z-1)}} R_{B_{(z)}}, a Q\right) \cdot e\left(s_{A_{(l)}} R_{A_{(l)}}+d_{A_{(l)}}, T_{B_{(u)}}\right) \\
& =e\left(s_{B_{(u)}} R_{B_{(u)}}+\sum_{z=1}^{u} s_{B_{(z-1)}} R_{B_{(z)}}, T_{A_{(l)}}\right) \cdot e\left(s_{A_{(l)}} R_{A_{(l)}}+d_{A_{(l)}}, T_{B_{(u)}}\right) \\
& =e\left(s_{B_{(u)}} R_{B_{(u)}}+d_{B_{(u)}}, T_{A_{(l)}}\right) \cdot e\left(s_{A_{(l)}} R_{A_{(l)}}+d_{A_{(l)}}, T_{B_{(u)}}\right) \\
& =e\left(s_{B_{(u)}} R_{B_{(u)}}+d_{B_{(u)}}, T_{A_{(l)}}\right) \cdot e\left(s_{A_{(l)}} R_{A_{(l)}}+\sum_{m=1}^{l} s_{A_{(m-1)}} R_{A_{(m)}}, b Q\right) \\
& =e\left(s_{B_{(u)}} R_{B_{(u)}}+d_{B_{(u)}}, T_{A_{(l)}}\right) \cdot e\left(s_{A_{(l)}} R_{A_{(l)}}+s_{A_{(l-1)}} R_{A_{(l)}}+\sum_{m=1}^{l-1} s_{A_{(m-1)}} R_{A_{(m)}}, Q\right)^{b} \\
& =e\left(s_{B_{(u)}} R_{B_{(u)}}+d_{B_{(u)}}, T_{A_{(l)}}\right) \cdot e\left(\left(s_{A_{(l)}}+s_{A_{(l-1)}}\right) R_{A_{(l)}}+\sum_{m=1}^{l-1} s_{A_{(m-1)}} R_{A_{(m)}}, Q\right)^{b} \\
& =e\left(s_{B_{(u)}} R_{B_{(u)}}+d_{B_{(u)}}, T_{A_{(l)}}\right) \cdot\left[e\left(\left(s_{A_{(l)}}+s_{A_{(l-1)}}\right) R_{A_{(l)}}, Q\right) \cdot \prod_{m=1}^{l-1} e\left(s_{A_{(m-1)}} R_{A_{(m)}}, Q\right)\right]_{b}^{b} \\
& =e\left(s_{B_{(u)}} R_{B_{(u)}}+d_{B_{(u)}}, T_{A_{(l)}}\right) \cdot\left[e\left(R_{A_{(l)}},\left(s_{A_{(l)}}+s_{A_{(l-1)}}\right) Q\right) \cdot \prod_{m=1}^{l-1} e\left(R_{A_{(m)}}, s_{A_{(m-1)}} Q\right)\right]^{b} \\
& =e\left(s_{B_{(u)}} R_{B_{(u)}}+d_{B_{(u)}}, T_{A_{(l)}}\right) \cdot\left[e\left(R_{A_{(l)}}, s_{A_{(l)}} Q+s_{A_{(l-1)}} Q\right) \cdot \prod_{m=1}^{l-1} e\left(R_{A_{(m)}}, s_{A_{(m-1)}} Q\right)\right]^{b} \\
& v_{B_{(u)} A_{(l)}}=e\left(s_{B_{(u)}} R_{B_{(u)}}+d_{B_{(u)}}, T_{A_{(l)}}\right) \cdot\left[e\left(R_{A_{(l)}}, X_{A_{(l)}}+X_{A_{(l-1)}}\right) \cdot \prod_{m=1}^{l-1} e\left(R_{A_{(m)}}, X_{A_{(m-1)}}\right)\right]^{b}
\end{aligned}
$$

Mais uma vez é demonstrada a consistência da chave de sessão gerada, assim conseguimo que o esquema para dois KGC seja ampliado para um esquema hierárquico.

\subsection{Operação não interativa}

A versão original do acordo de chaves de Mandt é interativo, e a troca de valores $T_{A}$ e $T_{B}$ são feitas durante o estabelecimento das chaves. A nossa proposta é fazer os valores $T_{A}$ e $T_{B}$ fazerem parte da chave pública, pois são gerados de forma igual ao valor da chave pública $X_{A}$ e $X_{B}$, apenas um valor aleatório escolhido pela entidade e multiplicado pelo valor global $Q$ (que é representado por um ponto da curva elíptica).

Quando não há troca de valores durante a fase de sessão, dizemos que o acordo é não interativo, porém diante disso admitimos que um adversário que conheça os segredos de uma entidade qualquer $A$, terá as mesmas condições de $A$ para calcular todas as chaves em comum à $A$.

A minimização deste problema é admitindo que as entidades tenham um valor $T_{*}$ usado em operações não interativas, e permitir que este valor possa ser negociado em operação interativas. 


\section{Capítulo 4}

\section{Implementação}

O objetivo da implementação é para comprovar que o protocolo sugerido é capaz de operar em um ambiente simulado, contudo em implementações reais haverá outros aspectos de segurança que não serão abordados neste trabalho, ou que serão apenas indicados.

A implementação apresentada neste trabalho é baseada na biblioteca MIRACL em C e $\mathrm{C}++$, a qual possui uma representação de curvas elípticas definidas sobre o corpo $G F\left(2^{m}\right)$, grandes números inteiros, exemplos de emparelhamentos e de protocolos de ciframento baseado na identidade.

Apesar da utilização de uma biblioteca de apoio, existem definições que devem ser tomadas para cada implementação, tais como a escolha da curva elíptica, função de emparelhamento, as funções hash, mapeamento da identidades em pontos da curva elíptica e dos parâmetros de segurança.

\subsection{Escolha da Curva}

Utilizamos para nosso protótipo curvas elípticas super-singulares tal como em [Barreto et al. 2004], onde provavelmente está definido os algoritmos de emparelhamentos de melhor performance conhecidos até o momento.

Escolhemos a curva $y^{2}=x^{3}+x^{2}+1$ definidas sobre o corpo finito de Galois $G F\left(2^{253}\right)$.

\subsection{Emparelhamento bilinear}

A função de emparelhamento utilizada é exatamente a função implementada no exemplo "dl2.cpp" da biblioteca MIRACL.

\subsection{Funções Hash}

Para implementação da função hash foi utilizado as funções hash da família SHA como apoio, sendo escolhido em tempo de compilação uma entre as funções SHA-256, SHA-384 ou SHA-512. A implementação das funções hash encontram-se no Anexo 01.

\subsection{Mapeamento das identidades em pontos da curva}

Ainda no Anexo 01, há o mapeamento das identidade para um ponto da curva elíptica, correspondente à função hash $H()$; nossa abordagem segue o sugerido em [Trappe e Washington 2005]. Após aplicar o hash ao texto de entrada verificamos se o valor resultante pode ser mapeado diretamente para um ponto da curva, caso não seja somamos 1 e verificamos novamente até um limite $\epsilon$, como aproximadamente a metade de todos os elementos de $G F\left(2^{m}\right)$ serão mapeados em pontos da curva, podemos supor que a probabilidade de falha é de $\frac{1}{2^{\epsilon}}$. 


\subsection{Parâmetros de segurança}

O parâmetro de segurança será escolhido implicitamente, pois usaremos curvas elípticas já definidas em outros protocolos.

\subsection{Simulação web}

É possível verificar a implementação do código anexo no seguinte endereço http://www2. ime.usp.br/ vilc/mandt. 


\section{Capítulo 5}

\section{Análise do Modelo}

Neste capítulo vamos verificar a segurança do protocolo proposto para operação não interativa, com suas limitações. E também será apresentado um pouco da complexidade do protocolo e como otimizar em implementações práticas.

\subsection{Modelo de Segurança}

O modelo de segurança de [Bellare e Rogaway 1993], que é o primeiro modelo para acordos de chaves com autênticação mútua. Cada instância de protocolo é tratado como um oráculo. O adversário possui controle de todas as comunicações do sistema, e interage com o sistema (oráculos e entidades) através de consultas que lhe são permitidas. O oráculo $\Pi_{i, j}^{s}$ é uma instância $s$ da entidade $i$ que deseja estabelecer uma chave comum com a entidade $j$. A instância de $j$ é $\Pi_{j, i}^{t}$ para algum $t$.

Dado uma mensagem de entrada, o oráculo $\Pi_{i, j}^{s}$ executa o protocolo $\Pi$ o qual gera a saída dada por $\Pi\left(1^{k}, i, j, S P_{i}, P_{j}, c o n v_{i, j}^{s}, r_{i, j}^{s}, x\right)=\left(m, \delta_{i, j}^{s}, \sigma_{i, j}^{s}\right)$, onde $x$ é a mensagem de entrada, $m$ é a mensagem de saída, $1^{k}$ é o parâmetro de segurança; $S P_{i}$ é o par de chaves secreta e pública da entidade $i, P_{j}$ é a chave pública da entidade $j, r_{i, j}^{s}$ é um bit aleatório da entidade $i, \delta_{i, j}^{s}$ é a decisão do oráculo e $\sigma_{i, j}^{s}$ é a chave de sessão gerada. Ao completar a execução o protocolo $\Pi$ atualiza a $\operatorname{conv}_{i, j}^{s}$ para $\operatorname{conv}_{i, j}^{s} \cdot x . m$, onde $x . m$ é a concatenação das mensagens $x$ e $m$.

Um oráculo pode estar nos seguintes estados: Estado aceito, onde o oráculo gera uma chave de sessão após receber apropriadamente todas as mensagens correspondente à execução do protocolo; Estado rejeitado, onde o oráculo não estabelece uma chave de sessão e não possui as mensagens apropriadas para execução do protocolo; e Estado não decidido, é o estado inicial e o estado onde o protocolo não decidiu qual estado assumir.

Após uma execução o oráculo $\left(\Pi_{i, j}^{s}\right)$ aceita a sessão se obtiver uma conversação correspondida $a^{1}$ com o oráculo $\left(\Pi_{j, i}^{t}\right)$, onde a saída de um oráculo é uma entrada válida para o outro. Neste caso os oráculos estabelecem uma sessão válida com uma chave de sessão comum.

As interações do adversário com o sistema são diferentes em cada modelo [Bellare e Rogaway 1993, Canetti e Krawczyk 2001,Swanson 2008,Lippold et al. 2009], porém para acordos de chaves sem certificados interativos consideramos o modelo de Swanson o mais completo. A seguir as consultas permitidas ao adversário neste modelo:

Send $\left(\Pi_{i, j}^{s}, x\right)$

$\Pi_{i, j}^{s}$ executa o protocolo $\Pi\left(1^{k}, i, j, S P_{i}, P_{j}, c o n v_{i, j}^{s}, r_{i, j}^{s}, x\right)$ e responde com $m$ e $\sigma_{i, j}^{s}$. Se o

\footnotetext{
${ }^{1}$ tradução de matching conversations
} 
oráculo $\Pi_{i, j}^{s}$ não existir, ele será criado. A consulta "Send" permite que um adversário envie uma mensagem para um oráculo $\Pi_{i, j}^{s}$, como se a mensagem fosse enviada pela entidade $j$. $\mathrm{O}$ adversário pode iniciar o protocolo usando tal consulta.

\section{Reveal Master Key}

O adversário obtém acesso a chave mestra do sistema, a chave secreta do KGC.

Reveal Session Key $\left(\Pi_{i, j}^{s}\right)$

$\Pi_{i, j}^{s}$ revela a saída privada $\sigma_{i, j}^{s}$ de uma sessão. A consulta "Reveal" permite um adversário perguntar ao oráculo $\Pi_{i, j}^{s}$ qual a chave de sessão que ele possui atualmente, se o oráculo estiver aceitado a sessão ele revela a chave de sessão secreta, caso contrário devolve $\perp$;

\section{Reveal Private Key $(i)$}

A entidade $i$ revela a chave parcial esquerda de posse exclusiva da entidade. Se a entidade $i$ tiver sua chave pública substituída anteriormente, então a consulta devolve $\perp$.

\section{Reveal Partial Key $(i)$}

A entidade $i$ responde com a chave parcial direita. Esta consulta permite ao adversário ter acesso a chave parcial de uma entidade. A chave parcial é privativa da entidade e por isso o adversário não pode substitui-la. Esta consulta simula a vantagem que possui o KGC sobre um adversário externo. Esta é uma consulta trivial para adversários que já obtiveram a chave mestra.

\section{Reveal Ephemeral Key $\left(\Pi_{i, j}^{s}\right)$}

O oráculo $\Pi_{i, j}^{s}$ revela qual a chave efêmera usada na sessão.

Replace Public Key $\left(\Pi_{i, j}^{s}\right), P$

O oráculo $\left(\Pi_{i, j}^{s}\right)$ atualiza $P_{j}=P$ quando $i \neq j$. Esta consulta permite ao adversário substituir a chave pública de uma entidade $j$ perante a entidade $i$. Como em esquemas sem certificados as entidades podem trocar as chaves públicas entre si, é natural que um adversário possa substituir a chave pública das entidades.

Test $\left(\Pi_{i, j}^{s}\right)$

Esta consulta gera aleatoriamente um bit $b \in\{0,1\}$. Se $b=0$, o adversário recebe a chave de sessão estabelecida, caso contrário o adversário recebe como saída uma chave de sessão válida escolhida aleatoriamente. Algum momento após esta consulta o adversário deverá dar um palpite a respeito do valor de $b$.

A vantagem do adversário em descobrir corretamente o valor do bit $b$ é dada por:

$$
\operatorname{Vantagem}^{E}(k)=\mid \operatorname{Pr}\left[\text { PalpiteCorreto }^{E}(k)\right]-\frac{1}{2} \mid
$$

De acordo com [Lippold et al. 2009] as consultas contra o algoritmo podem ser agrupadas em contra a segurança da identidade, "Reveal Master Key" e "Reveal Partial Key", contra a segurança da chave pública, "Reveal Private Key" e "Replace Public Key", e contra a segurança de uma sessão específica, "Reveal Ephemeral Key". 
Uma sessão estará totalmente corrompida: Em acordos de chaves interativos quando feita consultas nos três grupos acima, em sistemas não interativos a restrição é maior, pois não está definido a sessão. No acordo de [Mandt e Tan 2006] e suas variantes qualquer consulta acima irá comprometer a segurança do protocolo para adversários ativos, porém permanece seguro contra usuários passivos.

Uma vez que o adversário $E$ tenha decidido terminar a primeira fase de consultas ele deve escolher um oráculo $\left(\Pi_{i, j}^{s}\right)$ limpo ${ }^{2}$ para fazer-lhe a consulta "Test". Após esta consulta o adversário ainda poderá continuar a fazer novas consultas, contudo o oráculo $\left(\Pi_{i, j}^{s}\right)$ deve permanecer limpo. A definição de um oráculo limpo segue abaixo:

Definição 5.1.1. Um oráculo $\Pi_{i, j}^{s}$ está limpo se:

1. $\Pi_{i, j}^{s}$ aceita a sessão;

2. Não foi-lhe feito consultas "Reveal" (aberto);

3. A outra entidade da sessão $j$ não está totalmente corrompida;

4. Não existe um oráculo aberto $\Pi_{j, i}^{t}$ que possui uma conversação correspondida com $\Pi_{i, j}^{s}$.

Definição 5.1.2. Dizemos que um protocolo de acordo de chaves é seguro no modelo de Swanson se obedecida as seguintes condições:

1. Se entidades entidades limpas e que não houve substituição de chaves públicas, geram a mesma chave de sessão (exceto por alguma probabilidade desprezível).

2. Para qualquer adversário polinomial $E, \operatorname{Vantagem}^{E}(k)$ é ínfima.

\subsection{Segurança do Modelo Proposto}

Para demonstrar a segurança do nosso protocolo no modo não interativo iremos estabelecer um jogo entre um desafiante $\mathcal{B}$ que utiliza um adversário externo $\mathcal{M}$ que possua alguma vantagem para descobrir a chave resultante de uma sessão $\Pi_{i, j}^{s}$ limpa, estabelecida por uma entidade não corrompida. O objetivo de $\mathcal{B}$ é resolver uma instância do problema bilinear de Diffie-Hellman $(\mathrm{BDH})$, isto é, dados $(Q, a Q, b Q, c Q)$ encontrar o valor de $e(Q, Q)^{a b c}$.

\subsubsection{Redução para o modelo com 1 KGC}

Inicialmente vamos supor que a ordem de todas consultas do adversário $\mathcal{M}$ são conhecidas a priori (depois iremos remover esta condição). Então o desafiante estabelece o seguinte cenário para o adversário:

- $H_{1}\left(I D_{B}\right)=b Q$

- $T_{A}=a Q$

- $X_{b}=c Q-Q_{o}=c Q-s Q=(c-s) Q$

- $Y_{b}=s c Q-s^{2} Q=(c-s) s Q=(c-s) Q_{o}$

\footnotetext{
${ }^{2}$ tradução de fresh
} 
Todos os demais valores solicitados pelo adversário são escolhidos por $\mathcal{B}$ como se fosse uma verdadeira autoridade de confiança KGC. O adversário $\mathcal{M}$ também faz consultas ao desafiante para obter o resultado das funções hash $H_{1}()$ e $f$, na primeira consulta de uma determinada entrada, o desafiante $\mathcal{B}$ escolhe um valor aleatório possível para a função hash, responde com esse valor e armazena a entrada e o valor escolhido para as próximas consultas. Logo, as próximas consultas de uma entrada, o desafiante responde com o valor armazenado para ela.

Quando o adversário fizer a consulta 'Test' o desafiante recupera a entrada da função de derivação da chave de sessão, e então aborta e responde com o valor:

$$
e(Q, Q)^{a b c}=\frac{v_{a b}}{e\left(x_{A} H\left(I D_{A}\right)+s H\left(I D_{A}\right), b Q\right)}
$$

Verificação:

$$
\begin{aligned}
\frac{v_{a b}}{e\left(x_{A} H\left(I D_{A}\right)+s H\left(I D_{A}\right), b Q\right)} & =\frac{e\left(H 1\left(I D_{B}, X_{b}+Q_{o}\right)^{a} \cdot e\left(x_{A} H\left(I D_{A}\right)+s H\left(I D_{A}\right), b Q\right)\right.}{e\left(x_{A} H\left(I D_{A}\right)+s H\left(I D_{A}\right), b Q\right)} \\
& =e\left(H 1\left(I D_{B}, X_{b}+Q_{o}\right)^{a}\right. \\
& =e\left(b Q, c Q-Q_{o}+Q_{o}\right)^{a} \\
& =e(Q, Q)^{a b c}
\end{aligned}
$$

A suposição que fizemos do desafiante conhecer a ordem de todas as consultas é muito forte, por isso vamos analisar o impacto de retirá-la.

Seja $q_{1}$ a quantidade máxima de consultas $H_{1}$ distintas que o adversário $\mathcal{M}$ pode realizar e $q_{2}$ o número máximo de sessões válidas que uma entidade pode ter.

Então antes de iniciar o jogo, o desafiante $\mathcal{B}$ deverá supor quais serão as duas entidades participantes da sessão usada pelo adversário $\mathcal{M}$ na consulta 'Test'. A probabilidade de acerto é:

$$
\frac{1}{q_{1}\left(q_{1}-1\right)}>\frac{1}{q_{1}^{2}}
$$

Ainda assim o desafiante deverá supor qual sessão será utilizada pelo adversário na consulta 'Test', esta probabilidade é maior que:

$$
\frac{1}{q_{2} q_{1}^{2}}
$$

Caso o desafiante $\mathcal{B}$ não acerte em sua suposição inicial, ele interrompe o jogo. Se o desafiante não abortar o jogo, ele resolverá o desafio BDH com a vantagem:

$$
\operatorname{Vantagem~}^{\mathcal{B}}(k)[B D H]>\frac{\text { Vantagem }^{\mathcal{M}}(k)[\Pi]}{q_{2} q_{1}^{2}}
$$

\subsubsection{Redução para o modelo com 2 KGC}

Desta vez vamos utilizar um adversário $\mathcal{N}$ que consegue resolver o protocolo com dois KGC e vamos utilizá-lo para resolver o protocolo com apenas um KGC. O desafiante $\mathcal{C}$ precisa encontrar a chave da sessão $\Pi_{i, j}^{s}$ limpa.

O valor comum calculado para $1 \mathrm{KGC}$ é dado por: $v_{A B}=e\left(R_{B}, X_{B}+Q_{o}\right)^{a} \cdot e\left(x_{A} R_{A}+d_{A}, T_{B}\right)$

O valor comum calculado para $2 \mathrm{KGC}$ é dado por: $v_{A B}^{*}=\left[e\left(R_{B}^{*}, X_{B}^{*}+X_{K G C_{2}}^{*}\right) \cdot e\left(R_{K G C_{2}}^{*}, Q_{o}^{*}\right)\right]^{a^{*}}$. $e\left(x_{A}^{*} R_{A}^{*}+d_{A_{1}}, T_{B}^{*}\right)$ 
Então o desafiante escolhe um valor $\rho_{1} \in \mathbb{Z}_{q}^{*}$ e $\rho_{2} \in \mathbb{Z}_{q}^{*}$ e calcula:

$X_{B}^{*}=X_{B}-\rho_{2} Q=x_{A} Q-\rho_{2} Q=\left(x_{A}-\rho_{2}\right) Q$

$Y_{B}^{*}=Y_{B}-\rho_{2} Q_{o}=x_{A} Q_{o}-\rho_{2} Q_{o}=\left(x_{A}-\rho_{2}\right) Q_{o}$

$X_{K G C_{2}}^{*}=\rho_{2} Q$

$Y_{K G C_{2}}^{*}=\rho_{2} Q_{o}$

$Q^{*}=Q$

$Q_{o}^{*}=Q_{o}$

$H\left(K G C_{2}\right)=H\left(I D_{B}\right)$

Fazer o simétrico para os valores públicos de $A$ e $K G C_{1}$. Vamos verificar a validade da redução, para isso analisaremos somente a parte que está exponenciada por $a^{*}$, pois se for válida a outra parte será apenas uma simetria:

$$
\begin{aligned}
e\left(H\left(I D_{B}\right), X_{B}^{*}+X_{K G C_{2}}^{*}\right) \cdot e\left(H\left(K G C_{2}\right), Q_{o}^{*}\right) & =e\left(H\left(I D_{B}\right), X_{B}-\rho_{2} Q+\rho_{2} Q\right) \cdot e\left(H\left(I D_{B}\right), Q_{o}\right) \\
& =e\left(H\left(I D_{B}\right), X_{B}\right) \cdot e\left(H\left(I D_{B}\right), Q_{o}\right) \\
& =e\left(H\left(I D_{B}\right), X_{B}+Q_{o}\right)
\end{aligned}
$$

E portanto:

$$
\operatorname{Vantagem}^{\mathcal{C}}(k)\left[\Pi^{*}\right] \geq \operatorname{Vantagem}^{\mathcal{N}}(k)[\Pi]
$$

\subsubsection{Segurança independente dos elementos hierárquicos}

Uma desvantagem de modelos baseados em polinômios é que dado o conluio de $n+1$ entidades, tal que $n$ é o grau do polinômio, todo o polinômio poderá ser descoberto. E como a chave secreta é o próprio polinômio, o segredo fica exposto quando as entidades são comprometidas.

Nossa proposta é usar o PLD-CE para retirar as relações entre entidades pais e herdeiras. Os valores secretos $a$ e $x_{A}$, da entidade $A$, são escolhidos aleatoriamente pela própria entidade. O único valor que é dependente da entidade pai é o valor $d_{A_{(i)}}=x_{A_{(i-1)}} H\left(A_{(i)}\right)+d_{A_{(i-1)}}=$ $\sum_{l=0}^{i-1} s_{(l)} H\left(I D_{A_{(l+1)}}\right)$, contudo ainda que o adversário consiga obter todas as parcelas dos valores de $d_{A}$ não poderá ter acesso aos segredos $s_{(l)}$ das entidades superiores, pois todos estão protegidos pelo PLD-CE.

\subsection{Eficiência Computacional}

O nosso protocolo em sua versão mais simples com apenas um KGC usa quatro emparelhamentos e uma exponenciação modular, já no modelo mais simples com dois KGC usa sete emparelhamentos e uma exponenciação modular, e para a versão hierárquica usará mais três emparelhamentos para cada nível.

Contudo algumas otimizações podem ser feitas no caso do modelo hierárquico, tais como:

- Só há necessidade de verificar a validade ${ }^{3}$ das chaves públicas até a primeira autoridade de segurança em comum, daí em diante poderá assumir a validade da própria chave privada;

- A conferência de chaves públicas é realizada uma única vez, e pode ser reaproveitada para entidades de mesma subordinação;

\footnotetext{
${ }^{3}$ Esta verificação é somente para saber se foi propriamente formada e não como em uma PKI
} 
- É possível conferir as chaves públicas a priori quanto a sua validade, porém não significa que a chave possua uma certificação;

- No cálculo do valor comum, os emparelhamentos dentro da exponenciação modular são valores independentes e podem ser calculados em paralelo. 


\section{Capítulo 6}

\section{Conclusões}

\subsection{Considerações Finais}

Neste trabalho apresentamos uma deficiência no protocolo de acordo de chaves apresentado em [Mandt e Tan 2006] para operação com dois KGCs. Mostramos uma possível solução para esta deficiência, possíveis correção para a vulnerabilidade descrita em [Swanson 2008], baseadas na dificuldade de resolver o problema do logaritmo discreto sobre curvas elípticas e do problema de Diffie-Hellman bilinear, mantendo o algoritmo com os mesmos atributos de segurança descritos pelo autor.

O uso em esquemas hierárquicos pode ser ainda explorado para uso com maior eficiência, visto que não apresenta custódia de chaves, é um esquema bastante seguro contra comprometimento de nós.

É comum os autores de esquemas de acordo de chaves demonstrar a segurança para o protocolo base, sugerir a utilização para múltiplas autoridades de confiança e não demonstrar a segurança, a identificação desta deficiência também contribui para motivar os autores a desenvolverem demonstrações de segurança para seus protocolos estendidos.

\subsection{Tabela Comparativa}

Nossa proposta inicial era construir um modelo de acordo de chaves baseado em sistemas sem certificados mais eficiente que o apresentado em [Gennaro et al. 2008] que utilizava sistemas baseados na identidade. A tabela 6.1 sumariza as principais diferenças dos protocolos.

\begin{tabular}{|l|c|c|}
\hline Modelos & Gennaro & baseado em Mandt \\
\hline Sistema & Baseado em Identidade & Sem certificado \\
\hline Hierarquia & $\begin{array}{c}\text { Rígida, nós folhas estão } \\
\text { todos no mesmo nível }\end{array}$ & $\begin{array}{c}\text { Flexível, podendo assumir } \\
\text { uma forma desbalanceada }\end{array}$ \\
\hline Nível de Confiança & 1 & 2 \\
\hline Risco da chave mestra & Compromete todo o sistema & Compromete o nó \\
\hline Proteção das chaves & $\begin{array}{c}\text { Folhas por PLD-CE e } \\
\text { os demais por polinômio }\end{array}$ & $\begin{array}{c}\text { Todos os níveis } \\
\text { protegidos pelo PLD-CE }\end{array}$ \\
\hline $\begin{array}{l}\text { Complexidade: } \\
\text { No cálculo da chave }\end{array}$ & $\begin{array}{c}\text { Exponencial na profundidade } \\
\text { da hierarquia }\end{array}$ & $\begin{array}{c}\text { Linear na profundidade } \\
\text { da hierarquia }\end{array}$ \\
\hline Na conferência da chave & Não há & Linear na profundidade \\
\hline
\end{tabular}

Tabela 6.1: Tabela comparativa do protocolo proposto e o protocolo de Gennaro 


\subsection{Sugestões para Pesquisas Futuras}

- Apesar desse trabalho estar projetado para ser usado em esquemas não interativos, é possível minimizar o comprometimento da chave de sessão, usando múltiplas chaves públicas como definido no resumo estendido apresentado no SBSeg'2009, de acordo com a referência [Goya et al. 2009b].

- Nos trabalhos de [Icart 2009, Coron e Icart 2009] é construído um mapeamento de pontos sobre curvas elípticas indistinguível de um oráculo aleatório, por isso é possível verificar se o protocolo aqui apresentado permite usar tal mapeamento em substituição ao usado na implementação de acordo com [Trappe e Washington 2005].

- Pelo trabalho ter sua motivação no protocolo proposto por [Gennaro et al. 2008], há espaço para uma implementação dos dois protocolos em um mesmo ambiente simulado e verificar os limites de desempenho, pois o protocolo de Gennaro tende a ser mais eficiente em redes pequenas, mas com o crescimento da rede o protocolo proposto deve superá-lo. 


\section{Apêndice A}

\section{Implementação do Protocolo de Mandt com Correções}

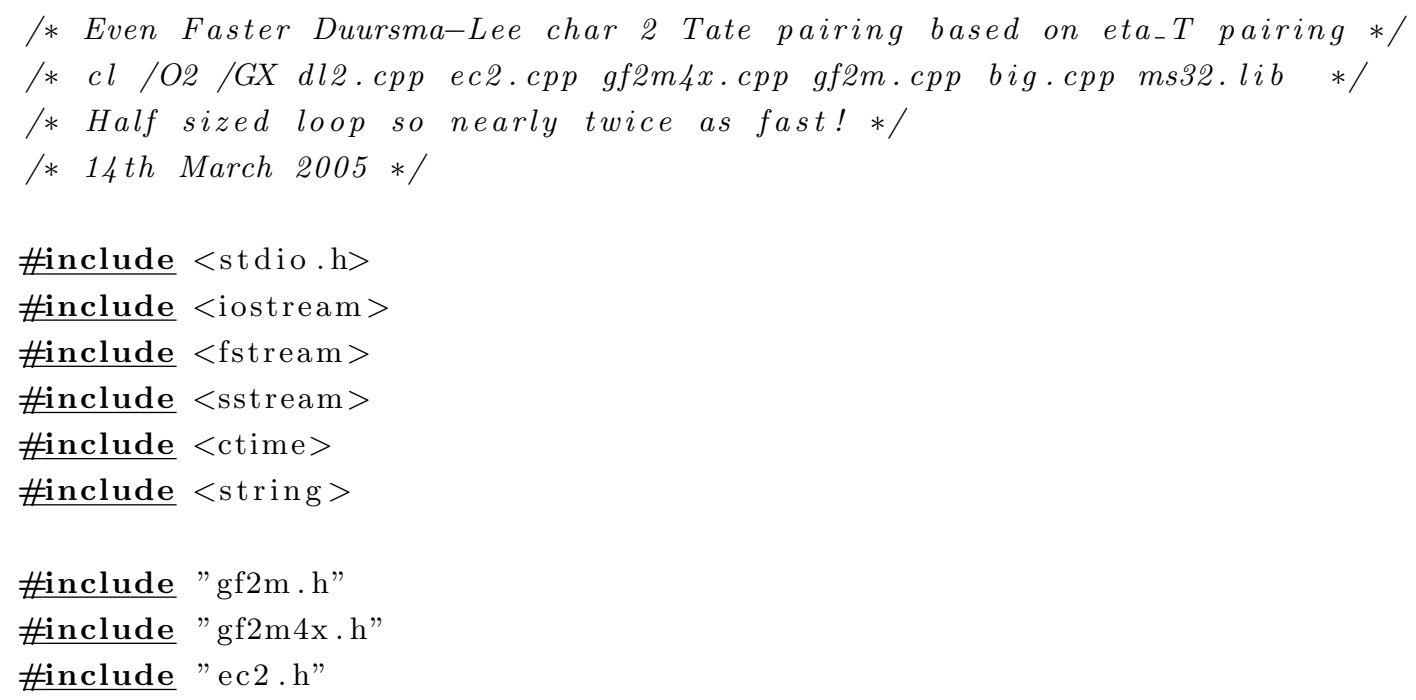


\#define -shs_process shs384_process

\#endif

\#i f HASH_SHA $=512$

\#define HASH_LEN_MAX 64

\#define HASH_LEN 64

\#define_sha sha512

\#define -shs_hash shs512_hash

\#define -shs_init shs512_init

\#define -shs_process shs512_process

\#endif

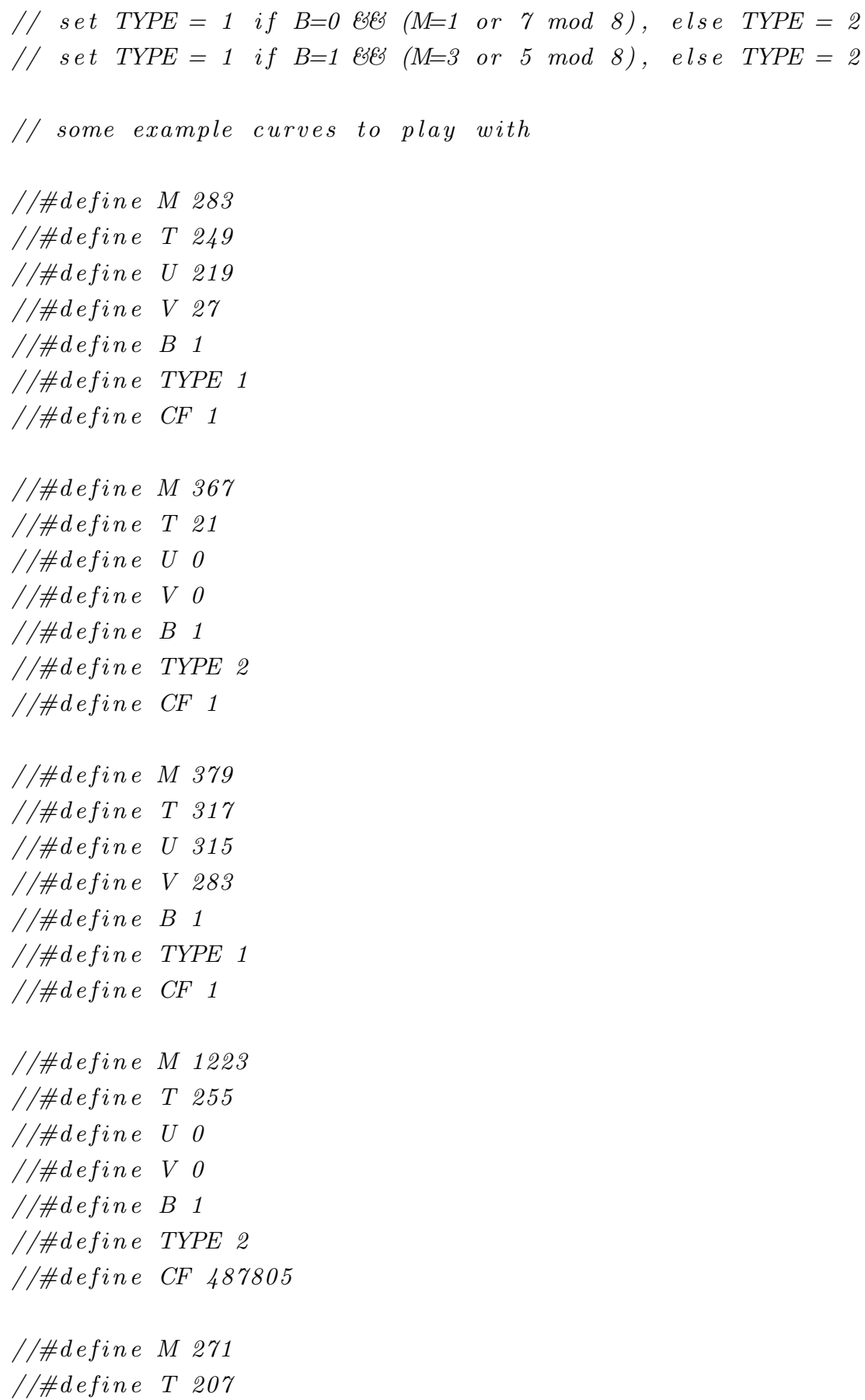


/ \#define U 175

//\#define V 111

//\#define $B O$

//\#define TYPE 1

//\#define CF 487805

\#define M 353

\#define B 1

\#define T 215

\#define $\mathrm{U} 0$

\#define $\mathrm{V} 0$

\#define TYPE 2

\#define $\mathrm{CF} 1$

//\#define M 271

//\#define U 0

//\#define $V 0$

//\#define T 201

//\#define $B 0$

//\#define TYPE 1

//\#define CF 487805

\#define IMOD4 ((M+1)/2)\%4

//\#define XX (IMOD4\%2)

//\#define YY (IMOD4/2)

//\#define NXX (1-XX)

$\underline{\text { using }} \underline{\text { namespace }}$ std;

Miracl precision $(46,0)$;

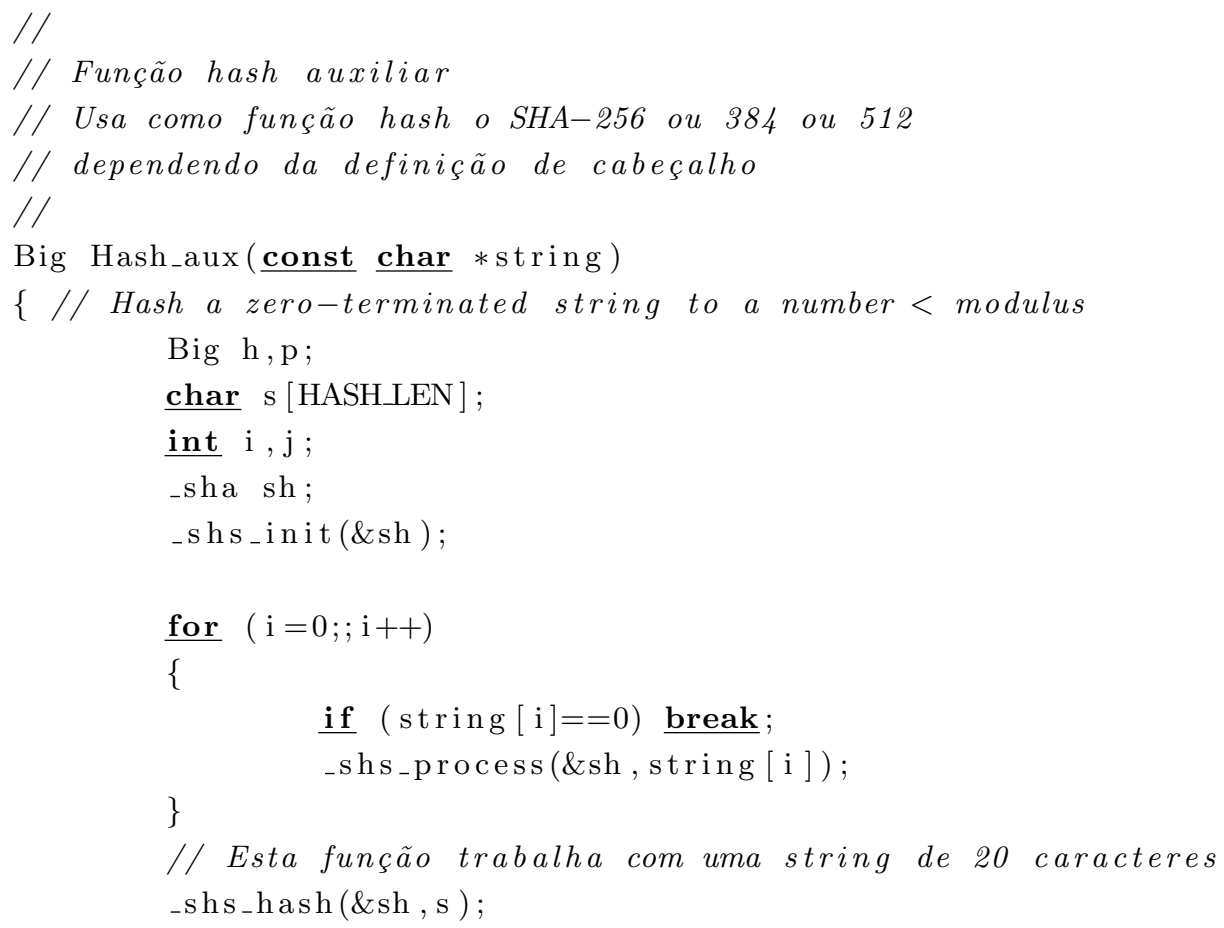




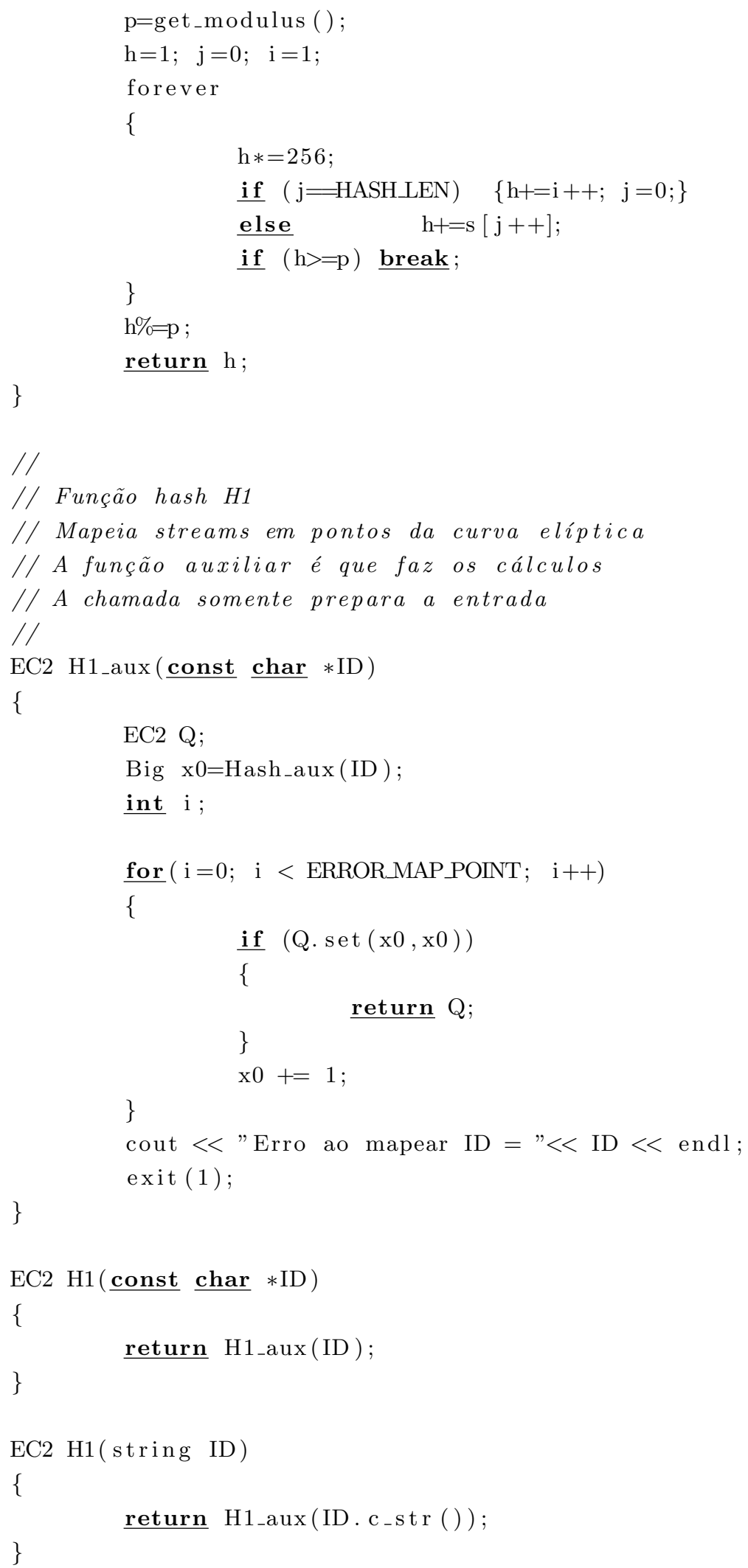




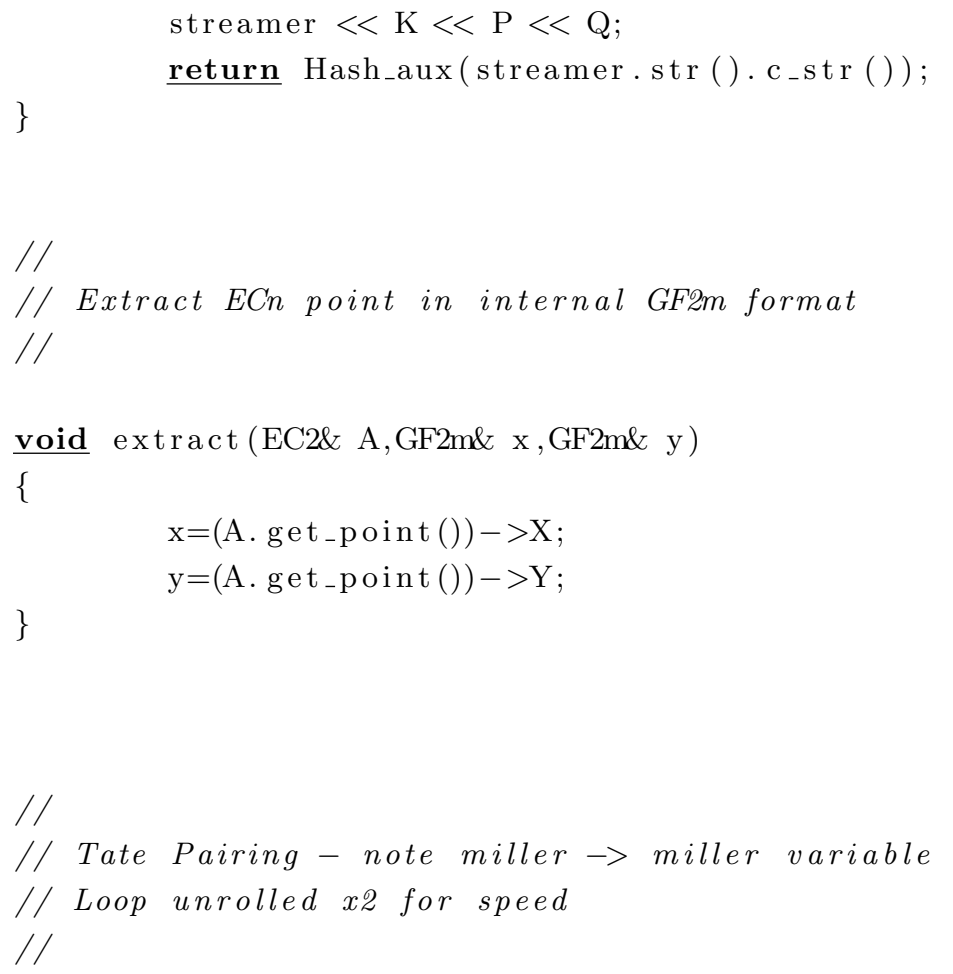

miller $=1$;

$\underline{\text { for }}(\mathrm{i}=0 ; \mathrm{i}<(\mathrm{m}-3) / 2 ; \mathrm{i}+=2)$

\{

$$
\mathrm{t}=\mathrm{xp}+1 ; \mathrm{xp}=\operatorname{sqrt}(\mathrm{xp}) ; \mathrm{yp}=\operatorname{sqrt}(\mathrm{yp}) ; \quad / / 1
$$


(X) $((X+1) *(x p+1)+Y)$
$\mathrm{u} 0$. set $(\mathrm{t} *(\mathrm{xp}+\mathrm{xq}+1)+\mathrm{yp}+\mathrm{yq}, \mathrm{t}+\mathrm{xq}+1, \mathrm{t}+\mathrm{xq}, 0) ;$
/ 10

$\mathrm{xq} *=\mathrm{xq} ; \mathrm{yq} *=\mathrm{yq} ;$

$\mathrm{t}=\mathrm{xp}+1 ; \mathrm{xp}=\mathrm{sqrt}(\mathrm{xp}) ; \mathrm{yp}=\operatorname{sqrt}(\mathrm{yp}) ;$

$\mathrm{u} 1$. $\operatorname{set}(\mathrm{t} *(\mathrm{xp}+\mathrm{xq}+1)+\mathrm{yp}+\mathrm{yq}, \mathrm{t}+\mathrm{xq}+1, \mathrm{t}+\mathrm{xq}, 0)$;

$\mathrm{xq} *=\mathrm{xq} ; \mathrm{yq} *=\mathrm{yq}$;

$\mathrm{u}=\mathrm{mul}(\mathrm{u} 0, \mathrm{u} 1)$;

miller $*=u$;

\}

// final step

$\mathrm{t}=\mathrm{xp}+1 ; \mathrm{xp}=\mathrm{sqrt}(\mathrm{xp}) ; \mathrm{yp}=\mathrm{sqrt}(\mathrm{yp}) ;$

$\mathrm{u} . \operatorname{set}(\mathrm{t} *(\mathrm{xp}+\mathrm{xq}+1)+\mathrm{yp}+\mathrm{yq}, \mathrm{t}+\mathrm{xq}+1, \mathrm{t}+\mathrm{xq}, 0)$;

miller $*=u$;

\section{\#endif}

\#if IMOD4 $=0$

$\begin{array}{ll}/ / & (X=0) \\ / / & (Y=0)\end{array}$

$\mathrm{t}=\mathrm{xp}+1 ;$

f. $\operatorname{set}(\mathrm{t} *(\mathrm{xq}+\mathrm{xp}+1)+\mathrm{yq}+\mathrm{yp}+\mathrm{B}, \mathrm{t}+\mathrm{xq}+1, \mathrm{t}+\mathrm{xq}, 0) ; \quad / / 0$

$(X+1)$

miller $=1$;

$\underline{\text { for }}(\mathrm{i}=0 ; \mathrm{i}<(\mathrm{m}-1) / 2 ; \mathrm{i}+=2)$

\{

// loop is unrolled $x 2$

$\mathrm{t}=\mathrm{xp} ; \mathrm{xp}=\operatorname{sqrt}(\mathrm{xp}) ; \mathrm{yp}=\operatorname{sqrt}(\mathrm{yp}) ;$

$(X)$

(X) $\quad((X+1) *(x p+1)+Y$
$\mathrm{u} 0$. set $(\mathrm{t} *(\mathrm{xp}+\mathrm{xq})+\mathrm{yp}+\mathrm{yq}+\mathrm{xp}+1, \mathrm{t}+\mathrm{xq}+1, \mathrm{t}+\mathrm{xq}, 0) ;$
// $0 x p+1$

$\mathrm{xq} *=\mathrm{xq} ; \mathrm{yq} *=\mathrm{yq} ;$

$\mathrm{t}=\mathrm{xp} ; \mathrm{xp}=\mathrm{sqrt}(\mathrm{xp}) ; \mathrm{yp}=\operatorname{sqrt}(\mathrm{yp}) ;$

$\mathrm{u} 1$. $\operatorname{set}(\mathrm{t} *(\mathrm{xp}+\mathrm{xq})+\mathrm{yp}+\mathrm{yq}+\mathrm{xp}+1, \mathrm{t}+\mathrm{xq}+1, \mathrm{t}+\mathrm{xq}, 0)$;

$\mathrm{xq} *=\mathrm{xq} ; \mathrm{yq} *=\mathrm{yq}$;

$\mathrm{u}=\mathrm{mul}(\mathrm{u} 0, \mathrm{u} 1)$;

miller $*=u$;

\}

\section{\#endif}

\#if IMOD4 $=2$
//
$(X=0)$
//
// 1
$(Y=1)$
$\mathrm{t}=\mathrm{xp}+1 ;$
f. $\operatorname{set}(\mathrm{t} *(\mathrm{xq}+\mathrm{xp}+1)+\mathrm{yq}+\mathrm{yp}+\mathrm{B}+1, \mathrm{t}+\mathrm{xq}+1, \mathrm{t}+\mathrm{xq}, 0) ; / / 1$
$(X+1)$
$(Y)$

miller $=1$;

for $(i=0 ; i<(m-1) / 2 ; i+=2)$ 


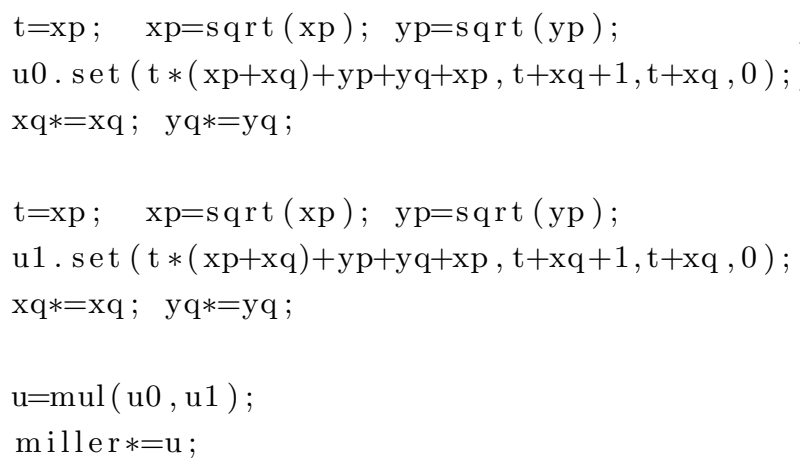

\section{\#endif}

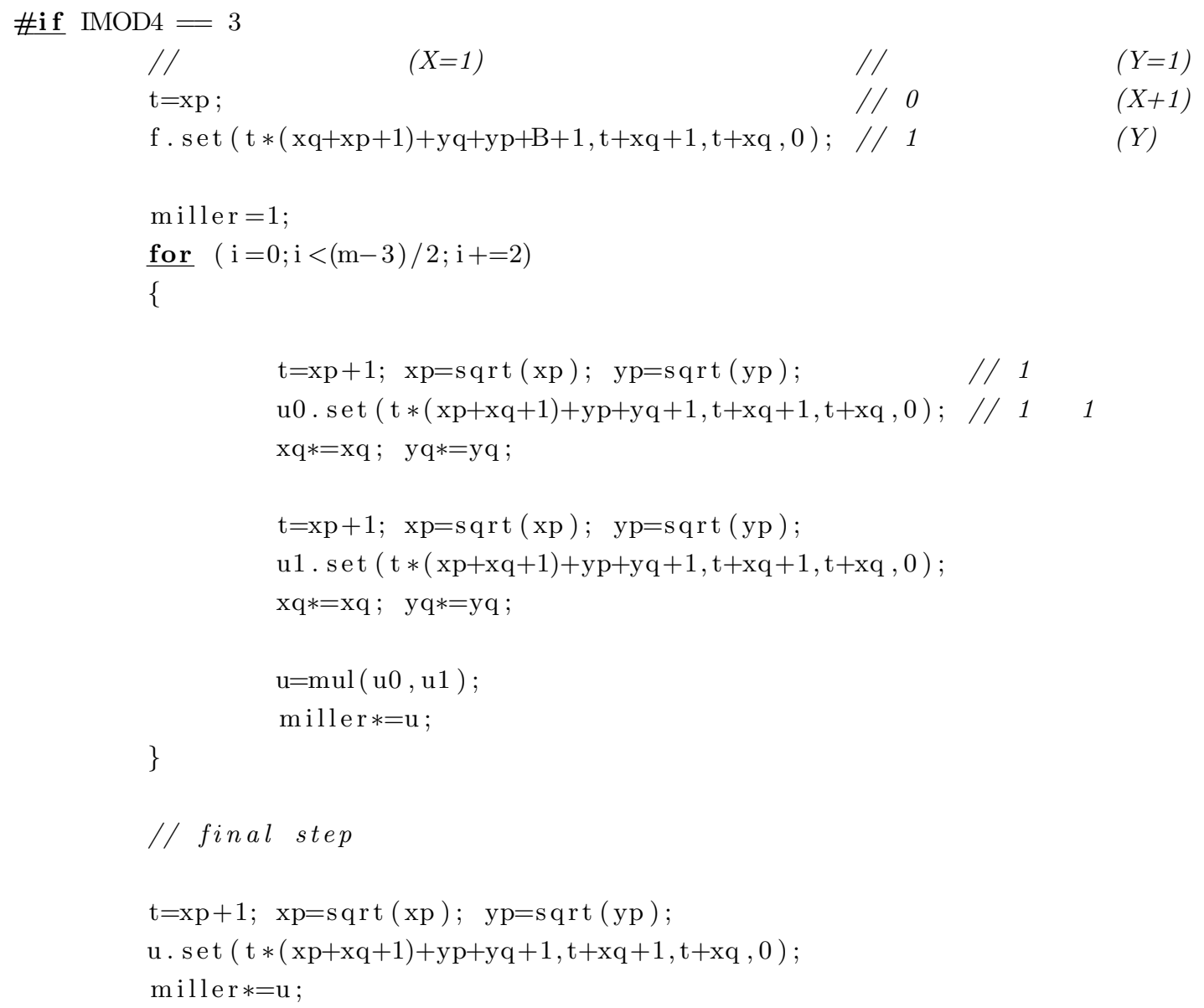


for $(i=0 ; i<(m+1) / 2 ; i++) \quad u *=u$;

$\# \mathbf{i f}$ TYPE $=1$
u. powq ( );
$\mathrm{w} \cdot \operatorname{powq}()$;
$\mathrm{v}=\mathrm{w}$;
$\mathrm{w} \cdot \operatorname{powq}()$;
res $=\mathrm{w}$;
w. powq ( );
$\mathrm{w} *=\mathrm{u}$;
$\mathrm{w} *=\mathrm{mill}$ er ;
res $*=\mathrm{v}$;
u. powq () ;
u. powq () ;
$\mathrm{res} *=\mathrm{u}$;

\#else

$\mathrm{u} \cdot \operatorname{powq}()$;

$\mathrm{v} \cdot \operatorname{powq}()$;

$\mathrm{w}=\mathrm{u} * \mathrm{v}$;

$\mathrm{v} \cdot \operatorname{powq}()$;

$\mathrm{w} *=\mathrm{v}$;

v. powq ( );

u. powq ( );

u. powq ( );

$\mathrm{res}=\mathrm{v} * \mathrm{u}$;

res $*=$ miller ;

\section{\#endif}

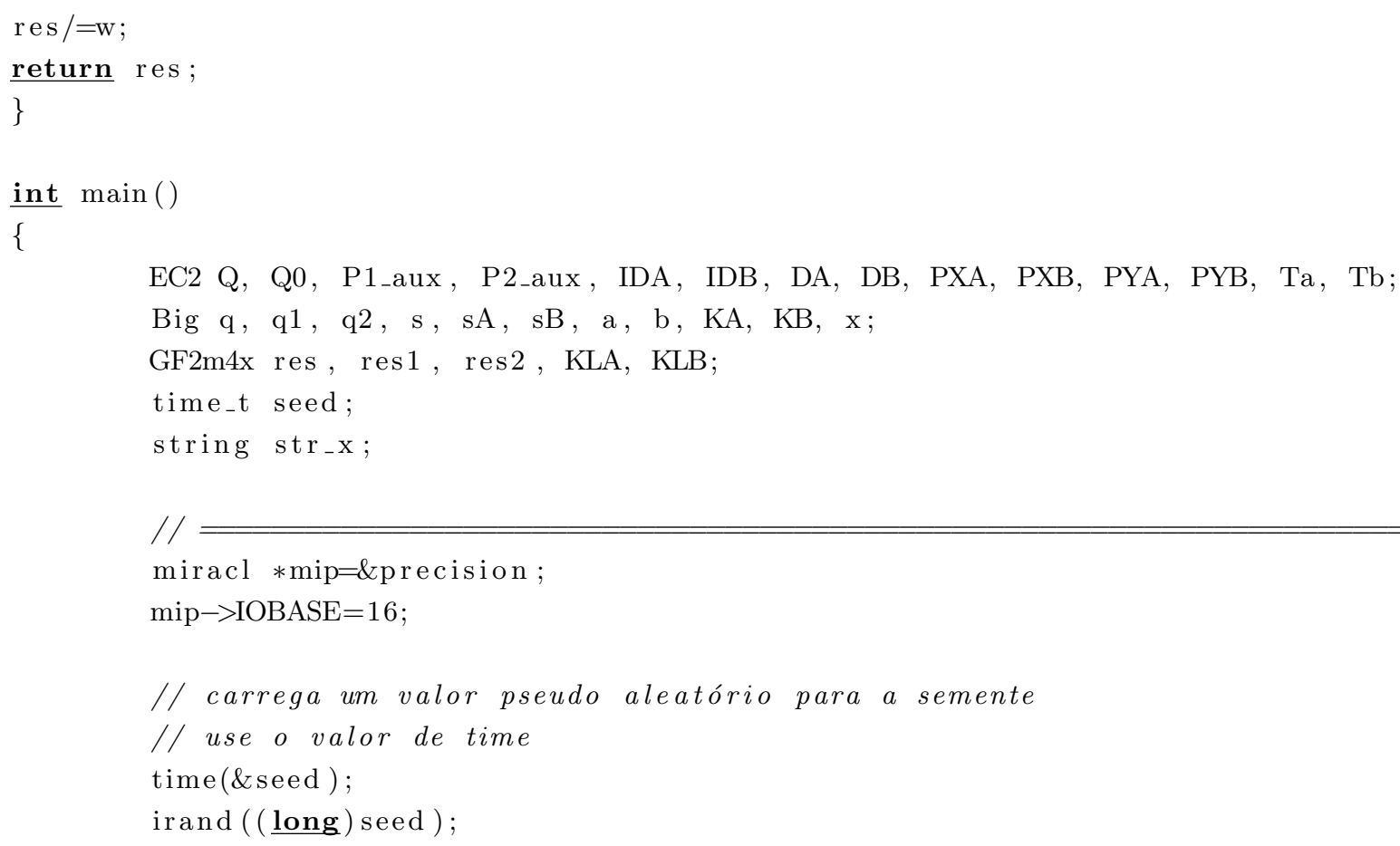




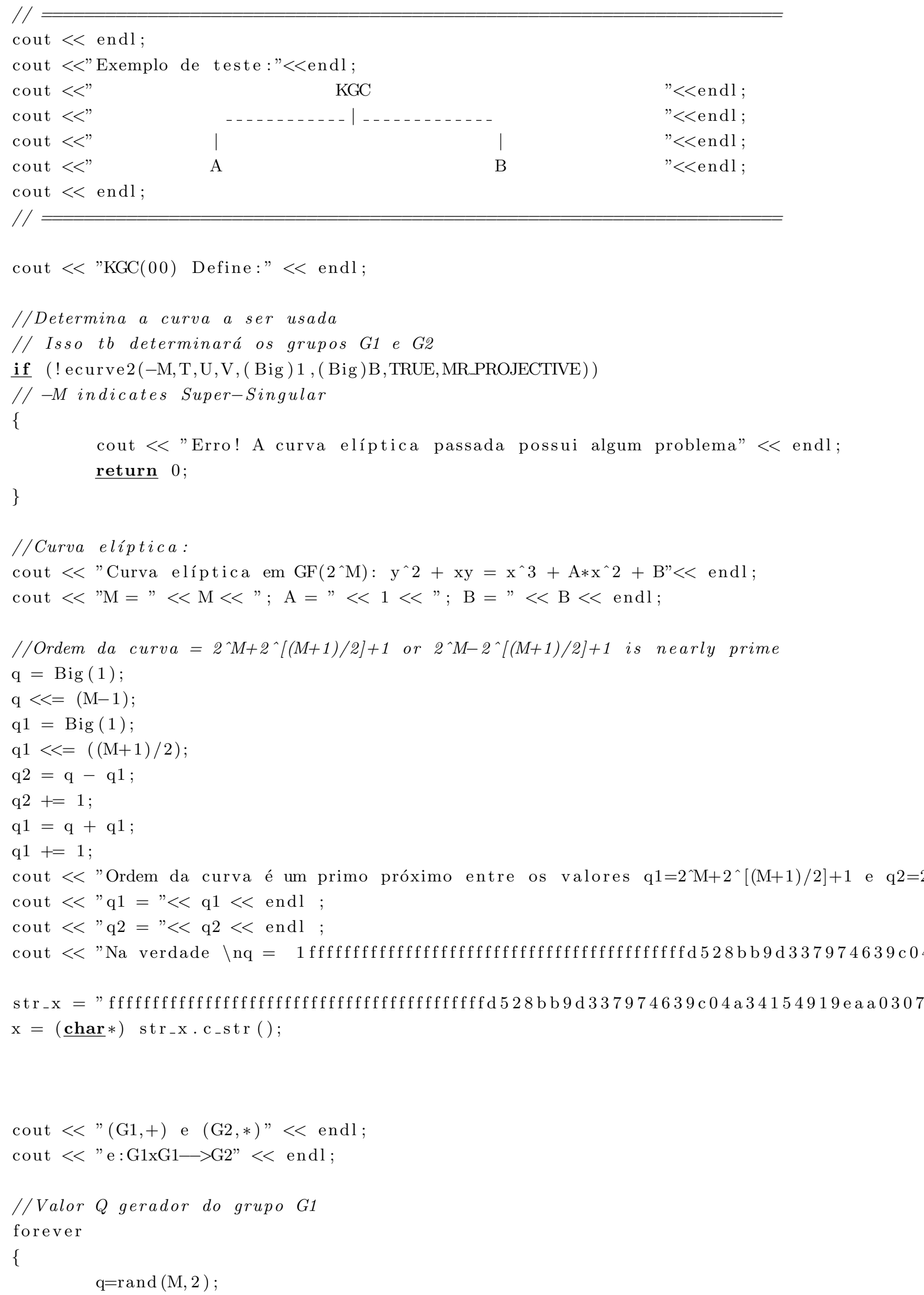




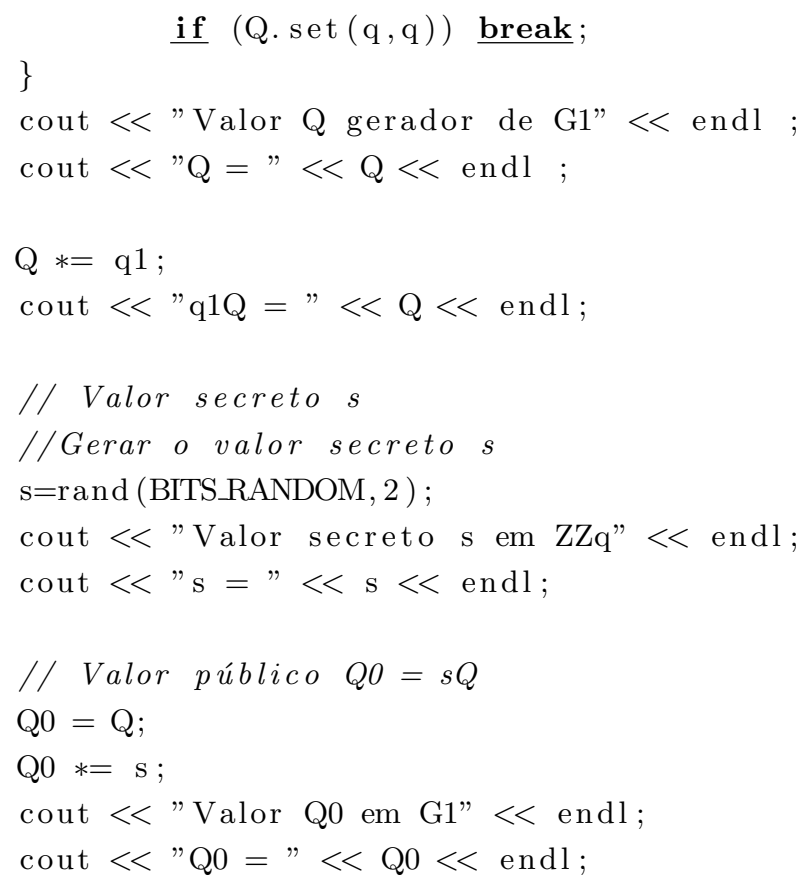




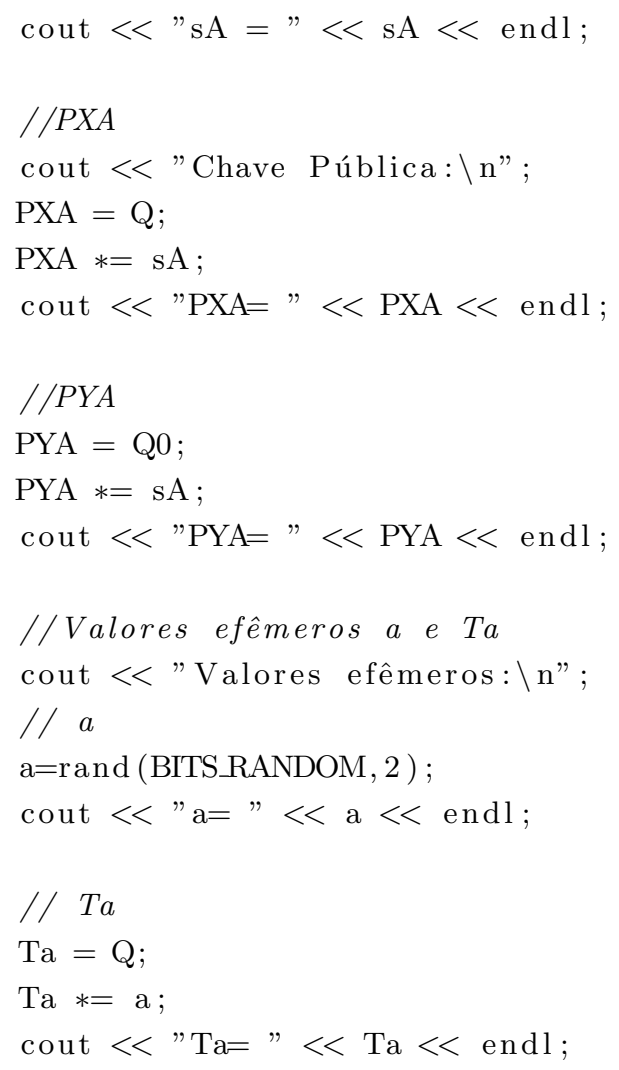




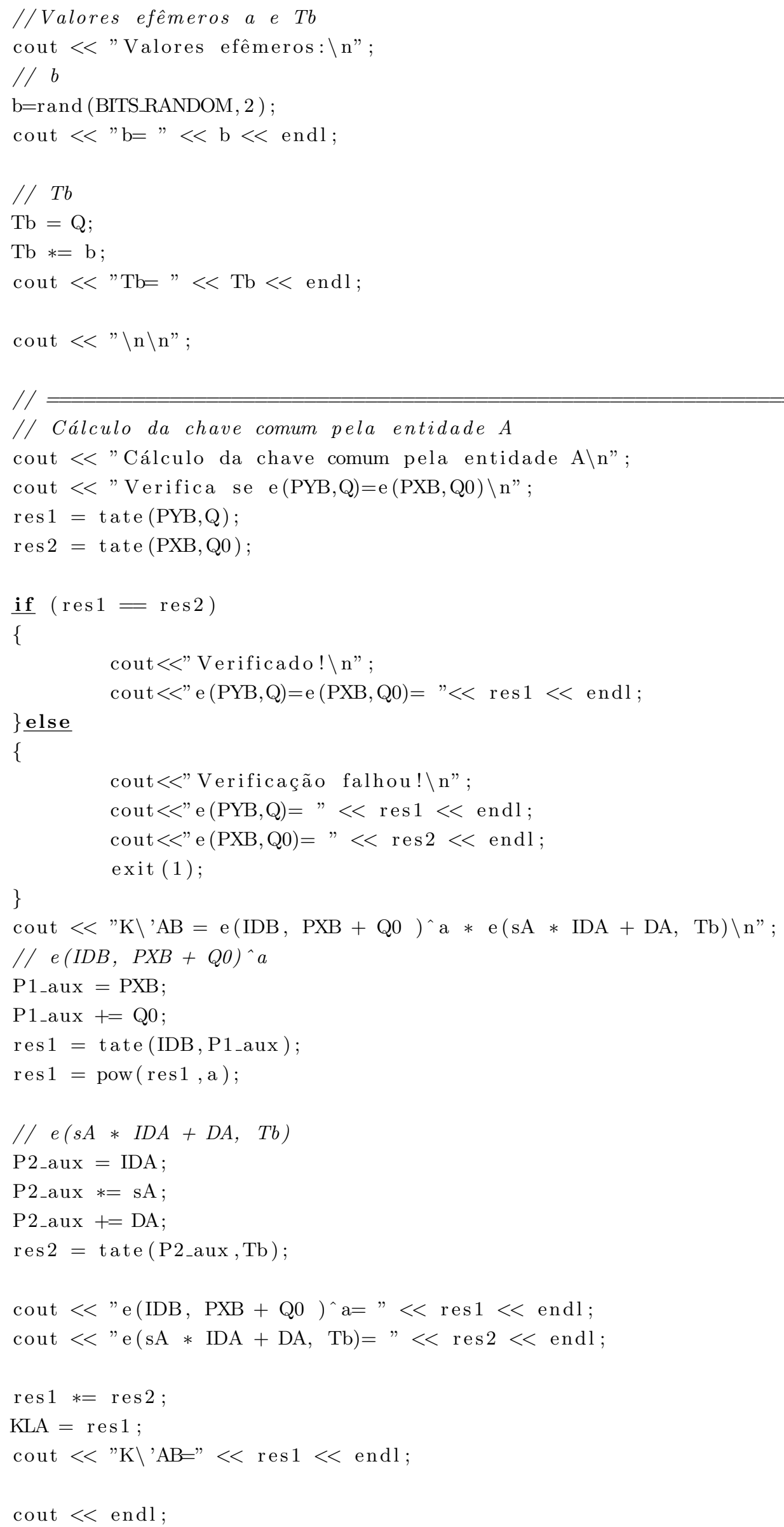




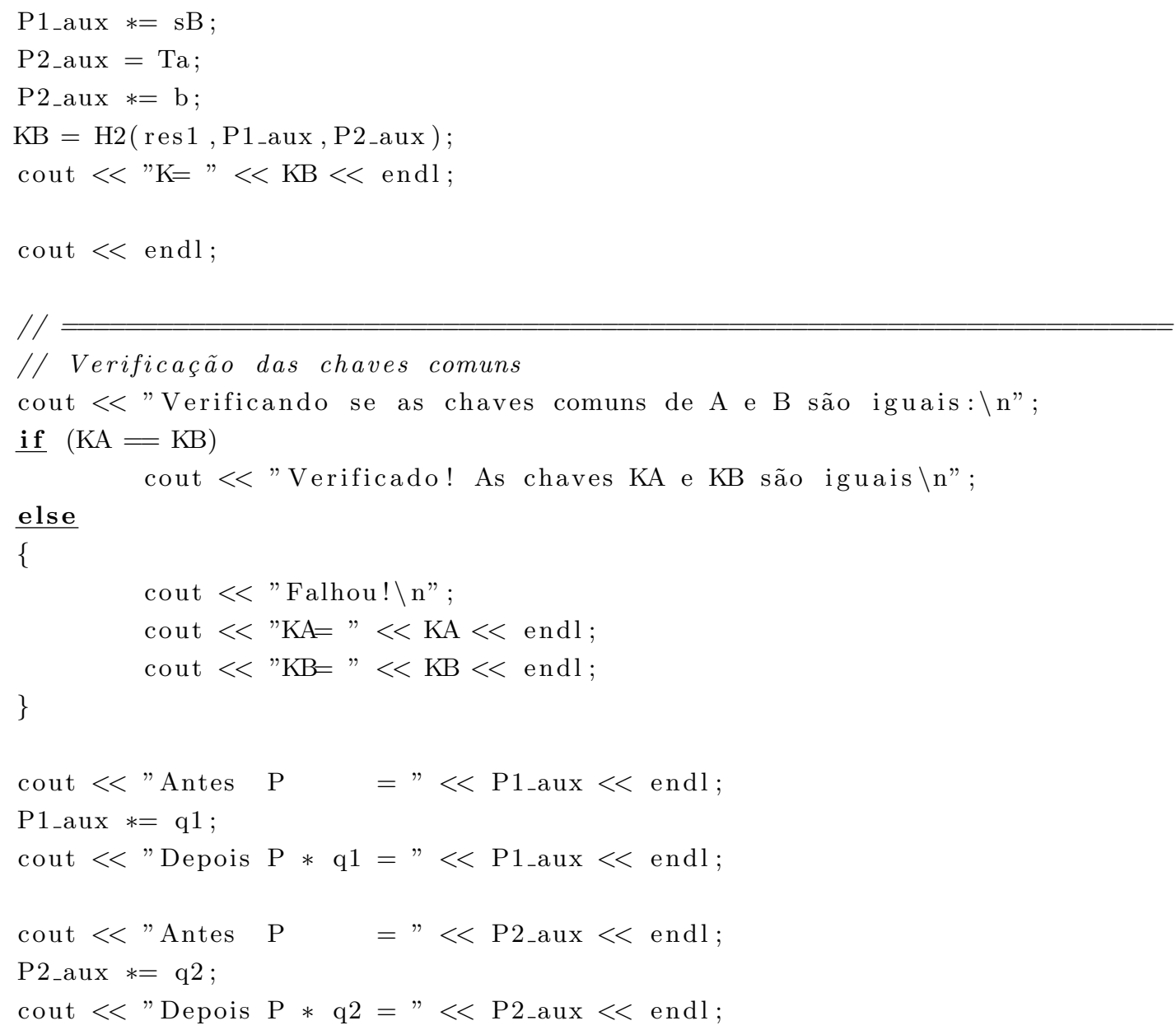

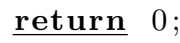

\} 


\section{Apêndice B}

\section{Implementação do Protocolo de Mandt para 2 KGC com Correções}

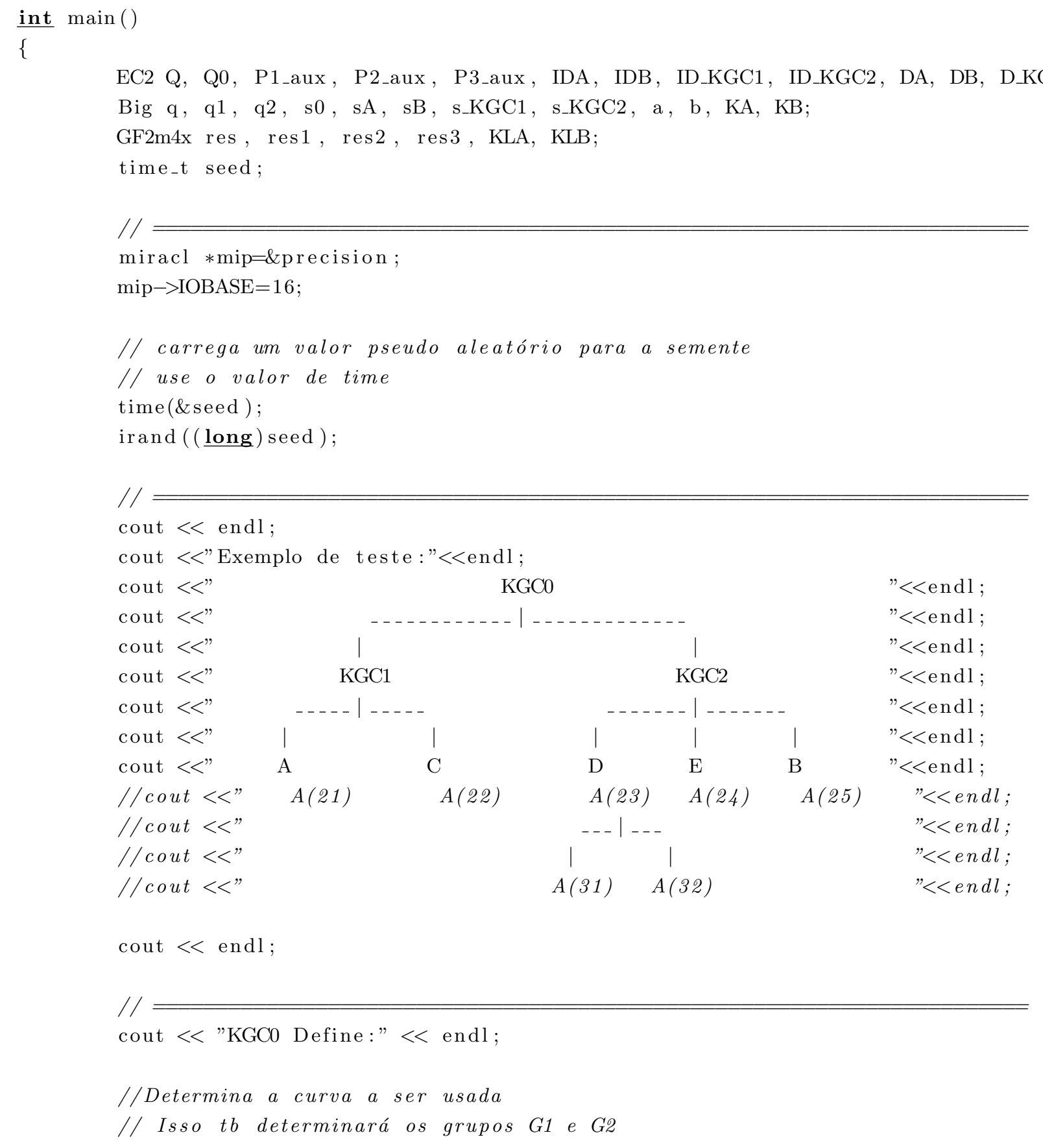


if $($ ! ecurve $2(-\mathrm{M}, \mathrm{T}, \mathrm{U}, \mathrm{V},(\mathrm{Big}) 1,(\mathrm{Big}) \mathrm{B}, \mathrm{TRUE}, \mathrm{MR}$ PROJECTIVE) $) / /-M$ indicates Super-Singular \{ cout $<$ "Erro! A curva elíptica passada possui algum problema" $<<$ endl;

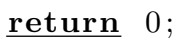

\}

//Curva eliptica:

cout $<$ "Curva elíptica em GF $\left(2^{\wedge} \mathrm{M}\right): \mathrm{y}^{\wedge} 2+\mathrm{xy}=\mathrm{x}^{\wedge} 3+\mathrm{A} * \mathrm{x}^{\wedge} 2+\mathrm{B} "<<$ endl;

cout $<<" \mathrm{M}="<<\mathrm{M}<<" ; \mathrm{A}="<<1<<" ; \mathrm{B}="<<\mathrm{B}<<$ endl;

$/ /$ Ordem da curva $=2^{\wedge} M+2^{\wedge}[(M+1) / 2]+1$ or $2^{\wedge} M-\mathscr{2}^{\wedge}[(M+1) / 2]+1$ is nearly prime $\mathrm{q}=\operatorname{Big}(1)$;

$\mathrm{q}<<=(\mathrm{M}-1)$;

$\mathrm{q} 1=\operatorname{Big}(1)$

$\mathrm{q} 1<<=((\mathrm{M}+1) / 2)$;

$\mathrm{q} 2=\mathrm{q}-\mathrm{q} 1$;

$\mathrm{q} 2+=1$;

$\mathrm{q} 1=\mathrm{q}+\mathrm{q} 1$;

$\mathrm{q} 1+=1$;

cout $<<$ "Ordem da curva é um primo próximo entre os valores $q 1=2^{\wedge} \mathrm{M}+2^{\wedge}[(\mathrm{M}+1) / 2]+1$ e $\mathrm{q} 2=$ cout $<<" \mathrm{q} 1="<<\mathrm{q} 1<<$ endl

cout $<<" \mathrm{q} 2="<<\mathrm{q} 2<<$ endl

cout $<<"(\mathrm{G} 1,+)$ e $(\mathrm{G} 2, *) "<<$ endl

cout $<<$ "e:G1xG1->G2" $<<$ endl;

//Valor Q gerador do grupo G1

forever

\{

$\mathrm{q}=\mathrm{rand}(\mathrm{M}, 2)$;

if $(Q \cdot \operatorname{set}(q, q))$ break;

\}

cout $<<$ "Valor Q gerador de G1" $<<$ endl ;

cout $<<" \mathrm{Q}="<<\mathrm{Q}<<$ endl ;

// Valor secreto so

//Gerar o valor secreto so

$\mathrm{s} 0=\mathrm{rand}$ (BITS_RANDOM, 2 );

cout $<$ "Valor secreto s em ZZq" $<<$ endl;

cout $<<"$ s0 $="<<$ s0 $<<$ endl;

$/ /$ Valor público $Q 0=s Q$

$\mathrm{Q} 0=\mathrm{Q}$;

$\mathrm{Q} 0 *=\mathrm{s} 0$;

cout $<<$ "Valor Q0 em G1" $<<$ endl;

cout $<<" \mathrm{Q} 0="<<\mathrm{Q} 0<<$ endl

$1 /$

// As funções hash

$/ *$

cout $<$ "H1:\{0,1 ${ }^{\wedge}\{*\} \rightarrow G 1 "<<$ endl 


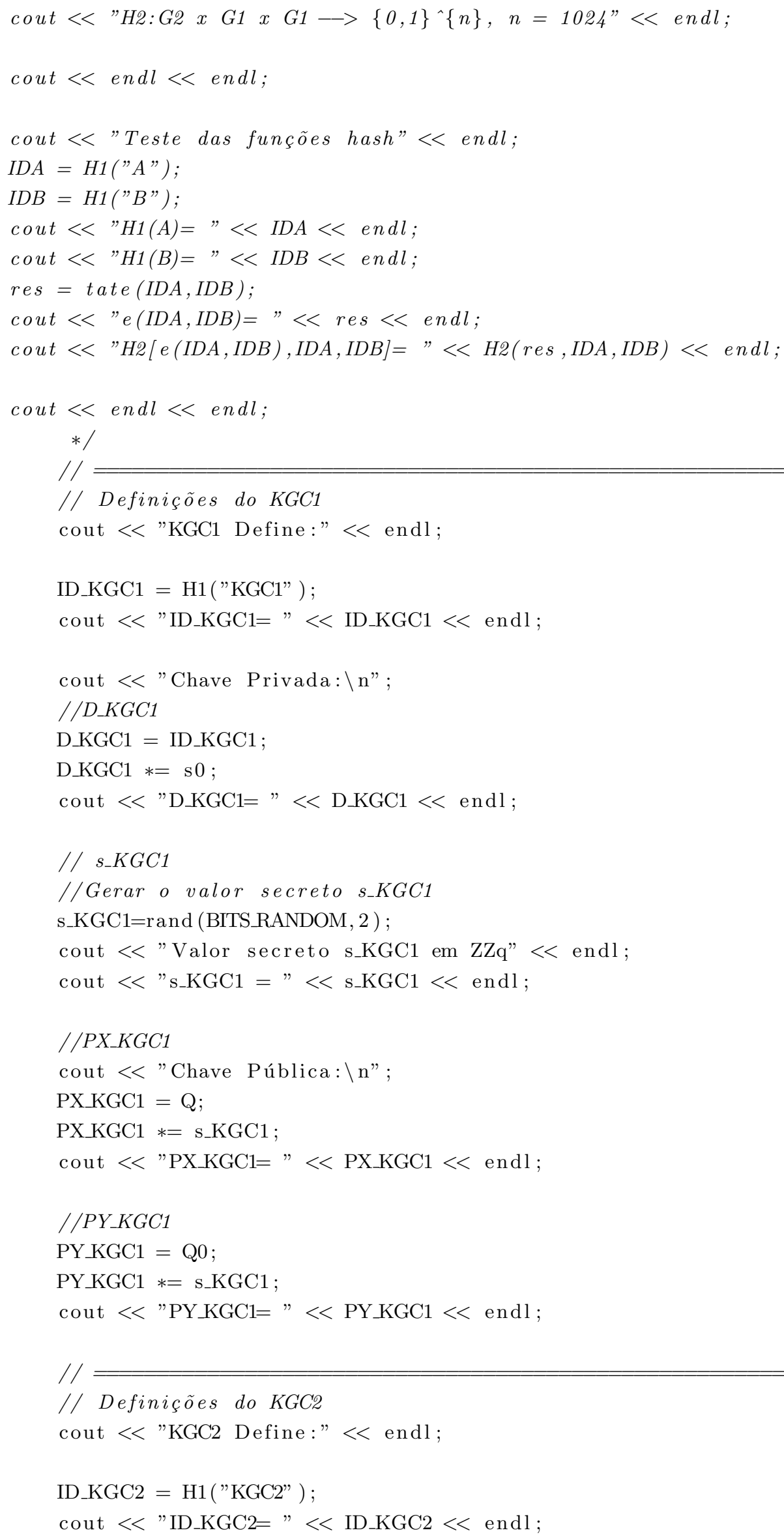




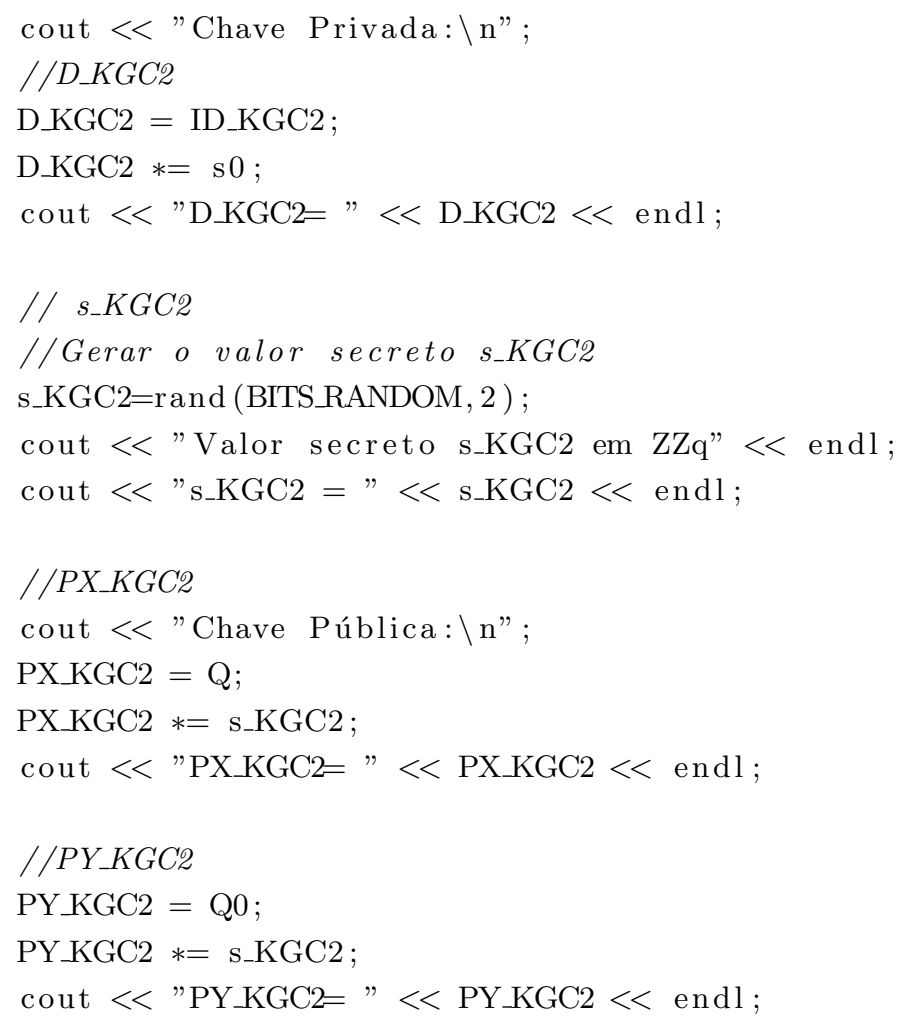




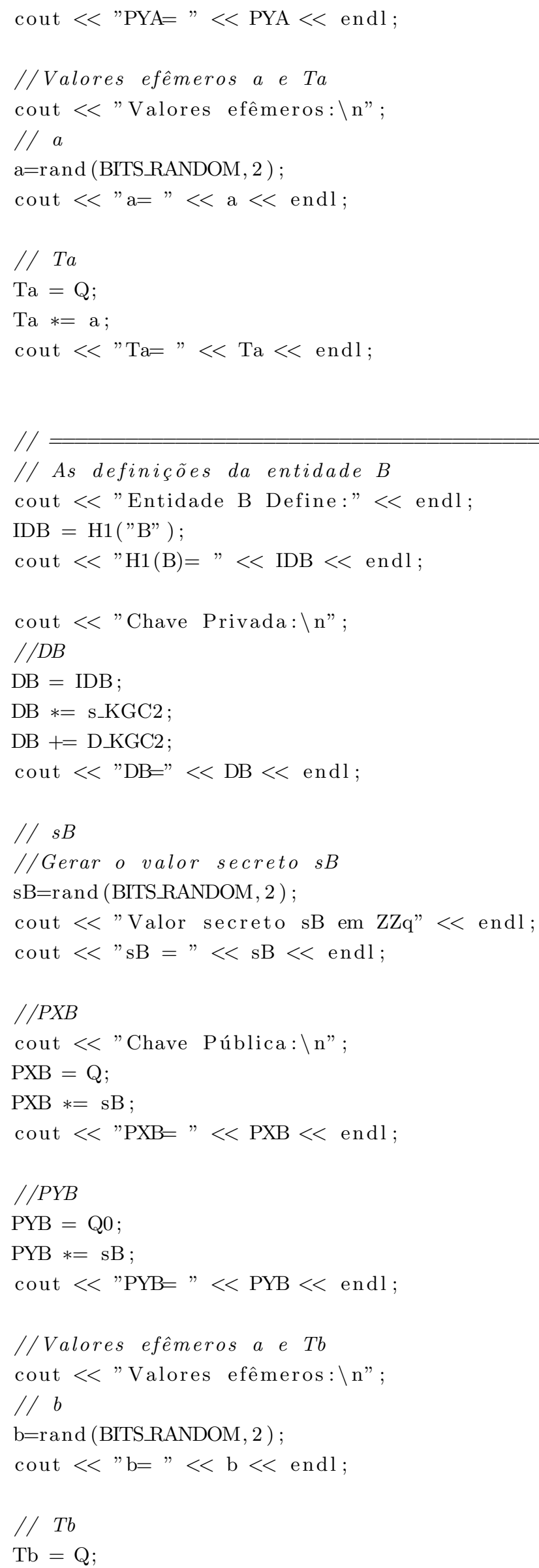




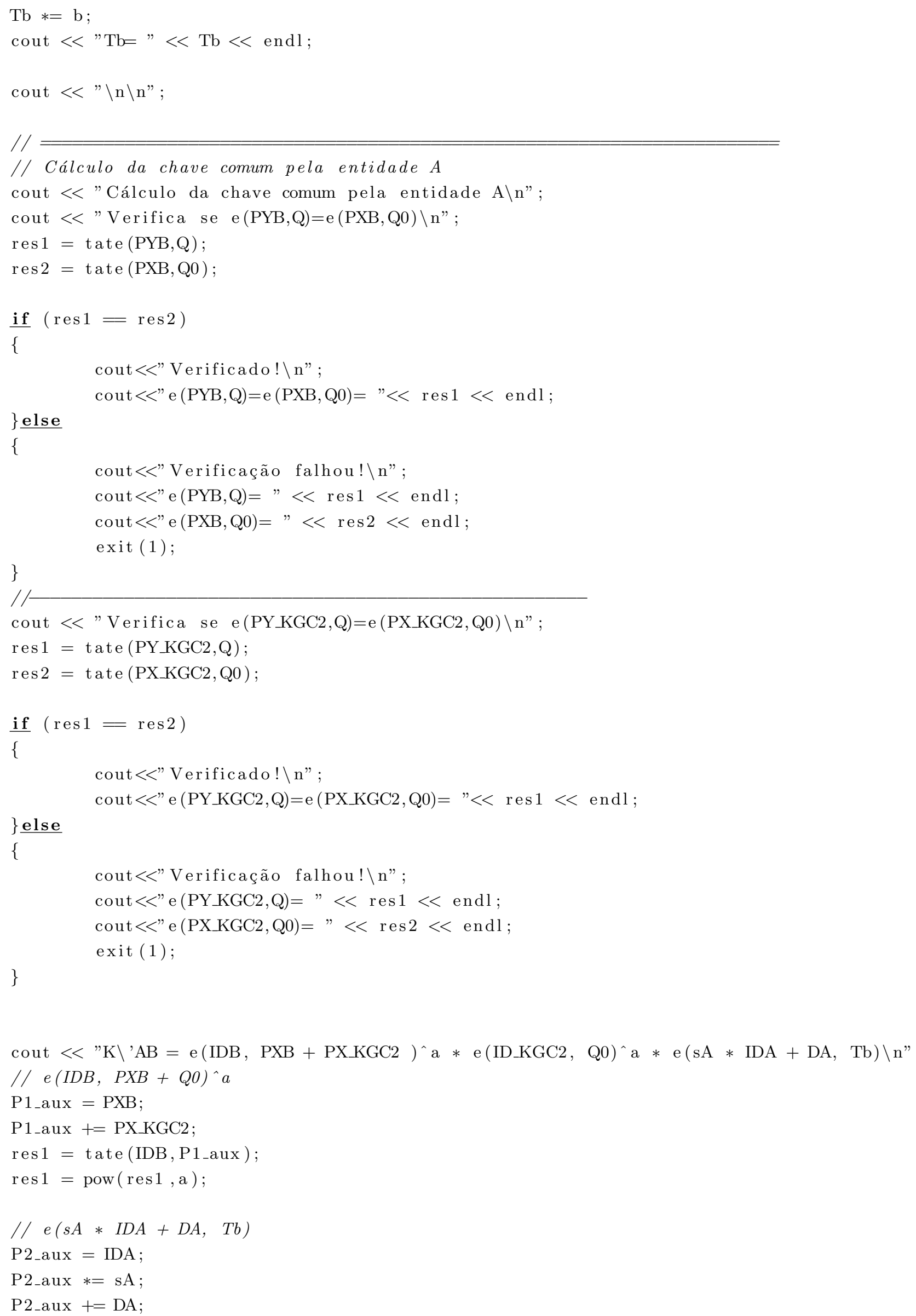




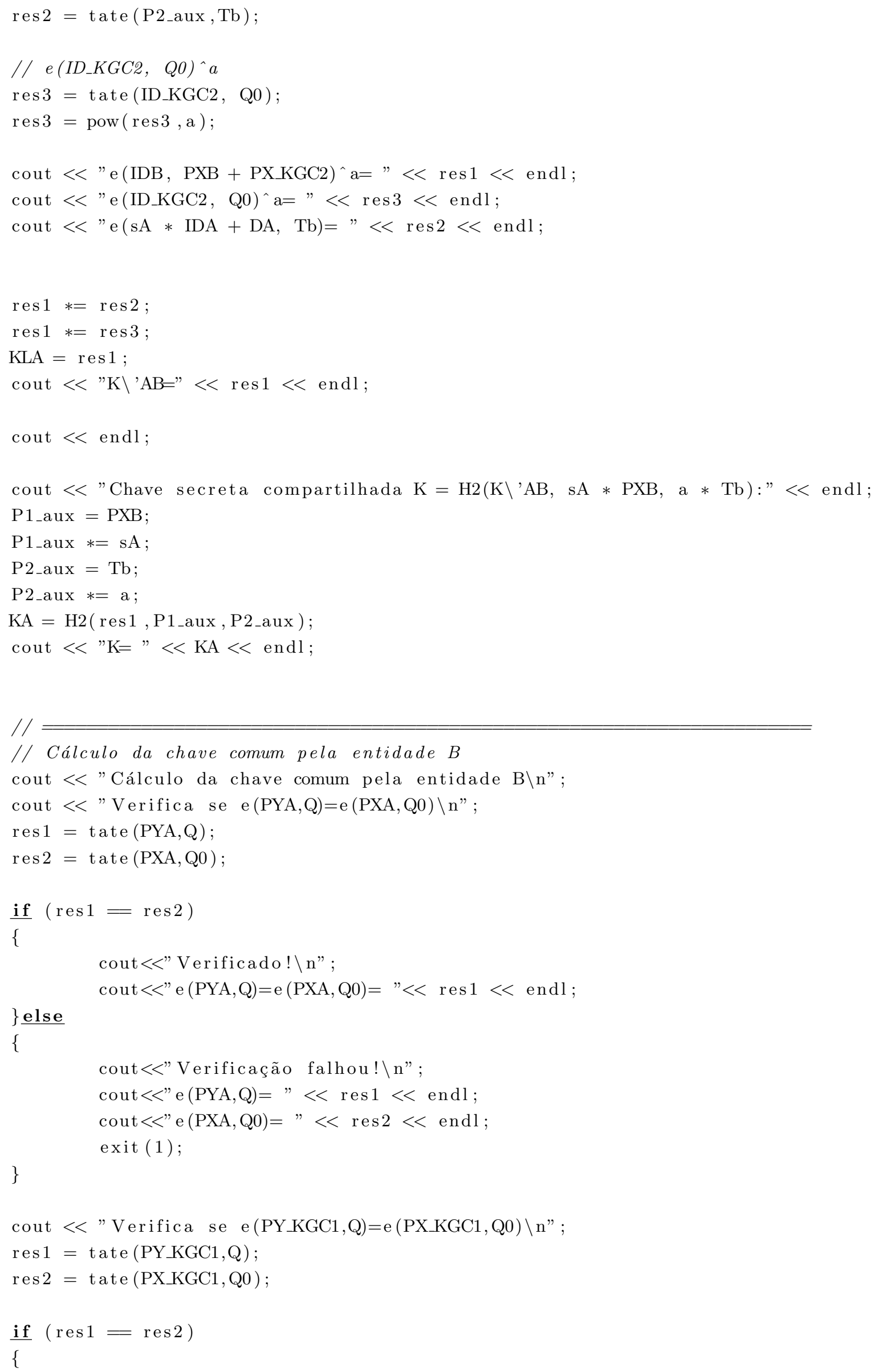




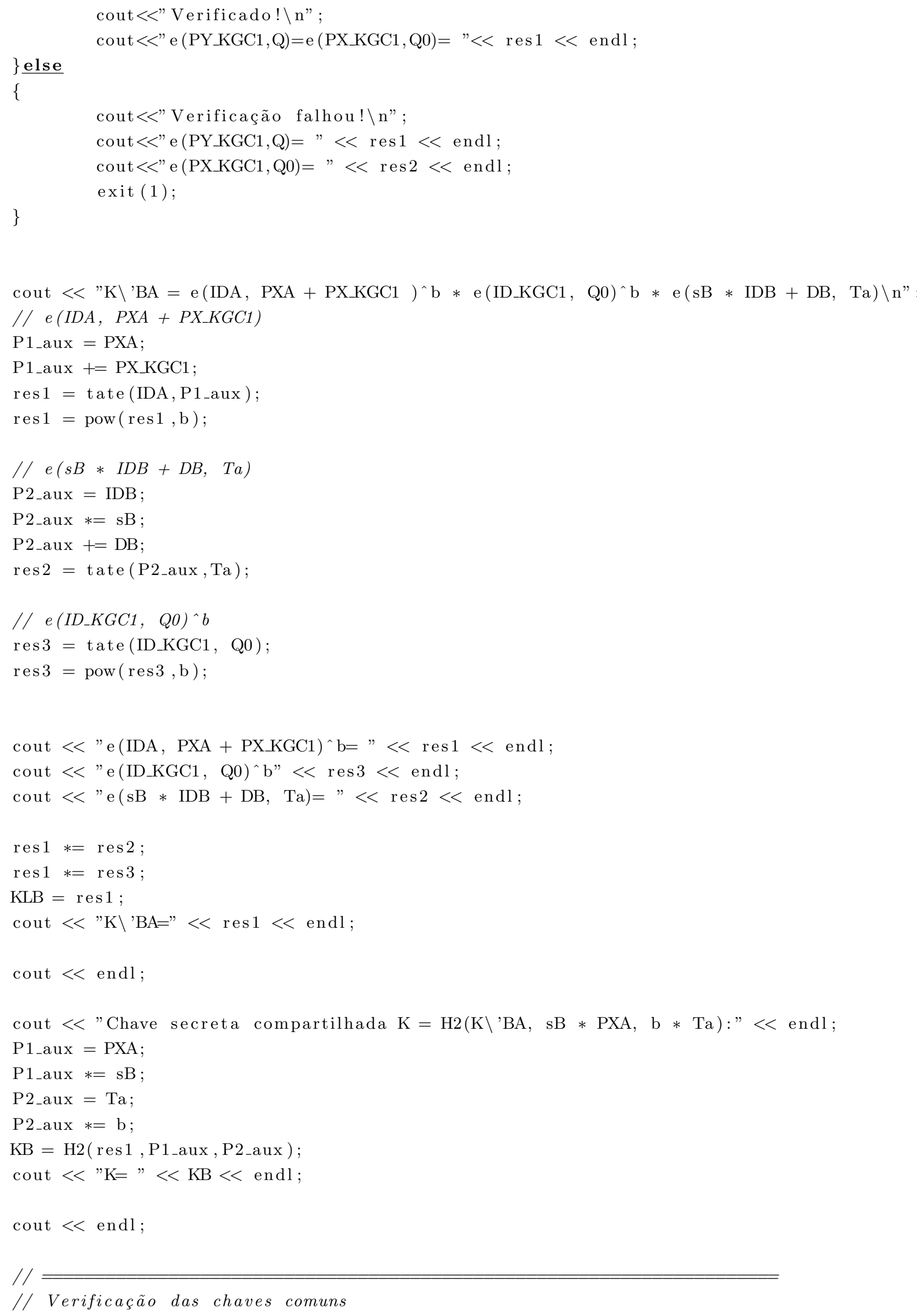


cout $<<$ "Verificando se as chaves comuns de A e B são iguais: $\backslash$ n"; if $(\mathrm{KA}=\mathrm{KB})$ cout $<$ "Verificado! As chaves KA e KB são iguais $\backslash$ n";

else

\{

cout $<<$ "Falhou! $\backslash \mathrm{n}$;

cout $<<$ "KA=" $<<\mathrm{KA}<<$ endl;

cout $<<" \mathrm{~KB}="<<\mathrm{KB}<<$ endl;

\}

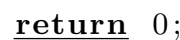

\} 


\section{Referências Bibliográficas}

[Al-Riyami e Paterson 2003] Al-Riyami, S. S. e Paterson, K. G. (2003). Certificateless public key cryptography. In LNCS - Asiacrypt'03, pages 452-473, Taipei, Taiwan. Springer-Verlag.

[Barreto et al. 2004] Barreto, P. S. L. M., Galbraith, S., hEigeartaigh, C. O., e Scott, M. (2004). Efficient pairing computation on supersingular abelian varieties. Cryptology ePrint Archive, Report 2004/375. http://eprint.iacr.org/.

[Bellare e Rogaway 1993] Bellare, M. e Rogaway, P. (1993). Entity authentication and key distribution. In LNCS - Crypto'93, pages 232-249. Springer Berlin. v.773.

[Blom 1985] Blom, R. (1985). An optimal class of symmetric key generation schemes. In LNCS - Eurocrypt'84, pages 335-338. Springer-Berlin. v.209.

[Blundo et al. 1993] Blundo, C., Santis, D. A., Herzberg, A., Kutten, S., Vaccaro, U., e Yung, M. (1993). Perfectly secure key distribution for dynamic conferences. In LNCS - Crypto'92, pages 471-486. Springer-Berlin. v.740.

[Boneh et al. 2005] Boneh, D., Boyen, X., e Goh, E.-J. (2005). Hierarchical identity based encryption with constant size ciphertext. Cryptology ePrint Archive, Report 2005/015. http: //eprint.iacr.org/.

[Boneh e Franklin 2001] Boneh, D. e Franklin, M. K. (2001). Identity-based encryption from the weil pairing. In LNCS - Cripto'01, pages 213-229, Santa Barbara, California, USA. Springer-Verlag. v.2139.

[Canetti e Krawczyk 2001] Canetti, R. e Krawczyk, H. (2001). Analysis of key-exchange protocols and their use for building secure channels. Cryptology ePrint Archive, Report 2001/040. http://eprint.iacr.org/.

[Coron e Icart 2009] Coron, J.-S. e Icart, T. (2009). An indifferentiable hash function into elliptic curves. Cryptology ePrint Archive, Report 2009/340. http://eprint.iacr.org/.

[de Castro et al. 2007] de Castro, R. D., Dahab, R., e Devegili, A. J. (2007). VII Simpósio Brasileiro em Segurança da Informação e de Sistemas Computacionais: Minicursos do SBSeg 200\%, chapter Introdução à Segurança Demonstrável, pages 103-152. UFRJ/NCE, Rio de Janeiro.

[Diffie e Hellman 1976] Diffie, W. e Hellman, M. (1976). New directions in cryptography. IEEE Transactions on Information Theory, 22:644-654.

[Ellison e Schneier 2000] Ellison, C. e Schneier, B. (2000). Ten risks of pki: What you're not being told about public key infrastructure. Computer Security Journal, 16(1):1-7.

[Gennaro et al. 2008] Gennaro, R., Halevi, S., Krawczyk, H., Rabin, T., Reidt, S., e Wolthusen, S. D. (2008). Strongly-resilient and non-interactive hierarchical key-agreement in manets. In LNCS - Esorics'08, volume 5283, pages 47-55. Springer-Berlin. v.5283. 
[Girault 1991] Girault, M. (1991). Self-certified public keys. In LNCS - EuroCrypt'91, pages 490-497. Springer Berlin. v.547.

[Goldwasser e Micali 1984] Goldwasser, S. e Micali, S. (1984). Probabilistic encryption. j-JCOMP-SYS-SCI, 28(2):270-299. Ver também versão preliminar em 14th STOC, 1982.

[Goya et al. 2009a] Goya, D., Misaghi, M., Rufino, V., e Terada, R. (2009a). IX Simpósio Brasileiro em Segurança da Informação e de Sistemas Computacionais: Minicursos do SBSeg 2009, chapter Modelos de Criptografia de Chave Pública Alternativos, pages 49-98. Unicamp, Campinas.

[Goya et al. 2009b] Goya, D. H., Rufino, V. Q., e Terada, R. (2009b). Acordo de chave sem certificados sob emissão de multiplas chaves públicas. In Anais - IX SBSeg, pages 241-242, Campinas. Resumo estendido.

[Horwitz e Lynn 2002] Horwitz, T. e Lynn, B. (2002). Towards hierarchical identity-based encryption. In LNCS - Eurocrypt'02, pages 466-481. Springer-Berlin. v.2332.

[Icart 2009] Icart, T. (2009). How to hash into elliptic curves. Cryptology ePrint Archive, Report 2009/226. http://eprint.iacr.org/.

[Kahan 1996] Kahan, D. (1996). The Codebreakers: The Comprehensive History of Secret Communication from Ancient Times to the Internet. Scribner, New York, rev edition.

[Koblitz 1994] Koblitz, N. (1994). A course in number theory and cryptography. SpringerVerlag, New York - NY - USA, 2 edition.

[Lippold et al. 2009] Lippold, G., Boyd, C., e Nieto, J. (2009). Strongly secure certificateless key agreement. Cryptology ePrint Archive, Report 2009/219. http://eprint.iacr.org/.

[Mandt e Tan 2006] Mandt, T. K. e Tan, C. H. (2006). Certificateless Authenticated TwoParty Key Agreement Protocols. In 11th Asian Computing Science Conference'06, pages 37-44. Springer Berlin. v.4435.

[Oliveira et al. 2007] Oliveira, L. B., Scott, M., López, J., e Dahab, R. (2007). Tinypbc: Pairings for authenticated identity-based non-interactive key distribution in sensor networks. Cryptology ePrint Archive, Report 2007/482. http://eprint.iacr.org/.

[Rufino 2009] Rufino, V. Q. (2009). Correção de deficiências no acordo de chaves de Mandt. In Anais - IX SBSeg, pages 101-114, Campinas.

[Sakai et al. 2000] Sakai, R., Ohgishi, K., e Kasahara, M. (2000). Cryptosystems based on pairing. In Symposium on Cryptography and Information Security, SCIS2000, pages 26-28, Okinawa, Japan.

[Shamir 1984] Shamir, A. (1984). Identity-based cryptosystems and signature schemes. In LNCS - Crypto'84, pages 47-53, Santa Barbara, California, USA. Springer-Verlag.

[Shannon 1945] Shannon, C. E. (1945). A mathematical theory of cryptography. Classified report, Bell Laboratories, Murray Hill, NJ, USA.

[Shannon 1949] Shannon, C. E. (1949). Communication theory of secrecy systems. Bell Systems Technical Journal, 28:656-715.

[Singh 2000] Singh, S. (2000). The Code Book: The Science of Secrecy from Ancient Egypt to Quantum Cryptography. Anchor, New York, rev edition. 
[Stinson 2006] Stinson, D. R. (2006). Cryptography Theory and Pratice. Chapman \& Hall/CRC, Waterloo.

[Strangio 2006] Strangio, M. A. (2006). On the resilience of key agreement protocols to key compromise impersonation. In LNCS - EuroPKI'06, pages 233-247. Springer-Berlin. v.4043.

[Swanson 2008] Swanson, C. M. (2008). Security in key agreement: Two-party certificateless schemes. Master's thesis, University of Waterloo - Canadá. http://hdl.handle.net/10012/ 4156.

[Terada 2008] Terada, R. (2008). Segurança de Dados - Criptografia em rede de computador. Blucher, 2 edition.

[Trappe e Washington 2005] Trappe, W. e Washington, L. C. (2005). Introduction to Cryptography with Coding Theory. Prentice Hall, 2 edition. 